\title{
Interventions for managing skeletal muscle spasticity following traumatic brain injury (Review)
}

Synnot A, Chau M, Pitt V, O'Connor D, Gruen RL, Wasiak J, Clavisi O, Pattuwage L, Phillips K

Synnot A, Chau M, Pitt V, O'Connor D, Gruen RL, Wasiak J, Clavisi O, Pattuwage L, Phillips K.

Interventions for managing skeletal muscle spasticity following traumatic brain injury.

Cochrane Database of Systematic Reviews 2017, Issue 11. Art. No.: CD008929.

DOI: 10.1002/14651858.CD008929.pub2.

www.cochranelibrary.com 
TABLE OF CONTENTS

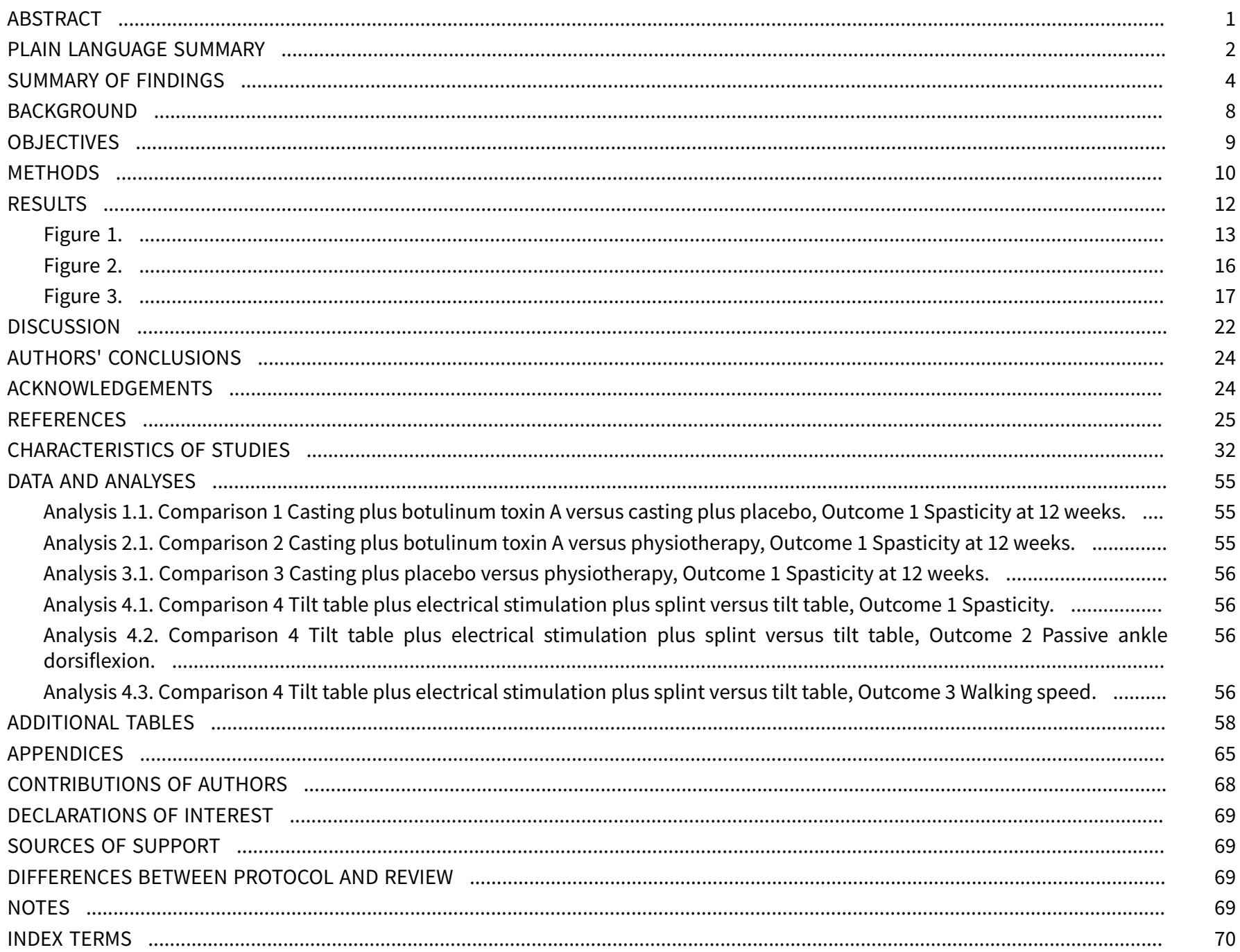


[Intervention Review]

\section{Interventions for managing skeletal muscle spasticity following traumatic brain injury}

Anneliese Synnot ${ }^{1,2}$, Marisa Chau ${ }^{2}$, Veronica Pitt ${ }^{3}$, Denise O'Connor ${ }^{4}$, Russell L Gruen ${ }^{5}$, Jason Wasiak ${ }^{6}$, Ornella Clavisi ${ }^{7}$, Loyal Pattuwage ${ }^{8}$, Kate Phillips 9

${ }^{1}$ Cochrane Australia, School of Public Health and Preventive Medicine, Monash University, Melbourne, Australia. ${ }^{2} \mathrm{National}$ Trauma Research Institute, Alfred Hospital, Monash University, Melbourne, Australia. ${ }^{3}$ Australian \& New Zealand Intensive Care Research Centre (ANZIC-RC), Monash University, Melbourne, Australia. ${ }^{4}$ School of Public Health and Preventive Medicine, Monash University, Melbourne, Australia. ${ }^{5}$ Lee Kong Chian School of Medicine, Nanyang Technological University, Singapore, Singapore. 6 Melbourne School of Health Sciences, University of Melbourne, Melbourne, Australia. ${ }^{7}$ MOVE muscle, bone \& joint health, Melbourne, Australia. ${ }^{8} \mathrm{Centre}$ for Evidence and Implementation, East Melbourne, Australia. ${ }^{9}$ School of Public Health \& Preventive Medicine, Monash University, Melbourne, Australia

Contact: Anneliese Synnot, Cochrane Australia, School of Public Health and Preventive Medicine, Monash University, L4 551 St Kilda Rd, Melbourne, Victoria, 3004, Australia.a.synnot@latrobe.edu.au, anneliese.synnot@monash.edu.

Editorial group: Cochrane Injuries Group.

Publication status and date: New, published in Issue 11, 2017.

Citation: Synnot A, Chau M, Pitt V, O'Connor D, Gruen RL, Wasiak J, Clavisi O, Pattuwage L, Phillips K. Interventions for managing skeletal muscle spasticity following traumatic brain injury. Cochrane Database of Systematic Reviews 2017, Issue 11. Art. No.: CD008929. DOI: 10.1002/14651858.CD008929.pub2.

Copyright @ 2017 The Cochrane Collaboration. Published by John Wiley \& Sons, Ltd.

\section{A B S T R A C T}

\section{Background}

Skeletal muscle spasticity is a major physical complication resulting from traumatic brain injury (TBI), which can lead to muscle contracture, joint stiffness, reduced range of movement, broken skin and pain. Treatments for spasticity include a range of pharmacological and non-pharmacological interventions, often used in combination. Management of spasticity following TBI varies from other clinical populations because of the added complexity of behavioural and cognitive issues associated with TBI.

\section{Objectives}

To assess the effects of interventions for managing skeletal muscle spasticity in people with TBI.

\section{Search methods}

In June 2017, we searched key databases including the Cochrane Injuries Group Specialised Register, CENTRAL, MEDLINE (Ovid), Embase (Ovid) and others, in addition to clinical trials registries and the reference lists of included studies.

\section{Selection criteria}

We included randomised controlled trials (RCTs) and cross-over RCTs evaluating any intervention for the management of spasticity in TBI. Only studies where at least $50 \%$ of participants had a TBI (or for whom separate data for participants with TBI were available) were included. The primary outcomes were spasticity and adverse effects. Secondary outcome measures were classified according to the World Health Organization International Classification of Functioning, Disability and Health including body functions (sensory, pain, neuromusculoskeletal and movement-related functions) and activities and participation (general tasks and demands; mobility; self-care; domestic life; major life areas; community, social and civic life). 


\section{Data collection and analysis}

We used standard methodological procedures expected by Cochrane. Data were synthesised narratively; meta-analysis was precluded due to the paucity and heterogeneity of data.

\section{Main results}

We included nine studies in this review which involved 134 participants with TBI. Only five studies reported between-group differences, yielding outcome data for 105 participants with TBI. These five studies assessed the effects of a range of pharmacological (baclofen, botulinum toxin A) and non-pharmacological (casting, physiotherapy, splints, tilt table standing and electrical stimulation) interventions, often in combination. The studies which tested the effect of baclofen and tizanidine did not report their results adequately. Where outcome data were available, spasticity and adverse events were reported, in addition to some secondary outcome measures.

Of the five studies with results, three were funded by governments, charities or health services and two were funded by a pharmaceutical or medical technology company. The four studies without useable results were funded by pharmaceutical or medical technology companies.

It was difficult to draw conclusions about the effectiveness of these interventions due to poor reporting, small study size and the fact that participants with TBI were usually only a proportion of the overall total. Meta-analysis was not feasible due to the paucity of data and heterogeneity of interventions and comparator groups. Some studies concluded that the intervention they tested had beneficial effects on spasticity, and others found no difference between certain treatments. The most common adverse event was minor skin damage in people who received casting. We believe it would be misleading to provide any further description of study results given the quality of the evidence was very low for all outcomes.

\section{Authors' conclusions}

The very low quality and limited amount of evidence about the management of spasticity in people with TBI means that we are uncertain about the effectiveness or harms of these interventions. Well-designed and adequately powered studies using functional outcome measures to test the interventions used in clinical practice are needed.

\section{PLAIN LANGUAGE SUMMARY}

\section{Treatments for spasticity (overactive muscle contractions) following brain injury}

\section{Review question}

We reviewed the evidence about the effect of treatments (drug and non-drug) for spasticity following a brain injury caused by a blow to the head (traumatic brain injury (TBI)).

\section{Background}

Many people with TBI experience muscle spasticity, when their muscles contract or tighten involuntarily. This can impact on a person's ability to carry out daily activities causing pain, stiffness and broken skin. There are many treatments used to manage spasticity, including medicines, casting, splints and stretches. Often, these treatments are used in combination.

\section{Study characteristics}

We included nine studies in this review which involved 134 participants with TBI. Only five studies, including 105 people provided usable results. These studies tested the effects of a range of treatments, including medicines (baclofen or botulinum toxin A), casting, physiotherapy, splints, a table that moves people from the lying position to standing and electrical stimulation (where electrical impulses are delivered to the muscles). Studies inadequately reporting results had tested the effect of medicines (baclofen or tizanidine).

\section{Study funding sources}

Of the five studies with results, three were funded by governments, charities or health services and two were funded by a drug manufacturer and medical technology company. The other four studies without useable results were funded by drug manufacturer or medical technology companies.

\section{Key results}

This evidence is current to June 2017.

Interpreting the results of the studies was difficult because of a lack of information and concerns about the quality of the evidence. For spasticity, some studies concluded that the treatment they tested made an improvement, and others found no difference between treatments. The most common side effect was minor skin damage in people who received casting. We believe it would be misleading to provide any further description of study results given the quality of the evidence was very low for all measurements.

\section{Quality of the evidence}


The quality of this evidence was very low; we only had five studies with results and none of the studies were large or comparable with one another. We also had concerns about how they were conducted or analysed. Because of this, we cannot draw any firm conclusions about the benefits and harms of different treatments for spasticity in people with TBI. 


\section{SUMMARY OF FINDINGS}

\section{Summary of findings for the main comparison. Baclofen compared with placebo for spasticity in people with traumatic brain injury}

\section{Baclofen compared with placebo for spasticity in people with traumatic brain injury}

Patient or population: adults with traumatic brain injury with spasticity in their arms and legs

Settings: outpatient rehabilitation clinic (US)

Intervention: intrathecal baclofen $50 \mu \mathrm{g}$ (injected into the lumbar spine)

Comparison: saline placebo

\begin{tabular}{|c|c|c|c|}
\hline Outcomes & Results and conclusions & $\begin{array}{l}\text { No of participants } \\
\text { (studies) }\end{array}$ & $\begin{array}{l}\text { Quality of the evi- } \\
\text { dence } \\
\text { (GRADE) }\end{array}$ \\
\hline $\begin{array}{l}\text { Spasticity at up to } 6 \text { hours after treatment } \\
\text { (measured by the Ashworth Scale, 0-, with a } \\
\text { higher score indicating greater spasticity) }\end{array}$ & $\begin{array}{l}\text { We are uncertain about the effect } \\
\text { of baclofen on spasticity compared } \\
\text { with placebo. }{ }^{1}\end{array}$ & $\begin{array}{l}11 \\
(1)^{2}\end{array}$ & $\begin{array}{l}\oplus \ominus \ominus \ominus \\
\text { V ery low } 3\end{array}$ \\
\hline Adverse events & $\begin{array}{l}\text { We are uncertain about the effect } \\
\text { of baclofen on adverse events com- } \\
\text { pared with placebo. } 4\end{array}$ & $\begin{array}{l}11 \\
(1)^{2}\end{array}$ & $\begin{array}{l}\oplus \ominus \ominus \ominus \\
\text { V ery low } 5\end{array}$ \\
\hline Sensory functions and pain & No study measured this outcome. & & \\
\hline $\begin{array}{l}\text { Neuromusculoskeletal and movement-relat- } \\
\text { ed functions up to } 6 \text { hours after treatment } \\
\text { (Measured by spasm and deep tendon reflex } \\
\text { scores, } 0-5 \text {, with } 0 \text { being no reflexes and } 5 \text { be- } \\
\text { ing clonus, or repeated involuntary muscle } \\
\text { contractions) }\end{array}$ & $\begin{array}{l}\text { We are uncertain about the effect } \\
\text { of baclofen on neuromusculoskele- } \\
\text { tal and movement-related functions } \\
\text { compared with placebo. }{ }^{6}\end{array}$ & $\begin{array}{l}11 \\
(1)^{2}\end{array}$ & $\begin{array}{l}\oplus \ominus \ominus \ominus \\
\text { V ery low } 7\end{array}$ \\
\hline General tasks and demands & No study measured this outcome. & & \\
\hline Mobility & No study measured this outcome. & & \\
\hline Self-care & No study measured this outcome. & & \\
\hline
\end{tabular}

GRADE Working Group grades of evidence

High quality: Further research is very unlikely to change our confidence in the estimate of effect.

Moderate quality: Further research is likely to have an important impact on our confidence in the estimate of effect and may change the estimate.

Low quality: Further research is very likely to have an important impact on our confidence in the estimate of effect and is likely to change the estimate.

Very low quality: We are very uncertain about the estimate.

\footnotetext{
1One study of baclofen reported an improvement in spasticity in the upper and lower limbs, compared to placebo, several hours after the injections but it was unclear how meaningful this improvement was due to reporting of P values only (Meythaler 1996).

2Three additional studies, with 35 participants, measured this outcome but had no useable results (Meythaler 1997; Meythaler 1999a; Meythaler 1999b).

3Downgraded four times due to risk of bias limitations (this study provided insufficient information about random sequence generation or allocation concealment), our concerns about indirectness of the Ashworth Score, an inability to assess imprecision relating to an absence
} 
of confidence intervals and a further downgrade for there only being one study for this outcome and the likelihood of publication bias in this area.

${ }^{4}$ No adverse events or changes in alertness level were observed in the baclofen or placebo group.

5 Downgraded three times due to risk of bias limitations (no study provided sufficient information about random sequence generation or allocation concealment), the fact that there was only one study for this outcome and the likelihood of publication bias in this area.

6 One study reported improvement in upper and lower limb spasm and reflexes compared to placebo several hours after treatment but it was unclear how meaningful this improvement was due to reporting of $P$ values only (Meythaler 1996).

${ }^{7}$ Downgraded four times due to risk of bias limitations (no study provided sufficient information about random sequence generation or allocation concealment), an inability to assess imprecision relating to an absence of confidence intervals, the fact that there was only one study for this outcome and the likelihood of publication bias in this area.

\section{Summary of findings 2. Botulinum toxin A (with and without casting) compared with placebo (with and without casting) for spasticity in people with traumatic brain injury}

\section{Botulinum toxin A (with and without casting) compared with placebo (with and without casting) for spasticity in people with} traumatic brain injury

Patient or population: adults with traumatic brain injury with spasticity in their arms (1 study) or calves ( 1 study)

Settings: rehabilitation/neurology clinics or acute general hospital, in Europe or the UK

Intervention: botulinum toxin $A \times 1$ dose $(500 / 1000 \mathrm{U})$ or botulinum toxin $\mathrm{A} \times 1$ dose of $200 \mathrm{U}+$ serial casting

Comparison: placebo $( \pm$ casting)

\begin{tabular}{|c|c|c|c|}
\hline Outcomes & Results and conclusions & $\begin{array}{l}\text { No of participants } \\
\text { (studies) }\end{array}$ & $\begin{array}{l}\text { Quality of the evi- } \\
\text { dence } \\
\text { (GRADE) }\end{array}$ \\
\hline $\begin{array}{l}\text { Spasticity at } \mathbf{4 - 1 2} \text { weeks (mea- } \\
\text { sured by both Modified Ashworth } \\
\text { Scale, } 0-5 \text {, at } 12 \text { weeks and Tardieu } \\
\text { Scale, } 0-5 \text {, at } 4 \text { weeks) }\end{array}$ & $\begin{array}{l}\text { We are uncertain about the effect of botulinum } \\
\text { toxin } A \text { ( } \pm \text { casting) vs placebo ( } \pm \text { casting) on } \\
\text { spasticity. }{ }^{1}\end{array}$ & $\begin{array}{l}47 \\
(2)^{2}\end{array}$ & $\begin{array}{l}\oplus \ominus \ominus \ominus \\
\text { Very low } 3\end{array}$ \\
\hline Adverse events & $\begin{array}{l}\text { We are uncertain about the effect of botulinum } \\
\text { toxin } A \text { ( } \pm \text { casting) vs placebo ( } \pm \text { casting) on ad- } \\
\text { verse events. }{ }^{4}\end{array}$ & $\begin{array}{l}47 \\
(2)^{2}\end{array}$ & $\begin{array}{l}\oplus \ominus \ominus \ominus \\
\text { Very low } 5\end{array}$ \\
\hline Sensory functions and pain & No study measured this outcome. & & \\
\hline $\begin{array}{l}\text { Neuromusculoskeletal and move- } \\
\text { ment-related functions at } 12 \\
\text { weeks (measured by ankle dorsi- } \\
\text { flexion) }\end{array}$ & $\begin{array}{l}\text { We are uncertain about the effect of botulinum } \\
\text { toxin } A \text { ( } \pm \text { casting) vs placebo ( } \pm \text { casting) on ad- } \\
\text { verse events. } 6\end{array}$ & $\begin{array}{l}47 \\
(2)^{2}\end{array}$ & $\begin{array}{l}\oplus \odot \ominus \ominus \\
\text { Very low } 7\end{array}$ \\
\hline General tasks and demands & No study measured this outcome. & & \\
\hline Mobility & No study measured this outcome. & & \\
\hline Self-care & No study measured this outcome. & & \\
\hline
\end{tabular}

GRADE Working Group grades of evidence

High quality: Further research is very unlikely to change our confidence in the estimate of effect.

Moderate quality: Further research is likely to have an important impact on our confidence in the estimate of effect and may change the estimate.

Low quality: Further research is very likely to have an important impact on our confidence in the estimate of effect and is likely to change the estimate.

Very low quality: We are very uncertain about the estimate. 
1 Gracies 2015 reported that "with abobotulinumtoxinA, the angle of catch (XV3 of the Tardieu Scale) improved in finger (+35 degree), elbow (+22 degree) and wrist (+12 degree) flexors" but no further outcome data were provided. For Verplancke 2005, we calculated the betweengroup difference in spasticity (as measured by the Modified Ashworth Scale) as mean difference 0.30 ( $95 \%$ confidence interval -0.87 to 1.47 ). 2Included studies: Gracies 2015; Verplancke 2005.

3Downgraded four times due to: risk of bias concerns for both studies (downgraded twice, because either insufficient information about random sequence generation and allocation concealment, in one study, and potential selective outcome reporting in both studies), indirectness (one study included mixed traumatic brain injury and stroke populations, and measured spasticity using the Modified Ashworth Scale) and a high likelihood of publication bias in this area.

${ }^{4}$ In the main trial of Gracies 2015 (in which the traumatic brain injury population was a part (9.5\%)) the most common botulinum toxin A-related adverse event was 'mild muscle weakness' and investigators reported that all adverse events were mild or moderate only. In Verplancke 2005, botulinum toxin A was reported to be well tolerated, with only one participant with 'flu-like' symptoms (i.e. shivering, sweating and fever). In groups who received casting (either alone, or in addition to botulinum toxin A), 41\% to 50\% developed 'minor' skin damage. Overall, $90.9 \%$ of those resolved spontaneously or with therapeutic dressing.

${ }^{5}$ Downgraded three times due to: risk of bias concerns for both studies (downgraded twice, because in one study there was insufficient information about random sequence generation and allocation concealment, and in both studies the adverse events data was reporting in percentages only) and a high likelihood of publication bias in this area.

6 Verplancke 2005 reported between-group differences in ankle dorsiflexion, finding no differences between groups in a one-way ANOVA (casting + placebo versus casting + botulinum toxin A: $\mathrm{P}=0.11$ ). However, they did not report any summary statistics for this, or any baseline scores.

${ }^{7}$ Downgraded four times due to: risk of bias concerns for both studies (downgraded twice, because either insufficient information about random sequence generation and allocation concealment, in one study, and potential selective outcome reporting in both studies), indirectness (one study included mixed traumatic brain injury and stroke populations) and a high likelihood of publication bias in this area.

\section{Summary of findings 3. Pseudoelastic orthosis versus traditional (static) splint for spasticity in people with traumatic brain injury}

\section{Pseudoelastic orthosis versus traditional (static) splint for spasticity in people with traumatic brain injury}

Patient or population: children/young people aged 4-18 years with traumatic brain injury and with 'mild to severe spastic tetraparesis' (weakness) in all limbs

Settings: Istituro Eugenio Media (Italy)

Intervention: repositioning splints equipped with participant-specific pseudoelastic hinges

Comparison: traditional splints with fixed angle braces

\begin{tabular}{|c|c|c|c|}
\hline Outcomes & Results and conclusions & $\begin{array}{l}\text { No of participants } \\
\text { (studies) }\end{array}$ & $\begin{array}{l}\text { Quality of the evi- } \\
\text { dence } \\
\text { (GRADE) }\end{array}$ \\
\hline $\begin{array}{l}\text { Spasticity at up to } 6 \text { hours after } \\
\text { treatment } \\
\text { (measured by the Modified Ash- } \\
\text { worth Scale, } 0-4 \text {, with a higher score } \\
\text { indicating greater spasticity) }\end{array}$ & $\begin{array}{l}\text { We are uncertain about the effect of pseudoe- } \\
\text { lastic splints compared with traditional splints } \\
\text { on spasticity. }{ }^{1}\end{array}$ & $\begin{array}{l}25 \\
(1)\end{array}$ & $\begin{array}{l}\oplus \odot \ominus \ominus \\
\text { Very low } 2\end{array}$ \\
\hline Adverse events & $\begin{array}{l}\text { We are uncertain about the effect of pseudoe- } \\
\text { lastic splints compared with traditional splints } \\
\text { on adverse events. }{ }^{3}\end{array}$ & $\begin{array}{l}25 \\
(1)\end{array}$ & $\begin{array}{l}\oplus \odot \odot \ominus \\
\text { Very low } 4\end{array}$ \\
\hline Sensory functions and pain & The included study did not report this outcome. & & \\
\hline $\begin{array}{l}\text { Neuromusculoskeletal and move- } \\
\text { ment-related functions post treat- } \\
\text { ment } \\
\text { (measured by range of movement) }\end{array}$ & $\begin{array}{l}\text { We are uncertain about the effect of pseudoe- } \\
\text { lastic splints compared with traditional splints } \\
\text { on range of movement. } 5\end{array}$ & $\begin{array}{l}25 \\
(1)\end{array}$ & $\begin{array}{l}\oplus \odot \odot \ominus \\
\text { Very low } 6\end{array}$ \\
\hline
\end{tabular}


General tasks and demands

\section{Mobility}

\begin{tabular}{l|l}
\hline Self-care & The included study did not report this outcome.
\end{tabular}

\section{GRADE Working Group grades of evidence}

High quality: Further research is very unlikely to change our confidence in the estimate of effect.

Moderate quality: Further research is likely to have an important impact on our confidence in the estimate of effect and may change the estimate.

Low quality: Further research is very likely to have an important impact on our confidence in the estimate of effect and is likely to change the estimate.

Very low quality: We are very uncertain about the estimate.

1One study comparing novel pseudoelastic orthoses to traditional fixed angle splints reported no improvement in spasticity in the upper and lower limbs, over a period of one month of intervention. and that results of the two steps were not significantly different (Pittaccio 2013).

2Downgraded four times due to risk of bias limitations (study provided no information about sequence generation and allocation concealment; blinding was impossible for participants or personnel and not reported for outcome assessors; selective outcome reporting bias was high); our concerns about indirectness of the Ashworth Score and indirectness due to $36 \%$ of participants not having traumatic brain injury and one participant was of dubious eligibility; an inability to assess imprecision relating to an absence of meaningful outcome data (no numerical data were provided for spasticity; investigators reported only that there were no significant differences), and there was only one study for this comparison/outcome and that publication bias was possible in this area.

${ }^{3} \mathrm{No}$ adverse events were reported for pseudoelastic orthoses neither did any require adjustments after fitting. Adjustments were required for $30 \%$ of traditional splints to reduce skin rash, haematomas and oedema.

${ }^{4}$ Downgraded four times due to risk of bias limitations (study provided insufficient information about sequence generation and allocation concealment, blinding was impossible for participants and personnel and not reported for outcome assessors, and selective reporting bias was high). We had concerns about indirectness given that $36 \%$ of participants did not have traumatic brain injury and one participant was of dubious eligibility. Furthermore, there was only one study for this comparison/outcome and publication bias was possible in this area. 5 One study reported no improvement in range of movement in the upper and lower limbs, over a period of one month of intervention (Pittaccio 2013).

${ }^{6}$ Downgraded five times due to risk of bias limitations (this study provided insufficient information about sequence generation and allocation concealment, blinding was impossible for participants and personnel and not reported for outcome assessors, and selective reporting bias was high). We had concerns about indirectness due to $36 \%$ of participants not having traumatic brain injury and one participant was of dubious eligibility; our inability to assess imprecision given that means and standard deviations were only presented within a small box and whiskers plot, and a further downgrade for there only being one study for this comparison/outcome and the likelihood of publication bias in this area. 


\section{B A C K G R O U N D}

Traumatic brain injury (TBI) is the result of an external force to the head, that can lead to permanent damage to the brain. There are many causes of TBI including motor vehicle accidents, falls, violent assaults or blast injuries (Maas 2008). In 2005, The US Centre for Disease Control and Prevention estimated at least 3.17 million Americans, approximately $1.1 \%$ of the US population, are living with long-term disability as a result of TBI (Summers 2009). In Europe, the incidence of TBI in studies published between 1983 and 2013 has been estimated to be between 47.3 to 849 per 100,000 population per year (Brazinova 2016). There are limited data available for low- to middle-income countries. The impact of TBI to a person can be far-reaching and may result in ongoing physical, cognitive and behavioural issues (Khan 2003). Skeletal muscle spasticity is one of the major physical complications following TBI (Brashear 2016).

\section{Description of the condition}

Spasticity is defined as an ongoing contraction of a muscle caused by an increase in muscle tone and deep tendon reflexes that is partly due to a reduction of the skeletal stretch reflex threshold (Lance 1980). It is often described as muscle overactivity. Spasticity occurs due to damage of upper motor neurons (UMN) of the corticoreticular pathways in the brain cortex or internal capsule, or damage to the UMNs in the reticulospinal or vestibulospinal tracts in the spinal cord (Pandyan 2005). Spasticity may occur sporadically or continuously, for periods of short and long duration.

Spasticity tends to affect the antigravity muscle groups in the upper and lower limbs (Nair 2014). In the upper limbs, this can commonly include the shoulder adductors, elbow, wrist and finger flexors, forearm pronators and thumb adductors. In the lower limbs, spasticity often affects the hip adductors, knee flexors, ankle plantarflexors and invertors, and big toe extensors (Nair 2014). Spasticity can also affect muscles in the neck.

There are limited epidemiological data regarding the prevalence of spasticity following TBI (Martin 2014; McGuire 2016). In one systematic review of the epidemiology of lower limb spasticity, Martin 2014 identified only one study (Singer 2004), conducted in 105 people with TBI that found the prevalence of ankle spasticity was $13 \%$. Similarly, McGuire 2016 was only able to find one study of spasticity prevalence following TBI (Wedekind 2005), which was a study of 32 people with TBI, in which the prevalence of spasticity (location unclear) was $32 \%$. While both the definition and measurement of spasticity is inconsistent, and often poorly defined (Malhotra 2009), McGuire 2016 suggests that by extrapolating data from studies in other populations (including people with stroke, spinal cord injury and multiple sclerosis), 'problematic' spasticity may occur in between $30 \%$ and $50 \%$ of people with TBI.

Spasticity can lead to a range of musculoskeletal issues such as muscle contracture, involuntary and uncontrollable shaking, joint stiffness, reduced range of movement, broken skin and pain (Ada 2006a; Ada 2006b). The debilitating nature of the condition can directly impact a person's ability to carry out normal activities of daily living (ADL), such as self-care and household tasks, and is likely to lead to dependency on carers or family members for assistance. Participation in daily life and opportunities for community integration can prove difficult and may ultimately impact the person's quality of life (Kwakkel 1999). Management of spasticity in people with TBI varies from other clinical populations primarily due to behavioural and cognitive issues that affect their ability to participate in, or tolerate, treatment (e.g. their ability to follow instructions, monitor use of a spastic limb or tolerate a cast). These factors are likely to impact on whether or not a treatment is effective in this population and limit the applicability of findings from other populations where behavioural and cognitive issues are not a primary concern (Manchester 1997; Wood 1999). Furthermore, some studies have shown that mobility limitations can be improved over time and that the presence, distribution and severity of spasticity may not necessarily be the best determinant in recovery and mobility outcomes (Williams 2015a; Williams 2015b).

The measurement of spasticity in clinical practice, and in research, is challenging (Malhotra 2009). The most common scales to measure spasticity are the (Modified) Ashworth Scale (Pandyan 1999) and the (Modified) Tardieu Scale (Haugh 2006). The (Modified) Ashworth Scale is commonly used by clinicians as it is the easier scale to complete (Pandyan 1999), however it only measures the resistance in a muscle, which may or may not be caused by spasticity (Patrick 2006). This is in contrast to the (Modified) Tardieu Scale which measures spasticity by the spasticity catch angle as well as resistance in the muscle (Haugh 2006). The Tardieu has also demonstrated greater test-retest and inter-rater reliability compared with the Modified Ashworth Scale (Mehrholz 2005). The (Modified) Tardieu includes a continuous and nominal (or sometimes considered ordinal (Haugh 2006)) component, and the (Modified) Ashworth is ordinal, but both are commonly treated as continuous scales by trialists. While there does not appear to be a clear consensus about the most appropriate way to analyse these scales, we note that for another five-point ordinal scale used in TBI (the Glasgow Outcome Scale (Jennett 1975)), a sliding dichotomy or proportional odds methodology is recommended for analysis (Maas 2010).

\section{Description of the intervention}

Interventions for managing skeletal muscle spasticity can be broadly categorised as either pharmacological or nonpharmacological. Examples of pharmacological interventions include baclofen (Becker 1997), botulinum toxin A, clonidine, dantrolene sodium, tizanidine and phenol injection (Meythaler 2001a; Yelnik 2009). Examples of non-pharmacological interventions include casting, splinting, stretching, strengthening, transcutaneous electric nerve stimulation (TENS) (Aydin 2005), Bobath treatment, weight bearing gait training and seating. In practice, a combination of both pharmacological and nonpharmacological interventions is used to manage spasticity. Interventions can be either focal or systemic in their action. Focal interventions involve treatment of one or two muscle groups whereas systemic interventions are used to treat generalised spasticity.

\section{How the intervention might work}

Interventions used to manage spasticity all aim to reduce overactivity within the muscle so that it can be lengthened (Esquenazi 2006).

Pharmacological interventions can act locally at the muscle or systemically through the central nervous system. For example, botulinum toxin $A$ and phenol are both injected locally at the site of the spastic muscle whereas other interventions such as 
tizanidine and clonidine are administered orally. Oral medications act systemically and can induce unwanted adverse effects, such as drowsiness. For those with severe spasticity in multiple areas, adverse effects associated with oral medications can sometimes outweigh the potential benefits of reduced spasticity. An alternative approach, as seen with baclofen, is to administer the treatment through a pump into the space around the spinal cord, thus reducing the impact of adverse effects whilst maintaining improved outcomes for spasticity (Becker 1997).
Non-pharmacological interventions involve the use of physical modalities such as stretching and strengthening to promote elongation and control of spastic muscles, or external devices such as casting or splinting to modify and maintain correct positioning of a spastic muscle. Table 1 provides a summary of the range of different interventions and their mode of action.

Table 1: Examples of the range of interventions to manage spasticity

\begin{tabular}{|c|c|c|}
\hline $\begin{array}{l}\text { Pharmacological } \\
\text { intervention }\end{array}$ & Mode of action & $\begin{array}{l}\text { Non-pharmacolog- } \\
\text { ical intervention }\end{array}$ \\
\hline
\end{tabular}

\begin{tabular}{|c|c|c|c|}
\hline Baclofen & $\begin{array}{l}\text { Administered orally or via intrathecal pump } \\
\text { to limit the release of excitatory neurotrans- } \\
\text { mitters in the spinal cord. }\end{array}$ & Casting & $\begin{array}{l}\text { Applied directly to the limb to main- } \\
\text { tain the muscle in an extended posi- } \\
\text { tion. }\end{array}$ \\
\hline
\end{tabular}

Botulinum toxin A A neurotoxin injected directly into the mus-

Splinting

Thermoplastic or fabric material that cle to block the release of the neurotransis customised to provide support to a person's limb and maintain the limb in the corrected position.

\begin{tabular}{|c|c|c|c|}
\hline Clonidine & $\begin{array}{l}\text { Administered orally or by transdermal patch } \\
\text { to act on the central nervous system by re- } \\
\text { ducing the excitability of alpha motor neu- } \\
\text { rons. }\end{array}$ & Seating & $\begin{array}{l}\text { Custom made seating for people to } \\
\text { provide maximal support and reduce } \\
\text { the impact of spasticity. }\end{array}$ \\
\hline $\begin{array}{l}\text { Dantrolene sodi- } \\
\text { um }\end{array}$ & $\begin{array}{l}\text { Administered orally to reduce the excita- } \\
\text { tion-contraction coupling within the skeletal } \\
\text { muscle and decrease the strength of muscle } \\
\text { contraction. }\end{array}$ & Stretching & $\begin{array}{l}\text { Promotes elongation of a muscle for } \\
\text { varying lengths of time causing viscous } \\
\text { deformation changes. }\end{array}$ \\
\hline Phenol & $\begin{array}{l}\text { Injected into specific nerves to induce neu- } \\
\text { rolysis to permanently block nerve transmis- } \\
\text { sion. }\end{array}$ & $\begin{array}{l}\text { Transcutaneous } \\
\text { electric nerve } \\
\text { stimulation }\end{array}$ & $\begin{array}{l}\text { Portable electric stimulator placed on } \\
\text { the skin over a spastic muscle to re- } \\
\text { duce pain. }\end{array}$ \\
\hline Tizanidine & $\begin{array}{l}\text { Administered orally to act on the central } \\
\text { nervous system and reduce the excitability } \\
\text { of alpha motor neurons. }\end{array}$ & Surgery & $\begin{array}{l}\text { Surgical techniques primarily aim to } \\
\text { alter the structure of a muscle or nerve } \\
\text { or relocate a tendon to change its func- } \\
\text { tion. }\end{array}$ \\
\hline
\end{tabular}

\section{Why it is important to do this review}

A range of interventions are currently used to manage skeletal muscle spasticity for people with TBI. Clinical management often involves a combination of pharmacological and non-pharmacological interventions. Management of spasticity following TBI varies from other clinical populations because of the added complexity of behavioural and cognitive issues associated with TBI. Furthermore, the current management for spasticity in other conditions may not be applicable to TBI as a result of global UMN damage that can occur such as axonal shearing, haemorrhage and hypoxia. A comprehensive systematic review of interventions assessed in the TBI population is needed to identify those likely to have the greatest impact for managing spasticity as well as determining whether the severity of TBI or the timing of an intervention is relevant to the outcome.
Reviews of interventions for spasticity in people with TBI are focused solely on the effect of one intervention (botulinum toxin A), and include people with spasticity due to other conditions, predominantly stroke (Baker 2015; Dashtipour 2016; Dong 2017). None of these reviews allow conclusions to be drawn specific to people with TBI. Systematic reviews that consider the effects of a broader range of interventions for managing spasticity have done so in populations other than TBI such as stroke (Taricco 2000) and spinal cord injury (Demetrios 2013; Hsieh 2012). To our knowledge, there are no systematic reviews that consider all potential interventions used to manage skeletal muscle spasticity specifically for people with TBI.

\section{OB JECTIVES}

To assess the effects of interventions for managing skeletal muscle spasticity in people with TBI. 


\section{METHODS}

\section{Criteria for considering studies for this review}

\section{Types of studies}

We included randomised controlled trials (RCT). Cross-over trials were included as long as the sequence of treatments was randomly allocated.

\section{Types of participants}

We included people with TBI of any age (i.e. children and adults), who had skeletal muscle spasticity experienced at any time after injury. We made a post-hoc decision to include only studies that either:

- included at least $50 \%$ of people with TBI amongst their participants;

- provided disaggregated data for participants with TBI if the proportion of participants within the trial was less than $50 \%$.

This decision was made in response to the identification of a large number of studies with mixed populations (e.g. stroke and TBI) that were found during screening to ensure the evidence would be applicable to people with TBI.

\section{Types of interventions}

We included studies that compared any of the following: pharmacological or non-pharmacological intervention (or a combination of both) or placebo/no treatment.

\section{Types of outcome measures}

\section{Primary outcomes}

- Spasticity, measured using common tools such as the Tardieu or Modified Tardieu Scale (Haugh 2006), or the Ashworth Scale or Modified Ashworth (Pandyan 1999).

- Adverse events.

As a post-hoc decision, we took Tardieu or Modified Tardieu, in preference to the (Modified) Ashworth Scale, in the instance that an included study used both these measures. This decision was made given the (Modified) Ashworth poorly differentiates between spasticity and contracture (Patrick 2006), and as the Tardieu is considered to have greater test-retest and inter-rater reliability compared with the Modified Ashworth Scale (Mehrholz 2005).

\section{Secondary outcomes}

A range of secondary outcomes were included, classified according to the World Health Organization International Classification of Functioning, Disability and Health (WHO 2010) using the following domains.

\section{Body functions}

- Sensory functions and pain (e.g. pain intensity).

- Neuromusculoskeletal and movement-related functions (e.g. goniometric measurement).

Activities and participation

- General tasks and demands (e.g. Canadian Occupational Performance Measure (Law 2000)).
- Mobility (e.g. gait and balance measures).

- Self-care (e.g. Functional Independence Measure (Keith 1987)).

- Domestic life (e.g. Goal Attainment Scale (Kiresuk 1994)).

- Major life areas (e.g. Functional Assessment Measure (Hall 1993)).

- Community, social and civic life (e.g. quality of life measures).

\section{Information size calculation}

In line with Cochrane Injuries policy, we undertook a post-hoc information size calculation, to determine the sample size required in a meta-analysis for the primary outcome, spasticity. Determining the parameters for this calculation was difficult, as the most commonly used measure of spasticity (the Ashworth or Modified Ashworth Scale) was not necessarily the most clinically meaningful, or appropriate (Haugh 2006), and it is also an ordinal scale that is frequently treated as continuous. Considering we could be combining more than one spasticity scale, we applied the 'rule of thumb' for determining a 'small' difference between two groups as a standardised mean difference (SMD) of 0.2 standard deviations (Guyatt 2011). Assuming 90\% power at the 5\% significance level, this means that we require 526 participants in both the intervention and control groups within a meta-analysis to be able to detect a difference between groups, if such a difference exists.

\section{Search methods for identification of studies}

To reduce publication and retrieval bias, we did not restrict our search by language, date or publication status.

\section{Electronic searches}

The information in this review is current to June 2017. Studies were identified through searches run in 2013, 2016 and 2017.

In November 2013, we searched the following databases:

- Cochrane Injuries Group specialised register (1 November 2013);

- the Cochrane Library (2013, Issue 10);

- Ovid MedLINE(R), Ovid MedLINE(R) In-Process \& Other Non-Indexed Citations, Ovid MEDLINE(R) Daily and Ovid OLDMEDLINE(R) (1946 to 1 November 2013);

- Embase Classic + Embase (OvidSP) (1947 to 1 November 2013);

- PubMed (www.ncbi.nlm.nih.gov/pubmed/) (1 November 2013);

- ISI Web of Science: Science Citation Index Expanded (SCIEXPANDED) (1970 to 01 November 2013);

- ISI Web of Science: Conference Proceedings Citation IndexScience (CPCI-S) (1990 to 1 November 2013);

- CINAHL Plus (1939 to 1 November 2013);

- PsycINFO (1806 to November 2013);

- PEDro (Physiotherapy Evidence Database) (1929 to November 2013);

- OTSeeker (Occupational Therapy Systematic Evaluation of Evidence) www.otseeker.com (1955 to November 2013);

- Database of Abstracts of Reviews of Effects (DARE) (November 2013).

In May 2016, the Cochrane Injuries Group Information Specialist developed and ran a new search. This was because of changes in the author team that meant we were unable to locate the exact search strategies used in the original search (beyond the MEDLINE strategy). The database list was reduced and included: 
- Cochrane Injuries Group Specialised Register (16 May 2016);

- MEDLINE (OvidSP) (16 May 2016);

- Embase Classic and Embase (OvidSP) (16 May 2016).

The search strategies for the 2016 search are listed in Appendix 1.

The Cochrane Injuries Information Specialist conducted a final prepublication search in June 2017. Given these searches were revised again by the Cochrane Injuries Information Specialist, we have listed the databases below. Some of the original databases were not searched in 2017 as the databases did not yield any unique studies in earlier searches.

We searched the following databases in June 2017 (and deduplicated against earlier yields):

- Cochrane Injuries Group Specialised Register (SR-INJ) (22 June 2017);

- the Cochrane Library (2017, Issue 6);

- Ovid MedLine(R), Ovid MedLINE(R) In-Process \& Other Non-Indexed Citations, Ovid MEDLINE(R) Daily and Ovid OLDMEDLINE(R) (2013 to 22 June 2017);

- Ovid Embase (1974 to 22 June 2017);

- PubMed (not MEDLINE) (www.ncbi.nlm.nih.gov/pubmed/) (22 June 2017);

- ISI Web of Science: Science Citation Index Expanded (SCIEXPANDED) (1970 to 22 June 2017);

- ISI Web of Science: Conference Proceedings Citation IndexScience (CPCI-S) (1990 to 22 June 2017);

- ClinicalTrials.gov (www.clinicaltrials.gov) (22 June 2017);

- WHO International Clinical Trials Registry Platform (apps.who.int/trialsearch/) (22 June 2017).

These search strategies are listed in Appendix 2 so they can be used in future updates.

\section{Searching other resources}

We screened the reference lists of all included articles and relevant reviews to identify additional studies for inclusion in the review.

\section{Data collection and analysis}

\section{Selection of studies}

Two review authors (KP, MC or AS) independently screened citations on abstract and title against the selection criteria. We obtained potentially eligible citations in full text and repeated the process. The two review authors discussed disagreements regarding study eligibility until consensus was reached or consulted a third review author for a final decision. For trials with mixed populations, we contacted study authors to obtain data or clarification (or both) to inform inclusion and exclusion decisions.

\section{Data extraction and management}

Two review authors (KP, MC or AS) independently extracted the data from included studies using a standardised data collection form, that was first piloted by two authors. One review author (KP) made a final check. We contacted the primary authors of included studies to provide data and clarification where adequate data were not reported.

\section{Assessment of risk of bias in included studies}

Two review authors (KP, MC or AS) independently assessed risk of bias of the included studies using the Cochrane 'Risk of bias' tool (Higgins 2011). We assessed sequence generation; allocation concealment; blinding of participants, personnel and outcome assessors; incomplete outcome data; selective outcome reporting; baseline imbalances and other bias issues. Additional domains for cross-over trials included appropriate study design and adequate washout period. Studies were rated as low, high or unclear risk of bias for each domain, according to the criteria used in the Cochrane 'Risk of bias' tool.

\section{Measures of treatment effect}

We extracted raw data (means and standard deviations for continuous outcomes and number of events for binary outcomes) for the primary and secondary outcomes. Where these were not provided, we extracted additional data such as sum scores and $\mathrm{P}$ values. We extracted postintervention scores over change scores.

Where possible, we calculated summary data as risk ratio (RR) with 95\% confidence intervals (Cl) (dichotomous outcomes) and mean difference (MD) with $95 \% \mathrm{Cl}$ (continuous data). Had we been able to pool continuous outcomes where the outcome was measured using different tools across studies, we would have used standardised mean difference (SMD) with $95 \% \mathrm{Cl}$. We analysed data in Review Manager 5 (RevMan 2011).

\section{Unit of analysis issues}

We sought to explore unit of analysis issues in the cross-over trials, but were unable to do so due to insufficient reporting.

\section{Dealing with missing data}

We contacted the primary authors of potentially eligible studies to provide data and clarification, where required. While several authors provided additional information to inform eligibility decisions, we did not receive any additional outcome data (some authors did not respond to our contact and others no longer had access to study data). We describe missing data and dropouts/ attrition for each included study in the 'Risk of bias' table, and discussed the extent to which the missing data could have altered the results and conclusions of the review.

\section{Assessment of heterogeneity}

We considered the clinical heterogeneity of studies, but statistical assessment of heterogeneity was not possible due to the absence of meta-analysis. If meta-analysis is possible in future updates, we will consider the magnitude and direction of effect and make a visual inspection of forest plots to assess the degree of overlap of $\mathrm{Cls}$ across separate studies and statistical heterogeneity quantified using the $\mathrm{I}^{2}$ statistic (Higgins 2011).

\section{Assessment of reporting biases}

Due to insufficient studies, formal assessment of reporting bias (via funnel plots) could not be carried out. In future updates, if there are more than 10 studies assessing the same outcome(s), we will construct a funnel plot to investigate small study effects (Higgins 2011). 


\section{Data synthesis}

We had planned to pool outcome data for studies that were considered sufficiently similar. The diversity of interventions and comparator groups as well as paucity of data available meant that a pooled analysis was not possible, therefore the results for each study are presented narratively. We grouped and assessed studies based on the type of intervention (pharmacological or non-pharmacological or a combination of both) and the comparison group (no treatment, placebo studies or an alternative intervention).

We assessed and reported the quality of the body of evidence contributing each outcome using the GRADE criteria (Schünemann 2011). These five criteria are: risk of bias, inconsistency, imprecision, indirectness and publication bias. Two review authors (AS, MC) independently assessed the quality of the evidence using the GRADE approach (Ryan 2016; Schünemann 2011).

\section{Subgroup analysis and investigation of heterogeneity}

We were unable to conduct planned subgroup analyses due to the lack of data. Should there be sufficient data in future updates, we will undertake subgroup analyses to investigate the effect of:

- timing of intervention post injury (i.e. early: within two years, versus late: at least two years' postinjury);

- severity of TBI defined by the Glasgow Coma Scale (Teasdale 1974);

- severity of spasticity as defined by the Ashworth Scale for muscle spasticity;

- single intervention versus combined interventions;

- mixed population studies versus studies with TBI participants only;

- adults versus children.

\section{Sensitivity analysis}

We were unable to conduct the planned sensitivity analysis due to the lack of available data. Should there be sufficient studies in future updates, we will investigate the effect of removing studies with inadequate or unclear allocation concealment from metaanalyses. This domain was selected as the allocation sequence can be concealed in all RCTs (unlike some domains, e.g. like blinding), and there is empirical evidence demonstrating the increased risk of selection bias that can be introduced by unconcealed allocation in studies with more subjective outcomes (such as spasticity and others assessed in this review) (Wood 2008).

\section{'Summary of findings' tables}

We made a post-hoc decision to prepare 'Summary of findings' tables to present the meta-analysed or narrative results along with the GRADE ratings of our main outcomes. These outcomes were selected on the basis of their clinical importance, rather than the study results. The outcomes included in the 'Summary of findings' table are: spasticity, adverse events, sensory functions and pain, neuromusculoskeletal and movement-related functions, general tasks and demands, mobility and self-care.

\section{RES U LTS}

\section{Description of studies}

\section{Results of the search}

Combining the yields of all searches up to June 2017, we identified 1743 citations after deduplication, excluding 1527 of these on title and abstract (see Figure 1). This left 216 citations assessed in full text, of which 201 were excluded (see Figure 1; Excluded studies; Characteristics of excluded studies table and Table 1 for more information and reasons). 
Figure 1. Study flow diagram for searches up until June 2017. TBA: traumatic brain injury.

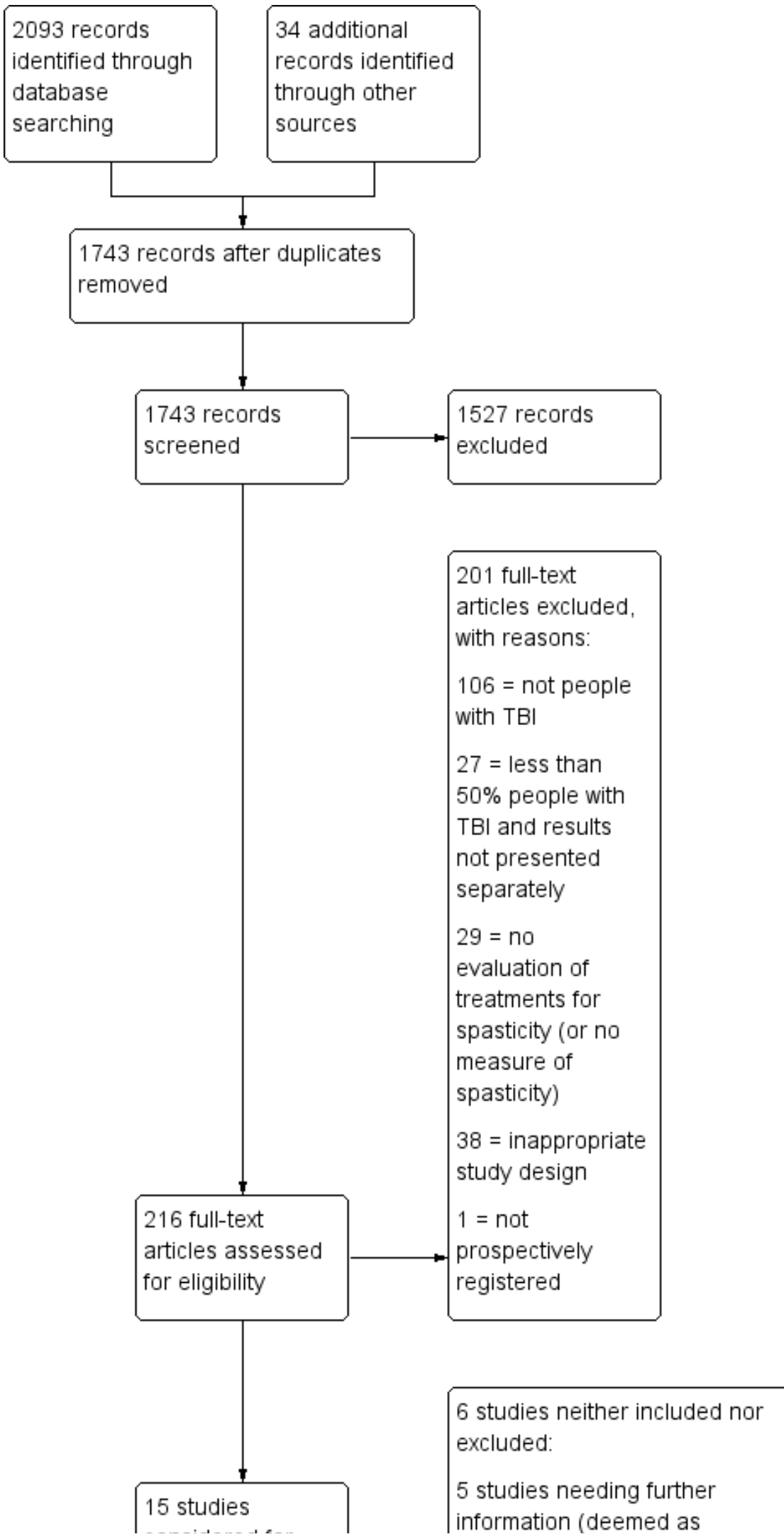


Figure 1. (Continued)

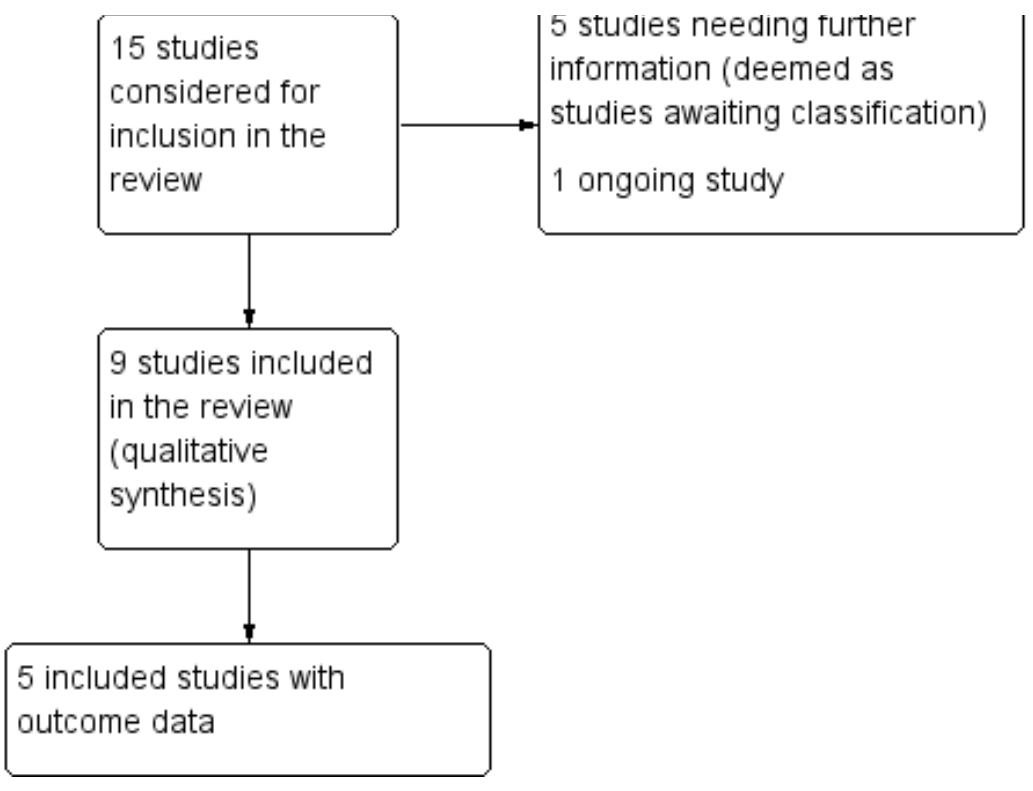

Of the remaining 15 studies that were considered for inclusion, we require further information about five studies (see the Characteristics of studies awaiting classification table) and one study is ongoing (see the Characteristics of ongoing studies table). The anticipated end date for the ongoing study investigating the combined effect of serial casting and botulinum toxin A on ankle contractures is September 2018 (ACTRN12615000821594).

We therefore included nine completed trials (Gracies 2015; Leung 2014; Meythaler 1996; Meythaler 1997; Meythaler 1999a; Meythaler 1999b; NCT00287157; Pittaccio 2013; Verplancke 2005).

\section{Included studies}

\section{Design}

We included nine studies involving data from 385 participants (134 with TBI) (Gracies 2015; Leung 2014; Meythaler 1996; Meythaler 1997; Meythaler 1999a; Meythaler 1999b; NCT00287157; Pittaccio 2013; Verplancke 2005; see Characteristics of included studies table). Of these, three were parallel group RCTs, with two (Leung 2014) or three comparator groups (Gracies 2015; Verplancke 2005). Six were randomised cross-over trials comparing treatment with placebo or standard care (Meythaler 1996; Meythaler 1997; Meythaler 1999a; Meythaler 1999b; NCT00287157; Pittaccio 2013).

Of the nine trials, three did not identify between-group differences in outcome data, neither did they report sufficient information about the results to allow us to calculate these differences (Meythaler 1997; Meythaler 1999a; Meythaler 1999b). Results from one trial remain unpublished and unavailable (NCT00287157). As such, only the data from five studies (combined 350 participants, of whom 105 had TBI) contributed outcome data to the results of this review (Gracies 2015; Leung 2014; Meythaler 1996; Pittaccio 2013; Verplancke 2005).

\section{Number of participants}

Within each study, the number of participants (TBI and nonTBI) ranged from six (Meythaler 1999a) to 243 (Gracies 2015). Most of these trials included mixed populations (TBI and non-
TBI). Two studies solely recruited people with TBI (51 combined participants) (Meythaler 1999b; Leung 2014), while Gracies 2015 provided disaggregated data for their subgroup of 23 participants with TBI (in the form of a conference abstract; O'Dell 2015). In the remaining six studies with mixed populations, the number of participants with TBI ranged from three (Meythaler 1999a) to 20 (Verplancke 2005), and the proportions of participants with TBI ranged from 50\% (Meythaler 1999a) to 91\% (Meythaler 1996).

\section{Setting}

All the trials were conducted in high-income settings, including the US (four trials), Australia (one trial), the UK (one trial), Italy (one trial) and Israel (one trial). One trial drew data from sites in nine high-income countries (Belgium, Czech Republic, France, Hungary, Italy, Poland, Russia, Slovakia, USA) (Gracies 2015). Participants were recruited from either tertiary care (outpatient or inpatient, or both) rehabilitation clinics or acute general hospitals.

Of the five studies with results, three were funded by governments, charities or health services (Meythaler 1996; Leung 2014; Pittaccio 2013), and two were funded by pharmaceutical/medical technology companies (Gracies 2015; Verplancke 2005). The four studies without useable results were funded by pharmaceutical/ medical technology companies (Meythaler 1997; Meythaler 1999a; Meythaler 1999b; NCT00287157).

\section{Participants}

\section{Age and sex}

With the exception of Gracies 2015, data for age and gender were not reported separately for TBI participants when they formed a proportion of 'mixed' populations. For this reason, the following information relates to the whole sample (including nonTBI participants) within trials except for Gracies 2015, along with Leung 2014 and Meythaler 1999b, which were the only trials in which all participants had a diagnosis of TBI.

Seven studies included adults, with a mean (or median) age of participants between 24 years (Meythaler 1996) and 41.5 years 
(Verplancke 2005). Two studies included children (NCT00287157; Pittaccio 2013); only Pittaccio 2013 reported the mean age of participants, being 7.75 years. Where reported, all studies include more males than females, ranging from 60\% (Meythaler 1999a) to 92\% (Meythaler 1997).

\section{Body part treated}

Four studies treated spasticity anywhere in the lower limbs, but also treated upper limb spasticity, if present (Meythaler 1996; Meythaler 1997; Meythaler 1999a; Meythaler 1999b). Two studies treated spasticity in the calf muscles (gastrocnemius, or gastrocnemius and soleus) (Leung 2014; Verplancke 2005), while Gracies 2015 treated spasticity in the upper limbs only (specifically elbow flexors, wrist flexors or finger flexors) and Pittaccio 2013 treated spasticity in the ankle or elbow. One study did not report the location of the spasticity (NCT00287157).

\section{Interventions and comparators}

The nine studies tested a varied range of pharmacological and nonpharmacological interventions. Pharmacological interventions that were tested against saline/placebo included intrathecal baclofen (Meythaler 1996; Meythaler 1997; Meythaler 1999a; Meythaler 1999b) and tizanidine (NCT00287157). Two additional, three-armed trials tested botulinum toxin A; Gracies 2015 tested two different doses of botulinum toxin $A$ against placebo, and Verplancke 2005 assessed botulinum toxin A plus casting against placebo plus casting and against physiotherapy.

Non-pharmacological interventions and comparisons tested include casting and physiotherapy (Verplancke 2005), pseudoelastic orthosis versus a traditional splint (Pittaccio 2013), and a combination of tilt table standing, electrical stimulation and ankle splinting versus tilt table standing alone (Leung 2014).

More details are provided about the interventions tested, grouped under different comparisons.

\section{Baclofen versus placebo}

Meythaler 1996 examined the effect of intrathecal baclofen for spastic hypertonia in the lower limbs. Eleven participants were allocated to receive a bolus intrathecal injection of either normal saline or baclofen $50 \mu \mathrm{g}$. Cross-over of participants occurred 48 hours after the initial administration. This study was in two parts: use of a bolus dose and then those participants with an adequate response were progressed to implantation of an intrathecal baclofen pump. This would be considered the usual method for evaluation for implantation of a baclofen pump.

The three other baclofen studies (Meythaler 1997; Meythaler 1999a; Meythaler 1999b) also assessed intrathecal baclofen infusion at the same dosage $(50 \mu \mathrm{g})$, but provided no useable results.

\section{Botulinum toxin A (with or without casting) versus placebo (with or without casting)}

Gracies 2015 assessed the effect of botulinum toxin A versus placebo for upper limb spasticity in 23 participants with TBI. In the initial treatment cycle, 14 participants received either abobotulinumtoxinA (500 U or $1000 \mathrm{U}$ ) and nine received placebo. The mode of administration was intramuscular injection. However, for participants with TBI, results were given in a binary method (only intervention versus placebo, without regard to dosage of abobotulinumtoxinA).
Verplancke 2005 compared the effects of three different interventions in 25 adults with lower limb spasticity, which we split into three, two-arm comparisons. The comparison included here is botulinum toxin A injections plus casting (12 participants) (200 $\mathrm{U} / \mathrm{leg}$ ) versus placebo plus casting (12 participants) (total of $4 \mathrm{~mL}$ saline injections).

\section{Physiotherapy versus placebo plus casting or botulinum toxin A plus} casting

The remaining comparisons for Verplancke 2005 were physiotherapy alone (11 participants) compared with casting plus botulinum toxin A injections (12 participants) $(200 \mathrm{U} / \mathrm{leg}$ ) or casting with placebo (12 participants) (total of $4 \mathrm{~mL}$ saline injections) in adults with lower limb spasticity.

\section{Tizanidine versus placebo}

NCT00287157 assessed the effect of tizanidine versus placebo on spasticity, cognition and daily function. The results were unpublished and no data were available.

\section{Pseudoelastic orthosis versus traditional splint}

In Pittaccio 2013, 25 children with elbow or ankle spasticity wore a spring-loaded orthosis comprised of two parts that could rotate relative to one another around a common axis that was individually customised and worn for one month. A traditional static splint was fitted and worn for one month. These treatments were delivered in a randomised cross-over manner.

\section{Tilt table standing, electrical stimulation and ankle splinting versus tilt table standing alone}

Leung 2014 (36 participants) evaluated a multi-modal treatment including 30 minutes of tilt table standing with electrical stimulation to the ankle dorsiflexors five times a week, with 12 hours per day of ankle splinting, at least five days a week. This was compared to the control group, who received 30 minutes of tilt table standing, three times a week. The total programme duration for intervention and control groups was six weeks.

\section{Outcomes}

For the five studies in which outcome data were provided, results were available for the primary outcomes of spasticity (assessed using the Tardieu Scale (Gracies 2015; Leung 2014), the Ashworth Scale (Meythaler 1996), or the Modified Ashworth Scale (Gracies 2015; Pittaccio 2013; Verplancke 2005)) and adverse events. All authors treated their measures of spasticity as continuous and numerical data provided were often sparse. Secondary outcomes measured included neuromusculoskeletal and movement-related functions (i.e. deep tendon reflexes, ankle range of movement), mobility, major life areas and community, social and civic life. The remaining secondary outcomes of interest to this review (sensory function and pain, general tasks and demands, self-care and domestic life) were not measured. Detailed information about the domains and scores used for these outcomes and the timing of their measurement in the studies is described in Table 2 and Table 3.

\section{Excluded studies}

In total, we excluded 169 studies on reading the full text, for reasons including no TBI participants (96 studies), less than 50\% of participants had TBI and results not presented separately ( 27 studies), no evaluation of treatments for spasticity (28 studies) 
or ineligible study design (e.g. review article; 18 references; see Characteristics of excluded studies for a list of 58 key studies excluded on full text).

Given the relatively large number of studies (27) that were excluded as less than $50 \%$ of study participants had a TBI (and the data for these participants were not presented separately), we provided more information in Table 1. Across these studies, there were 1000 participants, of whom $142(14 \%)$ had TBI. The percentage of people within each study who had TBI ranged from $2 \%$ to $47 \%$.

\section{Risk of bias in included studies}

The risk of bias for all included studies varied as detailed in the Characteristics of included studies table, and presented in Figure 2 and Figure 3. Many items were scored as 'unclear' due to poor reporting.

Figure 2. Risk of bias graph: review authors' judgements about each risk of bias item presented as percentages across all included studies. Nine studies are included in this review.

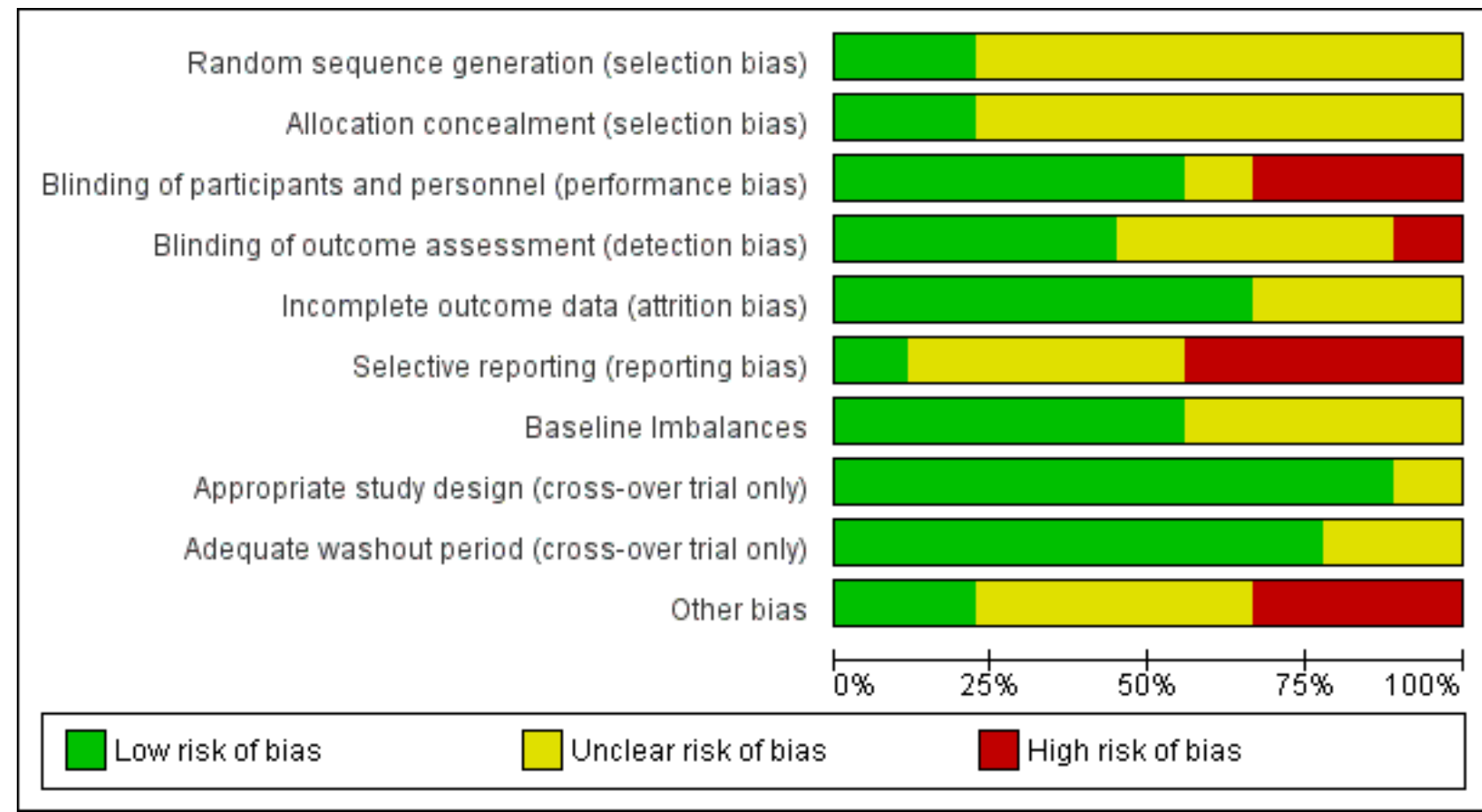


Figure 3. Risk of bias summary: review authors' judgements about each risk of bias item for each included study (note: only Meythaler 1996 and Verplancke 2005 contributed outcome data to the review).

\begin{tabular}{|c|c|c|c|c|c|c|c|c|c|c|}
\hline & 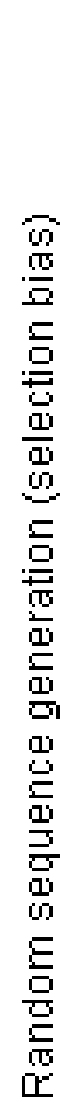 & 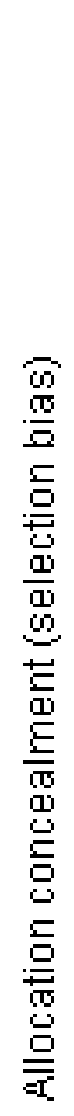 & 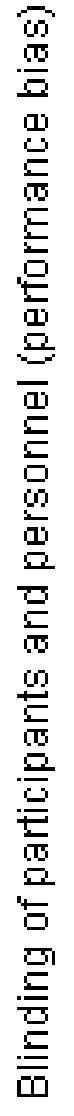 & 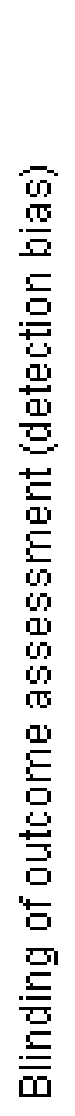 & 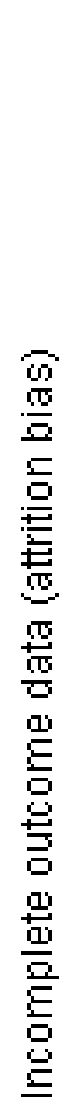 & 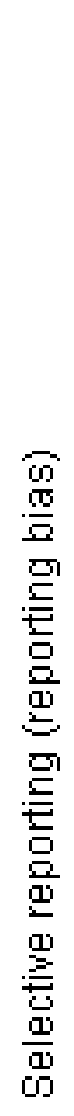 & 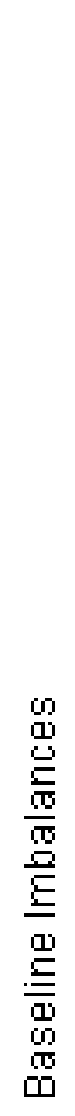 & 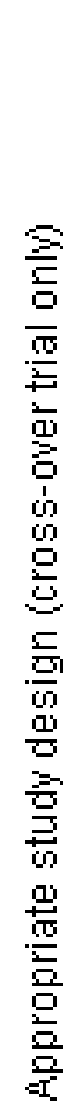 & 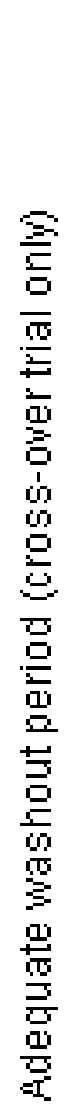 & 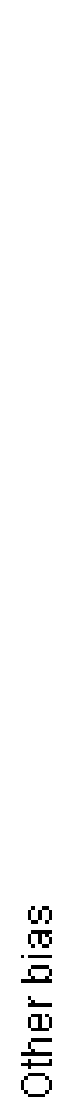 \\
\hline Gracies 2015 & + & + & & & & $?$ & $?$ & + & & ? \\
\hline Leung 2014 & + & + & & & $?$ & & $?$ & & & $?$ \\
\hline Meythaler 1996 & $?$ & $?$ & & + & & $?$ & + & & & \\
\hline Meythaler 1997 & $?$ & $?$ & & $?$ & & $?$ & & & & \\
\hline Meythaler 1999a & $?$ & $?$ & & $?$ & & & & & & \\
\hline Meythaler $1999 b$ & $?$ & $?$ & & $?$ & $A$ & $?$ & + & & $?$ & \\
\hline NCT00287157 & $?$ & $?$ & $?$ & $?$ & $?$ & & $?$ & $?$ & $?$ & $?$ \\
\hline Pittaccio 2013 & $?$ & $?$ & & & & & + & & + & $?$ \\
\hline Verplancke 2005 & $?$ & $?$ & & & $?$ & & $?$ & + & + & + \\
\hline
\end{tabular}




\section{Allocation}

Of the nine included studies, investigators involved in only two studies clearly reported the methods of both randomisation and allocation concealment, and these were assessed at low risk of bias for these domains (Gracies 2015; Leung 2014). None of the other study authors provided details of either randomisation or allocation concealment methods, making it difficult to determine any associated risks of bias. Seven studies were thus rated at 'unclear' risk of bias for both these domains.

\section{Blinding}

Five studies reported adequate blinding of participants and personnel (Gracies 2015; Meythaler 1996; Meythaler 1997; Meythaler 1999a; Meythaler 1999b). In three studies neither participants nor personnel could be blinded due to the obvious differences between interventions and controls (e.g. serial casting, different orthoses/splints), leading to ratings of high risk (Leung 2014; Pittaccio 2013; Verplancke 2005). The registry entry for NCT00287157 provided insufficient information and as such this study was rated as unclear.

Four studies explicitly reported that outcome assessors were blinded (Gracies 2015; Leung 2014; Meythaler 1996; Verplancke 2005). It is noteworthy that these were amongst the only studies with outcome data included in the review. In four studies, it was unclear if outcome assessors were blinded (Meythaler 1997; Meythaler 1999a; Meythaler 1999b; NCT00287157), and in one study outcome assessors could not be blinded, hence it was rated at high risk (Pittaccio 2013).

\section{Incomplete outcome data}

Six studies reported no losses to follow-up and were at low risk of attrition bias (Gracies 2015; Meythaler 1996; Meythaler 1997; Meythaler 1999a; Meythaler 1999b; Pittaccio 2013). Verplancke 2005 reported four withdrawals and three deaths; however, their final measurements for these participants were those taken before withdrawal from the study (rated as unclear as they did not report which group they were randomised to). Leung 2014 reported four losses to follow-up, with reasons that were unrelated to the trial; however, they were not balanced between groups. Both studies were rated as unclear risk of bias. The rating for NCT00287157 was 'unclear' due to lack of information.

\section{Selective reporting}

One study was at low risk of bias given the availability of a published protocol, which aligned with the subsequently published trial (Leung 2014). Three studies were at unclear risk of bias for selective reporting, as there were no published protocols (Meythaler 1996; Meythaler 1997; Meythaler 1999b). One study was also rated at unclear risk of bias as, while it did have a published protocol for the main study, the TBI subset outcome data for different doses of the active intervention were conflated and results were given in the form of percentages only (Gracies 2015). Three studies did not reference published protocols (neither could we identify any) and were at high risk due to additional incomplete reporting of their results (Meythaler 1999a; Pittaccio 2013; Verplancke 2005). NCT00287157 was at high risk of bias as the authors advised that the trial data were "negative," and was subsequently not published.

\section{Other potential sources of bias}

\section{Baseline imbalances}

With regards to baseline imbalances, five studies were at low risk of bias (Meythaler 1996; Meythaler 1997; Meythaler 1999a; Meythaler 1999b; Pittaccio 2013). Four studies were judged as unclear for this domain (Gracies 2015; Leung 2014; NCT00287157; Verplancke 2005). NCT00287157 was judged as unclear due to lack of information, whereas the other two studies described their groups as being 'similar' at baseline, but subsequently outlined some differences between the groups.

\section{Appropriate study design}

For the six cross-over trials, five used an appropriate study design (Meythaler 1996; Meythaler 1997; Meythaler 1999a; Meythaler 1999b; Pittaccio 2013). The remaining trial was at unclear risk of bias.

\section{Adequate washout period}

Three cross-over trials provided enough information to be judged as having an adequate washout period (low risk of bias) (Meythaler 1996; Meythaler 1997; Meythaler 1999a). Investigators in one trial judged it unethical to have a washout period (Pittaccio 2013). Statistical tests were conducted and presented demonstrating that sequential order did not affect treatment response, so this trial was also assessed as having a low risk of bias. The remaining two crossover trials were at unclear risk of bias for this domain (Meythaler 1999b; NCT00287157).

\section{Other bias}

With regards to 'other bias', three studies (Meythaler 1997; Meythaler 1999a; Meythaler 1999b) were at high risk of bias due to unit of analysis issues (outcomes were analysed by looking at upper versus lower extremities, rather than considering each muscle separately; scores for muscle tone, spasms and reflexes were averaged for the upper or lower extremities in each participant). Four studies were at unclear risk of bias due to insufficient information (NCT00287157); the close role of the funder (a pharmaceutical company) in the study design, conduct and analysis (Gracies 2015); the inclusion of a participant who did not meet the study inclusion criteria (Pittaccio 2013); and marked differences in the number of tilt table sessions between the intevention and control groups (Leung 2014). We did not identify any other bias concerns with the remaining two studies (Meythaler 1996; Verplancke 2005).

\section{Effects of interventions}

See: Summary of findings for the main comparison Baclofen compared with placebo for spasticity in people with traumatic brain injury; Summary of findings 2 Botulinum toxin A (with and without casting) compared with placebo (with and without casting) for spasticity in people with traumatic brain injury; Summary of findings 3 Pseudoelastic orthosis versus traditional (static) splint for spasticity in people with traumatic brain injury

\section{Baclofen versus placebo}

One study with usable results compared baclofen versus placebo (Meythaler 1996). (Three other studies compared baclofen to placebo but had no useable results; Meythaler 1997; Meythaler 1999a; Meythaler 1999b.) A summary of the results of the main 
outcomes for this comparison is provided in Summary of findings for the main comparison.

\section{Spasticity}

Meythaler 1996 (11 participants, all included in the analysis) reported between-group differences in both the lower and upper extremity Ashworth scores using P values, but with no effect sizes or Cls. It was unclear which statistical tests were used. As the study authors did not report any raw data for the placebo group results, we could do no further analysis. The authors reported a 'significant' improvement with baclofen compared to placebo at four hours ( $P$ $=0.0084)$ and six hours $(P=0.0163)$ after administration. Baclofen was also associated with 'significant' improvements compared to placebo for upper extremity Ashworth score $(P=0.0097)$ at four hours after administration, however this effect was not sustained at six hours ( $P$ value not reported).

The quality of the evidence on the effect of baclofen versus placebo for spasticity was very low (downgraded four times). This was due to risk of bias limitations (no study provided sufficient information about the random sequence generation or allocation concealment), our concerns about indirectness of the Ashworth score, an inability to assess imprecision relating to an absence of $\mathrm{Cls}$ and a further downgrade for there only being a single study for this outcome and the likelihood of publication bias in this area. Considered together with the fact that we could not judge how clinically relevant the improvements were in this study, we were very uncertain about the effect of baclofen on spasticity and unable to draw any conclusions.

\section{Adverse events}

There were no adverse events or changes in alertness level in the baclofen or placebo groups (see Table 4).

The quality of the evidence on the effect of baclofen versus placebo for spasticity was very low (downgraded three times). This was due to the same risk of bias concerns as for spasticity and that there was only one study for this outcome and the likelihood of publication bias in this area. As such, we were very uncertain about the effect of baclofen on adverse events compared to placebo and were unable to draw any conclusions.

\section{Neuromusculoskeletal and movement-related functions}

Meythaler 1996 (11 participants, all included in the analysis) reported that lower extremity spasm scores were significantly improved for baclofen versus placebo at four hours $(P=0.0073)$ and six hours $(P=0.0049)$ as were lower extremity reflex scores $(P$ $=0.0086$ at four hours and $P=0.0085$ at six hours). This effect was also observed for the upper extremity spasm scores $(P=0.0117)$ and reflex scores $(P=0.0272)$ at four hours after administration when baclofen was compared to placebo. This effect was not sustained at six hours ( $P$ value not reported).

The quality of this evidence was very low (downgraded four times, for all the reasons outlined for spasticity) and we are very uncertain about the effect of baclofen on neuromusculoskeletal and movement-related functions.

\section{Outcomes not measured}

The study did not report: sensory functions and pain; general tasks and demands; mobility; self-care; domestic life; major life areas; and community, social and civic life.

\section{Botulinum toxin A (with and without casting) versus placebo (with and without casting)}

Two studies compared botulinum toxin A (with and without casting) versus placebo (with and without casting) (Gracies 2015; Verplancke 2005). A summary of the results of the main outcomes for this comparison is provided in Summary of findings 2 .

\section{Spasticity}

Gracies 2015 (23 participants) report that four weeks after injection, "with abobotulinumtoxinA, the angle of catch (XV3 of the TS) improved in finger (+35 degree), elbow (+22 degree) and wrist (+12 degree) flexors, resulting in a gain in active muscle extension of at least 5 degrees active range of movement." No further outcome data were provided, and they did not comment on the 'statistical significance' of this result. We note that the dosage that produced this result (500 U or $1000 \mathrm{U}$ ) was unclear as data from both groups (total 14 participants) were pooled against placebo (nine participants).

Verplancke 2005 (35 participants) compared three different interventions, which we report as three two-arm comparisons (the authors analysed pre- and post-treatment differences in the Modified Ashworth Scale within groups, but not between groups). As such, we calculated the between-group difference in spasticity (as measured by the Modified Ashworth Scale at 12 weeks) for botulinum toxin A plus casting versus placebo plus casting as MD 0.30 points $(95 \% \mathrm{Cl}-0.87$ to 1.47 ; Analysis 1.1$)$.

The quality of the evidence for this outcome was very low (downgraded four times). This was due to risk of bias concerns for both studies (downgraded twice, because either insufficient information about random sequence generation and allocation concealment, in one study, and potential selective outcome reporting in both studies), indirectness (one study measured spasticity using the Modified Ashworth Scale) and a high likelihood of publication bias in this area. As such, we were very uncertain about the effect of botulinum toxin A with and without casting versus placebo with and without casting on spasticity and were unable to draw any conclusions.

\section{Adverse events}

In Gracies 2015, the authors reported that " 7 of 23 patients experienced a treatment emergent AE [adverse event]" and that of these, "none were unexpected." There was no further detail given in the short conference proceeding reporting results for the TBI population. In the main trial publication (of which people with TBI only made up $9 \%$ ), the most common treatment-related adverse event was 'mild muscle weakness' and investigators reported that all adverse events were mild or moderate only (see Table 4).

In Verplancke 2005, botulinum toxin A was to be well tolerated, with only one participant with 'flu-like' symptoms (i.e. shivering, sweating and fever). For the casting group, 50\% developed minor skin damage $(66.6 \%$ of those was partial thickness skin loss involving epidermis). Finally, in the botulinum toxin A plus casting group, $41.7 \%$ of participants developed skin damage $(60 \%$ of those 
was discolouration, but skin still intact). Overall, $90.9 \%$ of those resolved spontaneously or with therapeutic dressing (see Table 4).

The quality of the evidence for adverse events was very low (downgraded three times). This was due to risk of bias concerns for both studies (downgraded twice, because in one study there was insufficient information about random sequence generation and allocation concealment, and in both studies the adverse events data were reporting in percentages only) and a high likelihood of publication bias in this area. As such, we were very uncertain about the effect of botulinum toxin A with and without casting versus placebo with and without casting on adverse events and were unable to draw any conclusions.

\section{Neuromusculoskeletal and movement-related functions}

Verplancke 2005 reported between-group differences in ankle dorsiflexion, and found no differences between groups in a one-way ANOVA (placebo plus casting versus botulinum toxin A plus casting: $P=0.11$ ). However, they did not report any summary statistics for this, or any baseline scores.

The quality of the evidence for neuromusculoskeletal and movement-related functions was very low for the reasons outlined for spasticity (downgraded four times). As such, we were very uncertain about the effect of botulinum toxin $A$ with and without casting versus placebo with and without casting on neuromusculoskeletal and movement-related functions and were unable to draw any conclusions.

\section{Major life areas}

Both Gracies 2015 and Verplancke 2005 measured outcomes we classified under major life area outcomes. Gracies 2015 reported an "improvement in subjective function for the treated group $(>1$ grade decrease from baseline for the principal target of treatment on the Disability Assessment Scale (DAS)): $71 \%$ versus $22 \%$ for placebo." They did not provide this in absolute numbers, or comment on the 'statistical significance' of the result. Verplancke 2005 reported Glasgow Outcome Scale (GOS) and Glasgow Coma Scale scores at follow-up in each of the three groups, but reported mean values and did not report between-group differences.

The quality of the evidence for major life areas was very low (downgraded three times). This was due to risk of bias concerns for both studies (downgraded twice, because in one study there was insufficient information about random sequence generation and allocation concealment, and in both studies the outcome data were inappropriately analysed or reported in percentages only) and a high likelihood of publication bias in this area. As such, we were uncertain about the effect of botulinum toxin A with and without casting versus placebo with and without casting on major life areas and were unable to draw any conclusions.

\section{Community, social and civic life}

In Gracies 2015, the authors reported two quality of life measures (subscores of the 36-item Short Form Health (SF-36) and the EuroQol (EQ-5D); however, these outcomes were not reported separately for the subset of participants with TBI.

\section{Outcomes not measured}

The studies did not report: sensory functions and pain, general tasks and demands, mobility, self-care and domestic life.

\section{Physiotherapy versus placebo plus casting or botulinum toxin} A plus casting

One study compared physiotherapy versus placebo plus casting or botulinum toxin A plus casting (Verplancke 2005).

\section{Spasticity}

Verplancke 2005 compared three treatment groups: physiotherapy, placebo plus casting and botulinum toxin A plus casting. The authors analysed pre- and post-treatment differences in the Modified Ashworth Scale within but not between groups. As such, we calculated the following between-group differences in spasticity (as measured by the Modified Ashworth Scale at 12 weeks): botulinum toxin A plus casting versus physiotherapy (MD -0.50 points, $95 \% \mathrm{Cl}-1.82$ to 0.82 ; Analysis 2.1 ) and placebo plus casting versus physiotherapy (MD -0.80 points, $95 \% \mathrm{Cl}-2.00$ to 0.40 ; Analysis 3.1).

The quality of the evidence for physiotherapy compared to casting or botulinum toxin A plus casting on spasticity was very low. This was due to concerns about risk of bias related to insufficient information provided about allocation concealment and blinding, concerns about indirectness of the Modified Ashworth Scale, an inability to assess imprecision relating to an absence of $\mathrm{Cls}$ and a further downgrade for there only being one study for this outcome and the likelihood of publication bias in this area. As such, we are very uncertain about the effect of casting versus botulinum toxin $A$ plus casting versus physiotherapy on spasticity and were unable to draw any conclusions.

\section{Adverse events}

Verplancke 2005 withdrew two participants due to an adverse event (see Table 4). One was due to deep vein thrombosis (DVT) in the physiotherapy group and one was due to soft tissue contracture at the subtalar joint in the placebo plus casting group. For the adverse events related to botulinum toxin $A$, see the adverse events listed under the comparison above, botulinum toxin $A$ with and without casting versus placebo with and without casting.

The quality of the evidence for physiotherapy versus placebo plus casting or botulinum toxin A plus casting on adverse events was very low. This was due to concerns about risk of bias related to insufficient information provided about allocation concealment and blinding, and a further downgrade for there only being one study for this outcome and the likelihood of publication bias in this area. As such, we were very uncertain about the effect of casting versus botulinum toxin A plus casting versus physiotherapy on adverse events and were unable to draw any conclusions.

\section{Neuromusculoskeletal and movement-related functions}

Verplancke 2005 reported between-group differences in ankle dorsiflexion and found no differences between groups in a oneway ANOVA (physiotherapy versus placebo plus casting: $P$ value not significant, physiotherapy versus botulinum toxin A plus casting: $P$ $=0.07$ ). However, they did not report any summary statistics for this, or any baseline scores.

The quality of the evidence for physiotherapy versus placebo plus casting or botulinum toxin A plus casting on neuromuscular and movement-related outcomes was very low (downgraded three times). This was due to concerns about risk of bias (related to insufficient information provided about randomisation schedule 
generation and allocation concealment, a lack of blinding and selective outcome reporting), an inability to assess imprecision relating to an absence of data and a further downgrade for there only being one study for this outcome and the likelihood of publication bias in this area. As such, we were very uncertain about the effect of casting versus botulinum toxin A plus casting on neuromuscular and movement-related functions and were unable to draw any conclusions.

\section{Major life areas (e.g. Functional Assessment Measure)}

Verplancke 2005 reported GOS and GCS scores at follow-up in each of the three groups, but reported mean values and did not report between-group differences.

\section{Outcomes not measured}

The study did not report: sensory functions and pain; general tasks and demands; mobility; self-care; domestic life; and community, social and civic life.

\section{Pseudoelastic orthosis versus traditional (static) splint}

One study compared pseudoelastic orthosis versus traditional (static) splint in children (Pittaccio 2013). A summary of the results of the main outcomes for this comparison is provided in Summary of findings 3.

\section{Spasticity}

Pittaccio 2013 measured spasticity using the Ashworth Scale, but reporting for clinical outcomes in this paper was scant. The authors provided no outcome data for spasticity but stated that, "there were no significant differences on means by paired 2-tailed Student's t test" between the two types of splint.

The quality of the evidence was very low. The rating was downgraded four times due to risk of bias limitations (the study provided no information about sequence generation and allocation concealment; blinding was impossible for participants or personnel and not reported for outcome assessors; selective outcome reporting bias was high); our concerns about indirectness of the Ashworth score and indirectness due to $36 \%$ of participants not having $\mathrm{TBI}$ and one participant was of dubious eligibility; an inability to assess imprecision relating to an absence of meaningful outcome data (no numerical data were provided for spasticity; investigators reported only that there were no significant differences), there was only one study for this comparison/outcome and publication bias was possible in this area. As such, we were very uncertain about the effect of pseudoelastic orthoses versus a traditional (static) splint on spasticity and were unable to draw any conclusions.

\section{Adverse events}

Pittaccio 2013 reported that both participants and families 'reacted positively' to the pseudoelastic orthoses, which were described as well-tolerated for several hours a day, and never caused problems familiar to those using more traditional devices including a skin rash, haematomas or pain (see Table 4). None of the pseudoelastic orthoses had to be modified to improve comfort, while some adjustments were required for approximately $30 \%$ of traditional splints, in order to reduce skin rash, haematomas and oedema. Tolerability was assessed by questionnaire. The investigators conceded that true knowledge of comfort/discomfort experienced by children in the trial was impossible to assess as most participants were unable to communicate; nevertheless, questionnaire data were reported to be encouraging and on average, the pseudoelastic devices were tolerated $40 \%$ longer than traditional splints.

The quality of the evidence was very low (downgraded four times). The quality was downgraded due to risk of bias limitations (this study provided insufficient information about sequence generation and allocation concealment, blinding was impossible for participants and personnel and not reported for outcome assessors, and selective reporting bias was high). We had concerns about indirectness given that $36 \%$ of participants did not have TBI and one participant was of dubious eligibility. Furthermore, there was only one study for this comparison/outcome and publication bias was possible in this area. As such, we were very uncertain about the effect of pseudoelastic orthoses versus a traditional (static) splint on adverse events and were unable to draw any conclusions.

\section{Neuromusculoskeletal and movement-related functions}

Pittaccio 2013 reported results for range of motion as nonsignificant ("no significant differences on means by paired 2-tailed Student's t tests") and no further numerical data were given.

The quality of the evidence was very low. The quality of the evidence was downgraded five times due to risk of bias limitations (this study provided insufficient information about sequence generation and allocation concealment, blinding was impossible for participants and personnel and not reported for outcome assessors, and selective reporting bias was high). We had concerns about indirectness due to $36 \%$ of participants not having TBI and one participant was of dubious eligibility; our inability to assess imprecision given that means and standard deviations were only presented within a small box and whiskers plot, and a further downgrade for there only being one study for this comparison/outcome and the likelihood of publication bias in this area. As such, we were very uncertain about the effect of pseudoelastic orthoses versus a traditional (static) splint on neuromusculoskeletal and movement-related functions and were unable to draw any conclusions.

\section{Outcomes not measured}

The study did not report: sensory functions and pain; general tasks and demands; mobility; self-care; domestic life; major life areas; and community, social and civic life.

\section{Tilt table standing, electrical stimulation and ankle splinting versus tilt table standing alone}

One study compared tilt table standing, electrical stimulation and ankle splinting versus tilt table standing alone (Leung 2014).

\section{Spasticity}

Leung 2014 measured spasticity at six weeks (end of programme) and 10 weeks (end of trial) using the 5-point 'reaction to passive stretch at high speed' component of the Tardieu Scale. Leung 2014 treated this as a continuous scale and reported the difference between groups using change scores, which we plotted using postintervention scores only (see Analysis 4.1). This resulted in an MD of -1.00 points $(95 \% \mathrm{Cl}-1.66$ to -0.34 ) at week six (in favour of tilt table standing, electrical stimulation and ankle splinting) and 
an MD of 1.00 (95\% $\mathrm{Cl} 0.31$ to 1.69) at week 10 (in favour of tilt table standing alone). This is broadly consistent with the conclusions of the authors that "there was a small mean reduction of 1 point in spasticity at Week $6(95 \% \mathrm{Cl} 0.1$ to 1.8$)$ in favour of the experimental group, but this effect disappeared at Week 10."

The quality of the evidence for tilt table standing, electrical stimulation and ankle splinting versus tilt table standing alone on spasticity was very low (downgraded three times). This was due to concerns about indirectness (downgraded once for potentially inappropriate analysis of the Tardieu Scale as a continuous measure), imprecision (downgraded once as there was only one small study for this outcome) and the likelihood of publication bias in this area (downgraded once). As such, we were very uncertain about the effect of tilt table standing, electrical stimulation and ankle splinting versus tilt table standing alone on spasticity and were unable to draw any conclusions.

\section{Adverse events}

While Leung 2014 did not explicitly measure adverse events, they provided a description of a number of factors that influenced several participants' adherence to tilt table standing, including fainting, fatigue and storming (when someone with a head injury responds to a sensation with a tonic posture or sympathetic response). Additionally, two participants' adherence to splinting was affected by "skin problems" and "poor tolerance."

\section{Neuromusculoskeletal and movement-related functions}

Leung 2014 measured passive ankle dorsiflexion at $12 \mathrm{Nm}$ at six weeks (end of programme) and 10 weeks (end of trial). Dorsiflexion was measured relative to a neutral ankle position ( 0 degrees), with a positive score indicating dorsiflexion (the desired direction of movement) and a negative score indicating plantarflexion. They explored the differential effects using change scores, but we recalculated this using postintervention scores (see Analysis 4.2). This yielded an MD of -2.00 degrees $(95 \% \mathrm{Cl}-7.19$ to 3.19$)$ at six weeks and an MD of 1.00 degree $(95 \% \mathrm{Cl}-3.31$ to 5.31$)$ at 10 weeks.

The quality of the evidence for tilt table standing, electrical stimulation and ankle splinting versus tilt table standing alone on neuromuscular and movement-related functions was very low (downgraded three times). This was due to imprecision (downgraded once) related to the $\mathrm{Cl}$ including both a meaningful benefit and harm, using Leung 2014's prespecified 'minimum worthwhile treatment effect' of 5 degrees, there was only one study for this outcome (downgraded once) and the likelihood of publication bias in this area (downgraded once). As such, we were very uncertain about the effect of tilt table standing, electrical stimulation and ankle splinting versus tilt table standing alone on neuromusculoskeletal and movement-related functions and were unable to draw any conclusions.

\section{Mobility}

Leung 2014 measured mobility using walking speed (in metres/ second) at six weeks (end of programme) and 10 weeks (end of trial). They assessed between-group differences using change scores, which we recalculated using postintervention scores (see Analysis 4.3). This yielded a MD of $-0.10 \mathrm{~m} /$ second $(95 \% \mathrm{Cl}-0.43$ to $0.23)$ at six weeks and $0.00(95 \% \mathrm{Cl}-0.38$ to 0.38$)$ at 10 weeks.
The quality of the evidence for tilt table standing, electrical stimulation and ankle splinting versus tilt table standing alone on mobility was very low. The quality of the evidence was downgraded four times due to risk of bias concerns (participants and personnel could not be blinded and there were some imbalances between groups in the length of time since injury and the number of tilt table sessions received), for imprecision (single study and the $\mathrm{Cl}$ included a potential benefit and harm) and the likelihood of publication bias in this area. As such, we were uncertain about the effect of tilt table standing, electrical stimulation and ankle splinting versus tilt table standing alone on mobility and were unable to draw any conclusions.

The study did not report: sensory functions and pain; general tasks and demands; self-care; domestic life; major life areas; and community, social and civic life.

\section{Tizanidine versus placebo}

One study compared tizanidine versus placebo (NCT00287157) in children. However, we have no information regarding participants and no information about the effect of tizanidine versus placebo on spasticity or any other outcomes as the results of this study are unavailable and unpublished.

\section{DISCUSSION}

\section{Summary of main results}

We found nine RCTs, including 385 participants (of whom 134 had $\mathrm{TBI}$ ), that assessed the effect of a wide range of pharmacological and non-pharmacological treatments for spasticity as a result of TBI. Only five of these studies reported results in sufficient detail to allow synthesis in the review. As such, we included data from studies with 350 participants (105 of whom had TBI) in which baclofen, botulinum toxin A, casting, physiotherapy, splints, tilt table standing and electrical stimulation were tested, either alone or in combination.

Given such heterogeneity of interventions, trials for any given intervention were few, and sample sizes were small. Added to this, reporting of methods and results for trials was patchy, we had concerns about indirectness given the number of studies in this review with mixed populations, and publication bias given the known (and potentially unknown) unpublished studies in this area. These factors combined to mean there was a paucity of evidence about the effect of interventions for the management of spasticity in people with TBI. The quality of the evidence for all outcomes was very low.

In the interests of completeness, we provided a rudimentary summary of the results for the primary outcomes of spasticity and adverse events. Results were mixed for spasticity, but we cautioned against drawing conclusion given the very low quality evidence. For pharmacological interventions, baclofen had a greater effect than placebo after six hours of treatment in the lower limbs but not upper limbs (Meythaler 1996), and botulinum toxin A had a greater effect than placebo at four weeks in the upper limbs (Gracies 2015), but when combined with casting it had no greater effect than casting alone in the lower limbs (Verplancke 2005). For nonpharmacological studies, physiotherapy compared with casting in the lower limbs (Verplancke 2005), and novel pseudoelastic splints with traditional splints at the ankle or elbow (Pittaccio 2013), demonstrated no differences between treatments. 
For adverse events, the quality of the evidence was similarly very low, but the results were a little more consistent. For pharmacological treatments, there were no adverse events reported in the baclofen study (Meythaler 1996), or the group which received botulinum toxin A in Verplancke 2005, but $7 / 23$ participants in the botulinum toxin $A$ study by Gracies 2015 experienced a "treatment emergent adverse event" (no further information provided). Many of the non-pharmacological treatments were associated tolerability/ adherence issues, including traditional splints (Leung 2014; Pittaccio 2013) and tilt table standing (Verplancke 2005). In Verplancke 2005 , between $41.7 \%$ and $50 \%$ of participants who received casting developed minor skin damage, of which, $90 \%$ resolved spontaneously. In Verplancke 2005, two more serious adverse events developed in the physiotherapy group (DVT) and the casting plus placebo group (joint contracture).

Due to the very low quality of evidence, we were uncertain about the effects of any of these interventions for managing spasticity.

\section{Overall completeness and applicability of evidence}

This review indicated that the evidence for existing interventions for managing spasticity in TBI is limited. Given the paucity of welldesigned and reported trials, the applicability of this review to the TBI population was limited as there were many factors that needed to be considered which none of the studies addressed.

Clinicians can find the management of TBI challenging due to the varying extent of the UMN damage causing spasticity affecting many muscles and joints, trunk, limbs, head and neck leading to complex physical disabilities and often coexisting cognitive and behavioural impairments. These confounding factors can impact on spasticity management as people with TBI may have a lower tolerance for treatments, as well as an inability to monitor or participate in the learning and practice required for rehabilitation. Consideration for a greater research base to be developed in this area is extremely important.

There are varying levels of evidence for the management of spasticity in other neurological populations (Ade-Hall 2000; Amatya 2013; Duarte 2016; Demetrios 2013; Lindsay 2013; RCP 2009; Shakespeare 2003; Taricco 2000). There is an assumption made that the effects of pharmacological and non-pharmacological interventions in other conditions (e.g. multiple sclerosis, stroke) are the same for TBI. While at an impairment level the outcome may potentially be comparable, there can be a difference at a functional level. There is little evidence for the effect of these interventions at a functional level (Francis 2004).

\section{Quality of the evidence}

The quality of the evidence for all outcomes was very low due to risk of bias concerns (a combination of poor reporting and poor conduct), indirectness related to mixed populations or the outcome measures used (or both), imprecision and the likelihood of publication/reporting biases in this area. We did not formally downgrade the quality of the evidence for the analysis approach taken in studies that measured spasticity (where all the authors treated the ordinal scales as continuous) given the lack of consensus about how best to analyse these data, but this may introduce a further flaw in the interpretation.

\section{Potential biases in the review process}

The decision to limit inclusion of studies with a mixed clinical population to those with greater than $50 \%$ of participants with TBI had a major impact on the number of included studies in the review. Had we reduced or removed the threshold, we could have increased the number of included studies by a further 27. Had we increased the threshold to $100 \%$ (similar to the approach taken in one TBI trial overview (Bragge 2016)) we would have reduced the number of included studies to three. As such, the level of the threshold used in the review may have affected the results and conclusions. This threshold was set during the screening stages of the review (i.e. before extraction of results data) and was determined using clinical judgement.

\section{Agreements and disagreements with other studies or reviews}

As far as we are aware, this is the only systematic review evaluating any intervention for skeletal muscle spasticity, specifically in people with TBI. Three non-Cochrane systematic reviews of RCTs have each investigated the efficacy of botulinum toxin $A$ for spasticity (due to TBI and other causes) in the upper limbs (Dong 2017), lower limbs (Dashtipour 2016), and upper and lower limbs (Baker 2015). Each review included a majority of studies in people with stroke, but all included some studies with mixed stroke and TBI populations. Dashtipour 2016 was the only review to include any study (Gracies 2015) that was common to our review. These reviews concluded that there was favourable evidence to support the use of botulinum toxin A in the upper limb (both Baker 2015 and Dong 2017 found improvements in global benefit or "ease of care" measures) and either an absence of evidence (Baker 2015) or 'the beginnings of an evidence base' showing spasticity reductions (Dashtipour 2016) in the lower limb. Given the included studies in each of these reviews included predominantly people with stroke, we would question the applicability of these results to people with TBI. One other non-Cochrane systematic review looked at the use of casting in people with brain injury, the majority of whom had TBI (Mortenson 2003). Only five out of the 13 included studies measured spasticity as an outcome and reported improvement to some extent following casting. However, it was noted by the author that the quality of this evidence was low and that none of these studies used a true randomised design.

There are several Cochrane Reviews that investigated a broader range of treatments for spasticity in other conditions such as stroke (Demetrios 2013), multiple sclerosis (Amatya 2013; Shakespeare 2003), amyotrophic lateral sclerosis/motor neuron disease (Ashworth 2012), cerebral palsy (Ade-Hall 2000; Hoare 2010), and spinal cord injury (Taricco 2000). Interventions ranged from multidisciplinary rehabilitation following botulinum toxin A (and other intramuscular treatment), pharmacological (e.g. botulinum toxin $\mathrm{A}$, baclofen, tizanidine) and non-pharmacological interventions (e.g. physical activity), or a combination of interventions. It is notable that with the exception of one review (Hoare 2010), all reviews reported low or insufficient evidence for any of these interventions as a result of heterogeneity, high risk of bias and lack of information. Hoare 2010 found strong evidence to support botulinum toxin $\mathrm{A}$ as an adjunct to occupational therapy in managing upper limb spasticity in children with cerebral palsy. 


\section{AUTHORS' CONCLUSIONS}

\section{Implications for practice}

This review identified a number of studies in which the authors evaluated the effectiveness of spasticity treatment in traumatic brain injury (TBI); however, there is insufficient evidence from clinical trials to guide clinical practice.

\section{Implications for research}

There is an urgent need for more high quality, adequately powered trials in this area; the lack of TBI participants in studies is of great concern. In addition, there is a need for further evaluation of the assessment tools to ensure that the outcomes for people with $\mathrm{TBI}$ and spasticity are reliable. Any future studies should include specific functional measures which focus on goal attainment for individual patients.

Data need to be made available from studies which remain unpublished.

Outcome assessment of spasticity treatment is complicated. Two assessment scales measuring the impairment caused by spasticity are generally used; the Modified Ashworth Scale (Pandyan 1999) and the Modified Tardieu Scale (Haugh 2006). Four studies included within this review used the (Modified) Ashworth Scale. This scale is considered to measure resistance to passive movement not spasticity, as it does not evaluate a muscle's response to movement at speed (Allison 1995; Pandyan 2005). Spasticity is an indication of abnormal neural mechanisms causing a velocity-dependent increase in tonic stretch reflexes (Lance 1980). Therefore, by this definition, it will only be seen when a muscle is moved at speed. Where spasticity may be present in a muscle, the muscle may have altered mechanical properties that have developed over time causing a resistance to passive movement. It is these properties which can affect the quantification of spasticity by the Modified Ashworth Scale (Morris 2002). In comparison, the Modified Tardieu Scale (Haugh 2006; Mehrholz 2005), used by two studies included within this review (Gracies 2015; Leung 2014), is considered by many to be more appropriate measure with similar characteristics as the Modified Ashworth Scale; however, the scale requires that movement be carried out at two different speeds recording a 'catch angle.' It is this component of the scale that is more appropriate for measuring spasticity (Haugh 2006; Morris 2002). However, it is also notable that there are reliability issues with both measures; the Modified Tardieu Scale has very good test-retest reliability, but both have reduced inter-rater reliability (Fleuren 2010; Haugh 2006; Mehrholz 2005; Morris 2002).

Any spasticity intervention needs to address specific functional limitations for a person such as drinking from a glass or fastening a button (Francis 2004; Mayer 2008; Parke 1989; Pierson 1996). An individualised goal directed functional assessment combined with an impairment assessment is recommended to evaluate the effect of an intervention for people with a TBI. Global measures of function are only valid where global treatments such as baclofen are used. It is important that specific measures are identified for specific functional deficits so that any intervention can be assessed by the functional gains made by a person. Potential harms also need to be considered for treatments with proven effectiveness. Spasticity interventions can be costly and painful for a person. Spasticity can be blamed for weakness, contracture and loss of function, and if not clearly identified interventions for spasticity can be used inappropriately, causing further discomfort for no measurable benefit, and a waste of time and money. With respect to impairments such as pain and broken skin, impairment measures alone can indicate an effective outcome.

It has been acknowledged that spasticity intervention should occur within the context of a rehabilitation team, and little evidence exists to demonstrate how or where this should occur (Demetrios 2013; Giovannelli 2007; Olver 2010; RCP 2009). It is recommended that "botox injection must be part of a rehabilitation program involving post-injection exercise, muscle stretch and/or splinting to achieve an optimal clinical effect" (RCP 2009, p.vii). The implementation of 'botox' clinics which have a multidisciplinary approach to allow for assessment, treatment and review can mirror some of the rehabilitation processes that occur in a rehabilitation programme. However, when people have returned to living in the community these processes may not occur so effectively due to lack of access or funding. It is not only the complexity of TBI with its associated behaviours and cognitive issues that complicate managing this population, but also where a person lives, their access to services and the type of support they have available to live their life.

A moderate to severe TBI can lead to long-term disability impacting on ADL and quality of life. Impairments such as spasticity can reduce independence, and cause pain and dysfunction in a person's life. It is important to identify interventions for this population which will maximise the functional gains required for a person with TBI to achieve their goals. We need to assess these outcomes utilising reliable and valid assessment scales and this needs to occur within management programmes which have structure and support for clinicians and people with TBI alike.

\section{ACKNOWLEDGEMENTS}

The authors would like to thank Cochrane Injuries Group Managing Editor Helen Wakeford and Co-ordinating Editor Emma Sydenham for their helpful advice and assistance, along with Jane Dennis (Editor) for her help incorporating two studies and developing 'Summary of findings' tables, and Jo Weldon for serving as a consumer referee. We acknowledge Anne Parkhill for consultation and advice regarding the original search strategies, and would like to thank Deirdre Beecher and Sarah Dawson (Cochrane Injuries Information Specialists) for revising and rerunning subsequent searches. Finally, we thank current and former Cochrane Australia staff (Kelly Allen, Jo McKenzie, Miranda Cumpston and Simon Turner) for their valuable methodological and statistical input. 
R E F E R E N C E S

\section{References to studies included in this review}

\section{Gracies 2015 \{published data only\}}

Gracies JM, Brashear A, Jech R, McAllister P, Banach M, Valkovic $P$, et al. Safety and efficacy of abobotulinumtoxinA for hemiparesis in adults with upper limb spasticity after stroke or traumatic brain injury: a double-blind randomised controlled trial. Lancet Neurology 2015;14:992-1001.

* O'Dell MW, Walker HW, Edgley SR, Gracies JM, Gul F, Wimmer $\mathrm{M}$, et al. AbobotulinumtoxinA (Dysport ${ }^{\oplus}$ ) in the treatment of adult patients with upper limb spasticity due to traumatic brain injury. $P M \& R$ : the Journal of Injury, Function, and Rehabilitation 2015;7:S103.

\section{Leung 2014 \{published data only\}}

Leung J, Harvey LA, Moseley AM, Whiteside B, Simpson M, Stroud K. Standing with electrical stimulation and splinting is no better than standing alone for management of ankle plantarflexion contractures in people with traumatic brain injury: a randomised trial. Journal of Physiotherapy 2014;60:201-8.

\section{Meythaler 1996 \{published data only\}}

Meythaler JM, DeVivo MJ, Hadley M. Prospective study on the use of bolus intrathecal baclofen for spastic hypertonia due to acquired brain injury. Archives of Physical Medicine and Rehabilitation 1996; Vol. 77, issue 5:461-6.

\section{Meythaler 1997 \{published data only (unpublished sought but not used)\}}

Meythaler JM, McCary A, Hadley MN. Prospective assessment of continuous intrathecal infusion of baclofen for spasticity caused by acquired brain injury: a preliminary report. Journal of Neurosurgery 1997; Vol. 87, issue 3:415-9.

Meythaler 1999a \{published data only (unpublished sought but not used)\}

Meythaler JM, Guin-Renfroe S, Hadley MN. Continuously infused intrathecal baclofen for spastic/dystonic hemiplegia: a preliminary report. American Journal of Physical Medicine \& Rehabilitation 1999; Vol. 78, issue 3:247-54.

Meythaler 1999b \{published data only (unpublished sought but not used)\}

Meythaler JM, Guin-Renfroe S, Grabb P, Hadley MN. Long-term continuously infused intrathecal baclofen for spastic-dystonic hypertonia in traumatic brain injury: 1-year experience. Archives of Physical Medicine and Rehabilitation 1999; Vol. 80, issue $1: 13-9$.

NCT00287157 \{published data only (unpublished sought but not used)\}

NCT00287157. Pilot, proof-of-concept study of sublingual tizanidine in children with chronic traumatic brain injury (TBI). clinicaltrials.gov/ct2/show/NCT00287157 Date first received: 6 February 2006
Pittaccio 2013 \{published data only\}

Pittaccio S, Garavaglia L, Viscuso S, Beretta E, Strazzer S. Implementation, testing and pilot clinical evaluation of superelastic splints that decrease joint stiffness. Annals of Biomedical Engineering 2013;41:2003-17.

\section{Verplancke 2005 \{published data only\}}

Verplancke D, Snape S, Salisbury CF, Jones PW, Ward AB. A randomized controlled trial of botulinum toxin on lower limb spasticity following acute acquired severe brain injury. Clinical Rehabilitation 2005; Vol. 19, issue 2:117-25.

\section{References to studies excluded from this review}

\section{Armstrong 1997 \{published data only\}}

Armstrong RW, Steinbok P, Cochrane DD, Kube SD, Fife SE, Farrell K. Intrathecally administered baclofen for treatment of children with spasticity of cerebral origin. Journal of Neurosurgery 1997;87(3):409-14.

\section{Ashby 1972 \{published data only\}}

Ashby P, Burke D, Rao S, Jones RF. Assessment of cyclobenzaprine in the treatment of spasticity. Journal of Neurology, Neurosurgery, and Psychiatry 1972; Vol. 35, issue 5:599-605.

\section{Baricich 2008 \{published data only\}}

Baricich A, Carda S, Bertoni M, Maderna L, Cisari C. A singleblinded, randomized pilot study of botulinum toxin type a combined with non-pharmacological treatment for spastic foot. Journal of Rehabilitation Medicine 2008; Vol. 40, issue 10:870-2.

\section{Barnes 2010 \{published data only\}}

Barnes M, Schnitzler A, Medeiros L, Aguilar M, Lehnert-Batar A, Minnasch P. Efficacy and safety of NT 201 for upper limb spasticity of various etiologies - a randomized parallel-group study. Acta Neurologica Scandinavica 2010; Vol. 122, issue 4:295-302.

\section{Basmajian 1973 \{published data only\}}

Basmajian JV, Super GA. Dantrolene sodium in the treatment of spasticity. Archives of Physical Medicine and Rehabilitation 1973; Vol. 54, issue 2:61-4.

\section{Basmajian 1974 \{published data only\}}

Basmajian JV, Yucel V. Effects of a GABA-derivative (BA-34647) on spasticity. Preliminary report of a double-blind cross-over study. American Journal of Physical Medicine 1974; Vol. 53, issue $5: 223-8$

\section{Bensmail 2010 \{published data only\}}

Bensmail D, Robertson JVG, Fermanian C, Roby-Brami A. Botulinum toxin to treat upper-limb spasticity in hemiparetic patients: analysis of function and kinematics of reaching movements. Neurorehabilitation \& Neural Repair 2010; Vol. 24, issue $3: 273-81$. 


\section{Bes 1988 \{published data only\}}

Bes A, Eyssette M, Pierrot-Deseilligny E, Rohmer F, Warter JM. A multi-centre, double-blind trial of tizanidine, a new antispastic agent, in spasticity associated with hemiplegia. Current Medical Research and Opinion 1988; Vol. 10, issue 10:709-18.

\section{Bovend'Eerdt 2009 \{published data only\}}

Bovend'Eerdt TJH, Dawes H, Sackley C, Izadi H, Wade DT. Mental techniques during manual stretching in spasticity - a pilot randomized controlled trial. Clinical Rehabilitation 2009; Vol. 23 , issue 2:137-45. [0269-2155]

\section{Boyd 2001 \{published data only\}}

Boyd RN, Dobson F, Parrott J, Love S, Oates J, Larson A, et al. The effect of botulinum toxin type $A$ and a variable hip abduction orthosis on gross motor function: a randomized controlled trial. European Journal of Neurology 2001; Vol. 8, issue Suppl 5:109-19.

\section{Burbaud 1996 \{published data only\}}

Burbaud P, Wiart L, Dubos JL, Gaujard E, Debelleix X, Joseph PA, et al. A randomised, double blind, placebo controlled trial of botulinum toxin in the treatment of spastic foot in hemiparetic patients. Journal of Neurology, Neurosurgery, and Psychiatry. 1996/09/01 1996; Vol. 61, issue 3:265-9.

\section{Burke 1975 \{published data only\}}

Burke D, Hammond C, Skuse N, Jones RF. A phenothiazine derivative in the treatment of spasticity. Journal of Neurology, Neurosurgery, and Psychiatry 1975; Vol. 38, issue 5:469-74.

\section{Chang 2009 \{published and unpublished data\}}

Chang CL, Munin MC, Skidmore ER, Niyonkuru C, Huber LM, Weber DJ. Effect of baseline spastic hemiparesis on recover of upper-limb function following botulinum toxin type A injections and postinjection therapy. Archives of Physical Medicine and Rehabilitation 2009;90:1462-7.

\section{Childers 1996 \{published data only\}}

Childers MK, Stacy M, Cooke DL, Stonnington HH. Comparison of two injection techniques using botulinum toxin in spastic hemiplegia. American Journal of Physical Medicine \& Rehabilitation 1996; Vol. 75, issue 6:462-9.

\section{Cocchiarella 1967 \{published data only\}}

Cocchiarella A, Downey JA, Darling RC. Evaluation of the effect of diazepam on spasticity. Archives of Physical Medicine and Rehabilitation 1967; Vol. 48, issue 8:393-6.

\section{Cohan 1980 \{published data only\}}

Cohan SL, Raines A, Panagakos J, Armitage P. Phenytoin and chlorpromazine in the treatment of spasticity. Archives of Neurology 1980; Vol. 37, issue 6:360-4.

\section{Copley 2013 \{published data only\}}

Copley J, Kuipers K, Fleming J, Rassafiani M. Individualised resting hand splints for adults with acquired brain injury: a randomized, single blinded, single case design. Neurorehabilitation 2013;32:885-98.

\section{Corry 1998 \{published data only\}}

Corry IS, Cosgrove AP, Duffy CM, McNeill S, Taylor TC, Graham HK. Botulinum toxin A compared with stretching casts in the treatment of spastic equinus: a randomised prospective trial. Journal of Pediatric Orthopedics. 1998/05/26 1998; Vol. 18, issue 3:304-11.

\section{Fazekas 2007 \{published data only\}}

Fazekas G, Horvath M, Troznai T, Toth A. Robot-mediated upper limb physiotherapy for patients with spastic hemiparesis: a preliminary study. Journal of Rehabilitation Medicine 2007; Vol. 39, issue 7:580-2. [1650-1977]

Fietzek 2014 \{published data only\}

Fietzek UM, Kossmehl P, Schelosky L, Ebersbach G, Wissel J. Early botulinum toxin treatment for spastic pes equinovarus - a randomized double-blind placebo-controlled study. European Journal of Neurology 2014;21:1089-95.

\section{Francisco 2002 \{published data only\}}

Francisco GE, Boake C, Vaughn A. Botulinum toxin in upper limb spasticity after acquired brain injury: a randomized trial comparing dilution techniques. American Journal of Physical Medicine \& Rehabilitation 2002; Vol. 81, issue 5:355-63.

Gracies 2009 \{published data only\}

* Gracies JM, Lugassy M, Weisz DJ, Vecchio M, Flanagan S, Simpson DM. Botulinum toxin dilution and endplate targeting in spasticity: a double-blind controlled study. Archives of Physical Medicine and Rehabilitation 2009; Vol. 90, issue 1:9-16.

Gracies JM, Weisz DJ, Yang BY, Flanagan S, Simpson DM. Impact of botulinum toxin type A (BTX-A) dilution and endplate targeting technique in upper limb spasticity (abstract). Annals of Neurology 2002;52(Suppl 3):S87.

\section{Grazko 1995 \{published data only\}}

Grazko MA, Polo KB, Jabbari B. Botulinum toxin A for spasticity, muscle spasms, and rigidity. Neurology. 1995/04/01 1995; Vol. 45, issue 4:712-7. [0028-3878: (Print)]

\section{Guo 2006 \{published data only\}}

Guo F, Yue W, Ren L, Zhang YM, Yang J. Botulinum toxin type A plus rehabilitative training for improving the motor function of the upper limbs and activities of daily life in patients with stroke and brain injury. Neural Regeneration Research 2006; Vol. 1, issue 9:859-61.

\section{Harvey 1974 \{published data only\}}

Harvey MS, Knight JDS, Lal R, Stockley AGI, Timney AP, White $\mathrm{CJ}$, et al. A comparative trial of dimethothiazine in spastic conditions. A report from the General Practitioner Research Group. Practitioner 1974; Vol. 213, issue 1273:101-5.

\section{Harvey 2006 \{published data only\}}

Harvey L, de Jong I, Goehl G, Mardwedel S. Twelve weeks of nightly stretch does not reduce thumb web-space contractures in people with a neurological condition: a randomised controlled trial. Australian Journal of Physiotherapy 2006;52(4):251-8. 
Hill 1994 \{published data only\}

Hill J. The effects of casting on upper extremity motor disorders after brain injury. American Journal of Occupational Therapy 1994; Vol. 48, issue 3:219-24.

\section{Imle 1986 \{published data only\}}

Imle PC, Eppinghaus CE, Boughton AC. Efficacy of non-bivalved and bivalved serial casting on head injured patients in intensive care. Physical Therapy 1986; Vol. 66:748 (abstract).

\section{Krewer 2014 \{published data only\}}

Krewer C, Hartl S, Müller F, Koenig E. Effects of repetitive peripheral magnetic stimulation on upper-limb spasticity and impairment in patients with spastic hemiparesis: a randomized, double-blind, sham-controlled study. Archives of Physical and Medical Rehabilitation 2014;95:1039-47.

\section{Lannin 2003 \{published data only\}}

Lannin NA, Horsley SA, Herbert R, McCuskey A, Cusiek A. Splinting the hand in the functional position after brain impairment: a randomized, controlled trial. Archives of Physical Medicine and Rehabilitation 2003; Vol. 84, issue 2:297-302.

\section{Leung 2012 \{published data only\}}

Leung J, Harvey LA, Moseley AM, Tse C, Bryant J, Wyndham S, et al. Electrical stimulation and splinting were not clearly more effective than splinting alone for contracture management after acquired brain injury: a randomised trial. Journal of Physiotherapy 2012;58:231-40.

Levine 1969 \{published data only\}

Levine IM, Jossmann PB, Friend DG, DeAngelis V. Prazepam in the treatment of spasticity. A quantitative double-blind evaluation. Neurology 1969; Vol. 19, issue 5:510-6.

\section{Levine 1977 \{published data only\}}

Levine IM, Jossmann PB, DeAngelis V. Liorseal, a new muscle relaxant in the treatment of spasticity - a double-blind quantitative evaluation. Diseases of the Nervous System 1977; Vol. 38, issue 12:1011-5.

\section{Mancini 2005 \{published data only\}}

Mancini F, Sandrini G, Moglia A, Nappi G, Pacchetti C. A randomised, double-blind, dose-ranging study to evaluate efficacy and safety of three doses of botulinum toxin type $A$ (Botox) for the treatment of spastic foot. Neurological Sciences 2005; Vol. 26, issue 1:26-31. [1590-1874]

\section{Martin 2014 \{published data only\}}

Martin A, Abogunrin S, Kurth H, Dinet J. Epidemiological, humanistic, and economic burden of illness of lower limb spasticity in adults: a systematic review. Neuropsychiatric Disease and Treatment 2014;10:111-22.

\section{Mayer 2008 \{published data only\}}

Mayer NH, Whyte J, Wannstedt G, Ellis CA. Comparative impact of 2 botulinum toxin injection techniques for elbow flexor hypertonia. Archives of Physical Medicine and Rehabilitation 2008; Vol. 89, issue 5:982-7.

\section{McPherson 1982 \{published data only\}}

McPherson JJ, Kreimeyer D, Aalderks M, Gallagher T. A comparison of dorsal and volar resting hand splints in the reduction of hypertonus. American Journal of Occupational Therapy 1982; Vol. 36, issue 10:664-70.

\section{Meythaler 2001b \{published data only\}}

Meythaler JM, Guin-Renfroe S, Johnson A, Brunner RM. Prospective assessment of tizanidine for spasticity due to acquired brain injury. Archives of Physical Medicine and Rehabilitation 2001; Vol. 82, issue 9:1155-63.

\section{Middel 1997 \{published data only\}}

Middel B, KuipersUpmeijer H, Bouma J, Staal M, Oenema D, Postma T, et al. Effect of intrathecal baclofen delivered by an implanted programmable pump on health related quality of life in patients with severe spasticity. Journal of Neurology, Neurosurgery and Psychiatry 1997; Vol. 63, issue 2:204-9.

\section{Moseley 1997 \{published data only\}}

Moseley AM. The effect of casting combined with stretching on passive ankle dorsiflexion in adults with traumatic head injuries. Physical Therapy 1997; Vol. 77, issue 3:240-7. [0031-9023: (Print)]

\section{Moseley 2008 \{published data only\}}

Moseley AM, Hassett LM, Leung J, Clare JS, Herbert RD, Harvey LA. Serial casting versus positioning for the treatment of elbow contractures in adults with traumatic brain injury: a randomized controlled trial. Clinical Rehabilitation 2008; Vol. 22, issue 5:406-17.

\section{Nakhostin 2009 \{published data only\}}

Nakhostin Ansari N, Naghdi S, Hasson S, Rastgoo M. Efficacy of therapeutic ultrasound and infrared in the management of muscle spasticity. Brain Injury 2009; Vol. 23, issue 7-8:632-8.

\section{NCT00776048 \{published data only\}}

NCT00776048. Validation of an obstacle course used in patients with muscle tightness. clinicaltrials.gov/ct2/show/study/ NCT00776048 Date first received: 20 October 2008.

\section{NCT00900666 \{published data only\}}

NCT00900666. Efficacy of botulinum toxin Injections in the rectus femoris to treat stiff knee gait following acquired brain injury. clinicaltrials.gov/ct2/show/NCT00900666 Date first received: 13 May 2009.

\section{Pagano 1990 \{published data only\}}

Pagano MA, Frerreiro ME, Herskovits. Study using Tizanidina and Baclofen in patients with chronic spasticity. Revista Neurológica Argentina 1990; Vol. 15, issue 1:27-33.

\section{Penn 1988 \{published data only\}}

Penn RD. Intrathecal baclofen for severe spasticity. Annals of the New York Academy of Sciences 1988; Vol. 531:157-66.

Richardson 2000 \{published data only\}

* Richardson D, Sheean G, Werring D, Desai M, Edwards S, Greenwood R, et al. Evaluating the role of botulinum toxin in the management of focal hypertonia in adults. Journal of 
Neurology, Neurosurgery, and Psychiatry 2000; Vol. 69, issue 4:499-506.

Thompson AJ, Richardson D, Sheehan G, Desai M, Werring D, Edwards $S$, et al. Evaluating the role of botulinum toxin type $A$ in adults with focal spasticity. European Journal of Neurology 1999;6(Suppl 4):S75.

\section{Roussan 1985 \{published data only\}}

Roussan M, Terrence C, Fromm G. Baclofen versus diazepam for the treatment of spasticity and long-term follow-up of baclofen therapy. Pharmatherapeutica 1985; Vol. 4, issue 5:278-84.

\section{Sahuquillo 2000 \{published data only\}}

Sahuquillo J, Robles A, Poca A, Ballabriga A, Mercadal J, Secades JJ. A controlled, double-blind, randomized pilot clinical trial of nicardipine as compared with a placebo in patients with moderate or severe head injury. Revista de Neurologia 2000; Vol. 30, issue 5:401-8.

\section{Simpson 1996 \{published data only\}}

Simpson DM, Alexander DN, O'Brien CF, Tagliati M, Aswad AS, Leon JM, et al. Botulinum toxin type $A$ in the treatment of upper extremity spasticity: a randomized, double-blind, placebocontrolled trial. Neurology 1996; Vol. 46, issue 5:1306-10.

\section{Simpson 2009 \{published data only\}}

Simpson DM, Gracies JM, Yablon SA, Barbano R, Brashear A, BoNT/TZD Study Team. Botulinum neurotoxin versus tizanidine in upper limb spasticity: a placebo-controlled study. Journal of Neurology, Neurosurgery, and Psychiatry 2009; Vol. 80, issue 4:380-5.

\section{Smith 2000 \{published data only\}}

Smith SJ, Ellis E, White S, Moore AP. A double-blind placebocontrolled study of botulinum toxin in upper limb spasticity after stroke or head injury. Clinical Rehabilitation 2000; Vol. 14, issue 1:5-13.

\section{Snow 1990 \{published data only\}}

Snow BJ, Tsui JK, Bhatt MH, Varelas M, Hashimoto SA, Calne DB. Treatment of spasticity with botulinum toxin: a doubleblind study. Annals of Neurology 1990; Vol. 28, issue 4:512-5. [0364-5134: (Print)]

\section{Suputtitada 2005 \{published data only\}}

Suputtitada A, Suwanwela NC. The lowest effective dose of botulinum A toxin in adult patients with upper limb spasticity. Disability \& Rehabilitation 2005; Vol. 27, issue 4:176-84.

\section{Thibaut 2015 \{published data only\}}

Thibaut A, Deltombe T, Wannez S, Gosseries O, Ziegler E, Dieni C, et al. Impact of soft splints on upper limb spasticity in chronic patients with disorders of consciousness: a randomized, single-blind, controlled trial. Brain Injury 2015;29:830-6.

\section{Van Schaeybroeck 2000 \{published data only\}}

Van Schaeybroeck P, Nuttin B, Lagae L, Schrijvers E, Borghgraef C, Feys P. Intrathecal baclofen for intractable cerebral spasticity: a prospective placebo-controlled, doubleblind study. Neurosurgery 2000; Vol. 46, issue 3:603-9.

\section{Yelnik 2007 \{published data only\}}

Yelnik AP, Colle FM, Bonan IV, Vicaut E. Treatment of shoulder pain in spastic hemiplegia by reducing spasticity of the subscapular muscle: a randomised, double blind, placebo controlled study of botulinum toxin A. Journal of Neurology, Neurosurgery and Psychiatry 2007; Vol. 78, issue 8:845-8.

Zhao 2015 \{published data only\}

Zhao W, Wang C, Li Z, Chen L, Li J, Cui W, et al. Efficacy and safety of transcutaneous electrical acupoint stimulation to treat muscle spasticity following brain injury: a doubleblinded, multicenter, randomized controlled trial. PLOS One 2015;2:e0116976.

\section{References to studies awaiting assessment}

2009-015868-34 \{published data only\}

A phase III, multicentre, double-blind, prospective, randomized, placebo-controlled study, assessing the efficacy and safety of Dysport ${ }^{\circledast}$ used for the treatment of lower-limb spasticity in adult subjects with hemiparesis due to stroke or traumatic brain injury. www.clinicaltrialsregister.eu/ctr-search/search? query=eudract_number:2009-015868-34 Date first received: 15 February 2011.

\section{EUCTR2011-005375-16-SE \{published data only (unpublished} sought but not used)\}

A phase III prospective, multi-center, randomised evaluatorblinded study to compare neuromuscular junction (NMJ) targeted technique for Dysport injectives in upper limb spasticity post stroke or traumatic brain injury to the technique used in clinical practice. www.clinicaltrialsregister.eu/ctrsearch/trial/2011-005375-16/results Date first received: 24 September 2012.

\section{Gracies 2016 \{published data only\}}

Gracies JM, Esquenazi A, Brashear A, Edgley SR, O'Dell M, Hedera P, et al. Poster 288. Efficacy and safety of repeated abobotulinumtoxinA injections in adults with lower limb spasticity. PM \& R : the Journal of Injury, Function, and Rehabilitation 2016;8:S254.

Ipsen. Dysport ${ }^{\circledR}$ adult lower limb spasticity follow-on study. clinicaltrials.gov/ct2/show/NCT01251367 Date first received: 1 December 2010.

\section{IRCT2014041112777N \{published data only\}}

* Rasras S. Comparative efficacy of cyproheptadine and baclofen on spasticity in patients with head trauma. en.search.irct.ir/view/17738 Date first received: 13 May 2014.

Rasras S, Fallahpour S, Zeinali M, Soltani A, Bahrami R, Teymoori AR, et al. Survey effect of cyproheptadine-baclofen and cyproheptadine baclofen-thizanidine regimens on spasticity in patients with traumatic brain injury. Asian Journal of Medical and Pharmaceutical Researches 2014;4:142-6.

\section{NCT02052024 \{published data only\}}

NCT02052024. Myobloc atrophy study (MAS). Clinicaltrials.gov/ show/NCT02052024 Date first received: 31 January 2014. 


\section{References to ongoing studies}

ACTRN12615000821594 \{published data only\}

ACTRN12615000821594. Effectiveness of combining serial casting and botulinum toxin for the management of ankle contractures after traumatic brain injury: a randomised controlled study. www.anzctr.org.au/Trial/Registration/ TrialReview.aspx?id=365685 Date first received: 10 August 2015.

\section{Additional references}

\section{Ada 2006a}

Ada L, O'Dwyer N, O'Neill E. Relation between spasticity, weakness and contracture of the elbow flexors and upper limb activity after stroke: an observational study. Disability and Rehabilitation 2006; Vol. 28, issue 13-14:891-7.

\section{Ada 2006b}

Ada L, Dorsch S, Canning CG. Strengthening interventions increase strength and improve activity after stroke: a systematic review. Australian Journal of Physiotherapy 2006; Vol. 52, issue 4:241-8.

\section{Ade-Hall 2000}

Ade-Hall R, Moore P. Botulinum toxin type A in the treatment of lower limb spasticity in cerebral palsy. Cochrane Database of Systematic Reviews 2000, Issue 1. [DOI: 10.1002/14651858.CD001408]

\section{Allison 1995}

Allison SC, Abraham LD. Correlation of quantitative measures with the modified Ashworth Scale in the assessment of plantar flexor spasticity in patients with traumatic brain injury. Journal of Neurology 1995; Vol. 242, issue 10:699-706.

\section{Amatya 2013}

Amatya B, Khan F, La ML, Demetrios M, Wade DT. Non pharmacological interventions for spasticity in multiple sclerosis. Cochrane Database of Systematic Reviews 2013, Issue 2. [DOI: 10.1002/14651858.CD009974.pub2]

\section{Ashworth 2012}

Ashworth NL, Satkunam LE, Deforge D. Treatment for spasticity in amyotrophic lateral sclerosis/motor neuron disease. Cochrane Database of Systematic Reviews 2012, Issue 2. [DOI: 10.1002/14651858.CD004156.pub4]

\section{Aydin 2005}

Aydin G, Tomruk S, Keleş I, Demir S, Orkun S. Transcutaneous electrical nerve stimulation versus baclofen in spasticity: clinical and electrophysiologic comparison. American Journal of Physical Medicine \& Rehabilitation 2005; Vol. 84, issue 8:584-92. [0894-9115]

\section{Baker 2015}

Baker JA, Pereira G. The efficacy of botulinum toxin A on improving ease of care in the upper and lower limbs: a systematic review and meta-analysis using the Grades of Recommendation, Assessment, Development and Evaluation approach. Clinical Rehabilitation 2015;29:731-40.

\section{Becker 1997}

Becker R, Alberti O, Bauer BL. Continuous intrathecal baclofen infusion in severe spasticity after traumatic or hypoxic brain injury. Journal of Neurology 1997; Vol. 244, issue 3:160-6.

\section{Bragge 2016}

Bragge P, Synnot A, Maas Al, Menon DK, Cooper DJ, Rosenfeld JV, et al. A state of the science overview of randomised controlled trials evaluating acute management of moderate to severe traumatic brain injury. Journal of Neurotrauma 2016;33(16):1461-78.. [DOI: 10.1089/ neu.2015.4233]

\section{Brashear 2002}

Brashear A, Zafonte R, Corcoran M, Galvez-Jimenez N, Gracies JM, Gordon MF, et al. Inter- and intrarater reliability of the Ashworth Scale and the Disability Assessment Scale in patients with upper-limb poststroke spasticity. Archives of Physical and Medical Rehabilitation 2002;83:1349-54.

\section{Brashear 2016}

Brashear A, Elovic E. Why is spasticity important?. Spasticity: Diagnosis and Management. New York (NY): Demos Medical Publishing, 2016:3-4.

\section{Brazinova 2016}

Brazinova A, Rehorcikova V, Taylor MS, Buckova V, Majdan M, Psota M, et al. Epidemiology of Traumatic Brain Injury in Europe: A Living Systematic Review. Journal of Neurotrauma 2016:Epub ahead of print. [DOI: 10.1089/neu.2015.4126]

\section{Dashtipour 2016}

Dashtipour K, Chen JJ, Walker HW, Lee MY. Systematic literature review of abobotulinumtoxinA in clinical trials for lower limb spasticity. Medicine 2016;95:e2468.

\section{Demetrios 2013}

Demetrios M, Khan F, Turner-Stokes L, Brand C, McSweeney S. Multidisciplinary rehabilitation following botulinum toxin and other focal intramuscular treatment for post-stroke spasticity. Cochrane Database of Systematic Reviews 2013, Issue 6. [DOI: 10.1002/14651858.CD009689.pub2]

\section{Dong 2017}

Dong Y, Wu T, Hu X, Wang T. Efficacy and safety of botulinum toxin type $A$ for upper limb spasticity after stroke or traumatic brain injury: a systematic review with meta-analysis and trial sequential analysis. European Journal of Physical Rehabilitation Medicine 2017;53:256-67.

\section{Duarte 2016}

Duarte GS, Castelão M, Rodrigues FB, Marques RE, Ferreira J, Sampaio $C$, et al. Botulinum toxin type A versus botulinum toxin type B for cervical dystonia. Cochrane Database of Systematic Reviews 2016, Issue 10. [DOI: 10.1002/14651858.CD004314.pub3]

\section{Esquenazi 2006}

Esquenazi A. Improvements in healthcare and cost benefits associated with botulinum toxin treatment of spasticity and 
muscle overactivity. European Journal of Neurology 2006; Vol. 13 (Suppl 4):27-34

\section{Fleuren 2010}

Fleuren JFM, Voerman GE, Erren-Wolters CV, Snoek GJ, Rietman JS, Hermens HJ, et al. Stop using the Ashworth Scale for the assessment of spasticity. Journal of Neurology, Neurosurgery and Psychiatry 2010; Vol. 81, issue 1:46-52.

\section{Francis 2004}

Francis HP, Wade DT, Turner-Stokes L, Kingswell RS, Dott CS, Coxon EA. Does reducing spasticity translate into functional benefit? An exploratory meta-analysis. Journal of Neurology, Neurosurgery and Psychiatry 2004; Vol. 75, issue 11:1547-51.

\section{Giovannelli 2007}

Giovannelli M, Borriello G, Castri P, Prosperini L, Pozzilli C. Early physiotherapy after injection of botulinum toxin increases the beneficial effects on spasticity in patients with multiple sclerosis. Clinical Rehabilitation. London: SAGE PUBLICATIONS, INC., 2007; Vol. 21, issue 4:331-7. [02692155]

\section{Guyatt 2011}

Guyatt GH, Oxman AD, Kunz R, Brozek J, Alonso-Coello P, Rind $D$, et al. GRADE guidelines 6 . Rating the quality of evidence - imprecision. Journal of Clinical Epidemiology 2011;64:1283-93.

\section{Hall 1993}

Hall KM, Hamilton BB, Gordon WA, Zasler ND. Characteristics and comparisons of functional assessment indices: disability rating scale, functional independence measure, and functional assessment measure. Journal of Head Trauma Rehabilitation 1993;8:60-74.

\section{Haugh 2006}

Haugh AB, Pandyan AD, Johnson GR. A systematic review of the Tardieu Scale for the measurement of spasticity. Disability and Rehabilitation 2006; Vol. 28, issue 15:899-907.

\section{Higgins 2011}

Higgins JP, Altman DG, Gøtzsche PC, Jüni P, Moher D, Oxman AD, et al. Cochrane Bias Methods Group, Cochrane Statistical Methods Group. The Cochrane Collaboration's tool for assessing risk of bias in randomised trials. $B M J$ 2011;343:d5928.

\section{Hoare 2010}

Hoare BJ, Wallen MA, Imms C, Villanueva E, Rawicki HB, Carey L. Botulinum toxin $A$ as an adjunct to treatment in the management of the upper limb in children with spastic cerebral palsy (update). Cochrane Database of Systematic Reviews 2010, Issue 1. [DOI: 10.1002/14651858.CD003469.pub4]

\section{Hsieh 2012}

Hsieh JTC, Wolfe DL, Mclntyre A, Janzen S, Townson AF, Short C, et al. Spasticity following spinal cord injury. In: Eng JJ, Teasell RW, Miller WC, Wolfe DL, Townson AF, Hsieh JTC, et al. editor(s). Spinal Cord Injury Rehabilitation Evidence, Version 4.0. Vancouver (BC): SCIRE Project, 2012.

\section{Jennett 1975}

Jennett $B$, Bond M. Assessment of outcome after severe brain damage. Lancet 1975;1:480-4.

\section{Keith 1987}

Keith RA, Granger CV, Hamilton BB, Sherwin FS. The functional independence measure: a new tool for rehabilitation. Advances in Clinical Rehabilitation 1987;1:6-18.

\section{Khan 2003}

Khan F, Baguley IJ, Cameron ID. Rehabilitation after traumatic brain injury. Medical Journal of Australia. 2003/03/14 2003; Vol. 178 , issue 6:290-5.

\section{Kiresuk 1994}

Kiresuk TJ, Smith A, Cardillo JE. Goal Attainment Scaling: Applications, Theory, and Measurement. Hillsdale (NJ): Lawrence Erlbaum Associates, 1994.

\section{Kwakkel 1999}

Kwakkel G, Wagenaar R, Twisk J, Lankhorst G, Koetsier J. Intensity of leg and arm training after primary middle-cerebralartery stroke: a randomised trial. Lancet 1999; Vol. 354:191-6.

\section{Lance 1980}

Lance J. Pathophysiology of spasticity and clinical experience with baclofen. In: Lance JWFR, Young RR, Koella WP editor(s). Spasticity: Disordered Motor Control. Chicago (IL): Year Book Medical Publishers, 1980.

\section{Law 2000}

Law M, Baptiste S, Carswell A, McColl MA, Polatajko H, Pollock N. Canadian Occupational Performance Measure. Canada: CAOT Publications, 2000.

\section{Lindsay 2013}

Lindsay C, Pandyan AD. Pharmacological interventions other than botulinum toxin for spasticity after stroke. Cochrane Database of Systematic Reviews 2013, Issue 2. [DOI: 10.1002/14651858.CD010362.pub2]

\section{Maas 2008}

Maas Al, Stocchetti N, Bullock R. Moderate and severe traumatic brain injury in adults. Lancet Neurology. 2008/07/19 2008; Vol. 7 , issue 8:728-41.

\section{Maas 2010}

Maas AIR, Steyerberg EW, Marmarou A, McHugh GS, Lingsma HF, Butcher I, et al. IMPACT recommendations for improving the design and analysis of clinical trials in moderate to severe traumatic brain injury. Neurotherapeutics 2010;7:127-34.

\section{Malhotra 2009}

Malhotra S, Pandyan AD, Day CR, Jones PW, Hermens H. Spasticity, an impairment that is poorly defined and poorly measured. Clinical Rehabilitation 2009;23:651-8.

\section{Manchester 1997}

Manchester D, Hodgkinson A, Casey T. Prolonged, severe behavioural disturbance following traumatic brain injury: what can be done?. Brain Injury 1997;11:605-17. 


\section{McGuire 2016}

McGuire J. Epidemiology of spasticity in the adult and child. In: Brashear A editor(s). Spasticity: Diagnosis and Management. 2nd Edition. New York (NY): Demos Medical Publishing, 2016.

\section{Mehrholz 2005}

Mehrholz J, Major Y, Meissner D, Sandi-Gahun S, Koch R, Pohl M. The influence of contractures and variation in measurement stretching velocity on the reliability of the Modified Ashworth Scale in patients with severe brain injury. Clinical Rehabilitation 2005; Vol. 19, issue 1:63-72.

\section{Meythaler 2001a}

Meythaler JM, Guin-Renfroe S, Johnson A, Brunner RM. Prospective assessment of tizanidine for spasticity due to acquired brain injury. Archives of Physical Medicine and Rehabilitation 2001; Vol. 82, issue 9:1155-63.

\section{Morris 2002}

Morris S. Ashworth and Tardieu Scales: their Clinical Relevance for Measuring Spasticity in Adult and Paediatric Neurological Populations. Physical Therapy Reviews 2002; Vol. 7, issue 1:53-62.

\section{Mortenson 2003}

Mortenson PA, Eng JJ. The use of casts in the management of joint mobility and hypertonia following brain injury in adults: a systematic review. Physical Therapy 2003;83:648-58.

\section{Nair 2014}

Nair KPS, Marsden J. The management of spasticity in adults. BMJ 2014;349:g4737.

\section{O'Dell 2015}

O'Dell MW, Walker HW, Edgley SR, Gracies JM, Gul F, Wimmer M, et al. AbobotulinumtoxinA (Dysport ${ }^{\oplus}$ ) in the treatment of adult patients with upper limb spasticity due to traumatic brain injury. PM \& R: the Journal of Injury, Function, and Rehabilitation 2015;7:S103.

\section{Olver 2010}

Olver J, Esquenazi A, Fung VSC, Singer BJ, Ward AB. Botulinum toxin assessment, intervention and aftercare for lower limb disorders of movement and muscle tone in adults: international consensus statement. European Journal of Neurology 2010;17:57-73.

\section{Pandyan 1999}

Pandyan AD, Johnson GR, Price $\mathrm{Cl}$, Curless RH, Barnes MP, Rodgers $\mathrm{H}$. A review of the properties and limitations of the Ashworth and modified Ashworth Scales as measures of spasticity. Clinical Rehabilitation 1999; Vol. 13, issue 5:373-83.

\section{Pandyan 2005}

Pandyan A, Gregoric M, Barnes M, Wood D, Van Wijck F, Burridge J, et al. Spasticity: clinical perceptions, neurological realities and meaningful measurement. Disability and Rehabilitation 2005; Vol. 27:2-6.

\section{Parke 1989}

Parke B, Penn RD, Savoy SM, Corcos D. Functional outcome after delivery of intrathecal baclofen. Archives of Physical Medicine and Rehabilitation 1989; Vol. 70, issue 1:30-2.

\section{Patrick 2006}

Patrick E, Ada L. The Tardieu Scale differentiates contracture from spasticity whereas the Ashworth Scale is confounded by it. Clinical Rehabilitation 2006;20:173-82.

\section{Pierson 1996}

Pierson SH, Katz DI, Tarsy D. Botulinum toxin A in the treatment of spasticity: functional implications and patient selection. Archives of Physical Medicine and Rehabilitation 1996; Vol. 77, issue 7:717-21.

\section{RCP 2009}

Royal College of Physicians. Spasticity in Adults: Management using Botulinum Toxin: National Guidelines. London (UK): Royal College of Physicians, 2009.

\section{RevMan 2011 [Computer program]}

The Nordic Cochrane Centre, The Cochrane Collaboration. Review Manager (RevMan). Copenhagen: The Nordic Cochrane Centre, The Cochrane Collaboration, 2011.

\section{Ryan 2016}

Ryan R, Hill S. How to GRADE the quality of the evidence. Cochrane Consumers and Communication Group, Version 3.0 December 2016. cccrg.cochrane.org/sites/cccrg.cochrane.org/ files/public/uploads/how_to_grade_revising_1_december_ 2016.pdf (accessed prior to 25 October 2017).

\section{Schünemann 2011}

Schünemann HJ, Oxman AD, Higgins JPT, Vist GE, Glasziou P, Guyatt GH. Chapter 11: Presenting results and 'Summary of findings' tables. In: Higgins JP, Green S, editor(s). Cochrane Handbook for Systematic Reviews of Interventions Version 5.1.0 (updated March 2011). The Cochrane Collaboration, 2011. Available from handbook.cochrane.org.

\section{Shakespeare 2003}

Shakespeare D, Boggild M, Young CA. Anti-spasticity agents for multiple sclerosis. Cochrane Database of Systematic Reviews 2003, Issue 4. [DOI: 10.1002/14651858.CD001332; CD001332]

\section{Singer 2004}

Singer BJ, Jegasothy GM, Singer KP, Allison GT, Dunne JW. Incidence of ankle contracture after moderate to severe acquired brain injury. Archives of Physical Medicine and Rehabilitation. 2004/09/18 2004; Vol. 85, issue 9:1465-9.

\section{Summers 2009}

Summers CR, Ivins B, Schwab KA. Traumatic brain injury in the United States: an epidemiologic overview. Mount Sinai Journal of Medicine 2009; Vol. 76, issue 2:105-10.

\section{Taricco 2000}

Taricco M, Adone R, Pagliacci C, Telaro E. Pharmacological interventions for spasticity following spinal cord injury. 
Cochrane Database of Systematic Reviews 2000, Issue 2. [DOI: 10.1002/14651858.CD001131]

\section{Teasdale 1974}

Teasdale G, Jennett B. Assessment of coma and impaired consciousness. Lancet 1974;304:814.

\section{Wedekind 2005}

Wedekind C, Lippert-Grüner M. Long-term outcome in severe traumatic brain injury is significantly influenced by brainstem involvement. Brain Injuries 2005;19:681-4.

\section{WHO 2010}

World Health Organization. International Classification of Functioning, Disability \& Health. apps.who.int/classifications/ icfbrowser/ (accessed 2 July 2010).

\section{Williams 2015a}

Williams G, Banky M, Olver J. Severity and distribution of spasticity does not limit mobility or influence compensatory strategies following traumatic brain injury. Brain Injury 2015;29(10):1232-8.

\section{Williams 2015b}

Williams G, Banky M, Olver J. Distribution of lower limb spasticity does not influence mobility outcome following traumatic brain injury: an observational study. Journal of Head Trauma Rehabilitation 2015;30(5):E49-57.

\section{Wood 1999}

Wood RL, McCrea JD, Wood LM, Merriman RN. Clinical and cost effectiveness of post-acute neurobehavioural rehabilitation. Brain Injury 1999;13:69-88.

\section{Wood 2008}

Wood L, Egger M, Gluud LL, Schulz K, Jüni P, Altman DG, et al. Empirical evidence of bias in treatment effect estimates in controlled trials with different interventions and outcomes: meta-epidemiological study. BMJ 2008;336:601-5.

\section{Yelnik 2009}

Yelnik AP, Simon O, Bensmail D, Chaleat-Valayer E, Decq P, Dehail P, et al. Drug treatments for spasticity. Annals of Physical \& Rehabilitation Medicine 2009; Vol. 52, issue 10:746-56.

* Indicates the major publication for the study

\section{CHARACTERISTICS OF STUDIES}

Characteristics of included studies [ordered by study ID]

\section{Gracies 2015}

Methods

Randomised controlled trial (3 arms).

Setting: 34 neurology or rehabilitation clinics in 9 countries (Belgium, Czech Republic, France, Hungary, Italy, Poland, Russia, Slovakia, USA).

Funding: Ipsen (pharmaceutical company).

Participants

Total participants: 243 overall study, including 23 with TBI (65\% male), for whom results were presented separately. Number of participants in each study arm: 9 (placebo), 8 (abobotulinumtoxinA $500 \mathrm{U}$ ) and 6 (abobotulinumtoxinA $1000 \mathrm{U}$ ).

Adults: 23, children: 0 .

People with TBI: mean age 35 years (SD 13, range not reported).

Inclusion criteria:

- aged $18-80$ years;

- hemiparesis for at least 6 months post TBI (or stroke);

- Modified Ashworth Scale score in the target muscle group $\geq 2$ (if never had botulinum toxin injection) or $\geq 3$ (if had botulinum toxin A injection before);

- Disability Assessment Scale score $\geq 2$ on the principal target of treatment;

- spasticity angle of least $10^{\circ}$ in the primary target muscle group and

- mean Modified Frenchay Score of 1-8 (out of possible 10).

\section{Exclusion criteria:}

- major limitations of passive range of motion in the paretic limb;

- intrathecal baclofen or physiotherapy initiated < 4 weeks prior to expected enrolment;

- anticipated botulinum toxin A treatment during study period; 
- administration of any alcohol or phenol in the study limb any time before the study;

- previous primary or secondary non-response to any botulinum toxin for the targeted condition;

- previous surgery to treat spasticity of the affected upper limb;

- any medical disorder increasing the risk of adverse events from botulinum toxin A administration;

- major additional neurological impairment that could affect functional performance;

- known disease of the neuromuscular junction;

- known sensitivity to botulinum toxin or any excipient of Dysport;

- infection at the injection site(s);

- any current or planned treatment that interferes with neuromuscular function;

- pregnant or women not willing to use contraception.

Location of spasticity:

- upper limb: elbow flexors, wrist flexors, finger flexors.

For each participant, the investigators selected the most hypertonic muscle group (defined by Modified Ashworth Scale score) out of elbow flexors, wrist flexors and finger flexors, and gave an additional injection to 2 other muscle groups (including these groups + shoulder extensors).

Interventions AbobotulinumtoxinA $500 \mathrm{U}: 2$ vials ( 1 of placebo and 1 of abobotulinumtoxinA $500 \mathrm{U}$ ) were each diluted with $2.5 \mathrm{~mL}$ saline and combined into a single injection of $5 \mathrm{~mL}$ solution. This was injected into target muscle group and at least 2 other muscle groups (guided by electrical stimulation to identify the correct location).

AbobotulinumtoxinA 1000 U: same as above (except 2 vials of active compound were used).

Placebo: same as above (except 2 vials of placebo were used).

Outcome assessed at: baseline, and 1, 4 and 12 weeks.
Primary outcomes:
- spasticity/muscle tone: Tardieu Scale (at 4 weeks);
- safety assessments (adverse events).
Secondary outcomes:
- upper limb function using the Disability Assessment Scale (4-point scale);
- quality of life (subscores of the SF-36 and the EQ-5D).
Length of follow-up: 12 weeks.

Notes

The full study (Gracies 2015) included more than just participants with TBI, but the results for participants with TBI were presented separately in the conference abstract by (O'Dell 2015). However, these results did not distinguish between different dosages and reported results as if for a 2-armed trial (abobotulinumtoxinA $550 \mathrm{U}$ and abobotulinumtoxinA $1000 \mathrm{U}$ vs placebo). This study also measured spasticity using the Modified Ashworth Scale, but we reported Tardieu Scale results given we prespecified this as our preferred measure. The authors also used the Physician Global Assessment scale for assessing the 'severity' of a condition. Given this is not a brain injury or rehabilitation-specific measure, neither is it clear which functional domain this outcome fitted within, this outcome was not included in the review.

\section{Risk of bias}

Bias Authors' judgement Support for judgement

Random sequence genera- Low risk tion (selection bias)
"Patients were randomly allocated in a ratio of 1:1:1.... Computer-generated randomisation lists were created by a sponsor statistician independent from the study..." Furthermore, "randomisation was stratified by botulinum-toxin-A treatment status at baseline only... irrespective of the centre of recruitment 
Gracies 2015 (Continued)

or of the cause of spastic paresis.... no rationale exists for stratification of patients by cause [stroke and traumatic brain injury]."

\begin{tabular}{ll}
\hline $\begin{array}{l}\text { Allocation concealment } \\
\text { (selection bias) }\end{array}$ & Low risk \\
& $\begin{array}{l}\text { "Computer-generated randomisation lists were created by a sponsor statisti- } \\
\text { cian independent from the study and treatment numbers were assigned when } \\
\text { patients entered the study with a 24-h interactive response system from an ex- } \\
\text { ternal contract research organisation..." }\end{array}$ \\
\hline
\end{tabular}

$\begin{array}{ll}\begin{array}{l}\text { Blinding of participants } \\ \text { and personnel (perfor- }\end{array} & \text { "A double-dummy technique was used to maintain masking of patients and in- } \\ \text { mance bias) } & \text { vestigators. A treatment pack contained two vials of abobotulinumtoxinA } 500 \\ \text { All outcomes } & \mathrm{U}(1000 \mathrm{U} \text { group), one vial of abobotulinumtoxinA } 500 \mathrm{U} \text { plus one vial of place- } \\ & \text { bo }(500 \mathrm{U} \text { group), or two vials of placebo (placebo group). The [treatment] } \\ & \text { packs were identical in appearance and the procedure for reconstitution in } \\ & \text { each group was identical." }\end{array}$

\begin{tabular}{|c|c|c|}
\hline $\begin{array}{l}\text { Blinding of outcome as- } \\
\text { sessment (detection bias) }\end{array}$ & Low risk & $\begin{array}{l}\text { "The [treatment] packs were identical in appearance and the procedure for re- } \\
\text { constitution in each group was identical." }\end{array}$ \\
\hline
\end{tabular}
All outcomes

Incomplete outcome data Low risk (attrition bias)

\begin{abstract}
In the main study (of which the TBI participants formed a subgroup of $<10 \%$, i.e. 23 of 243 participants) reported that $>94 \%$ of those randomised completed the study to 12 -week follow-up and that those lost were relatively evenly spread between groups. Reasons for discontinuation were provided, and ITT methods for missing data appeared appropriate. In the subgroup reported in a conference abstract, it would appear that all participants with TBI were retained within the study.
\end{abstract}

\begin{tabular}{|c|c|c|}
\hline $\begin{array}{l}\text { Selective reporting (re- } \\
\text { porting bias) }\end{array}$ & Unclear risk & $\begin{array}{l}\text { Study protocol was registered on clinicaltrials.gov (NCT01313299). Outcome } \\
\text { data reported appeared in line with those prospectively stated; however, for } \\
\text { the TBI subset of participants included in this review, outcome data for differ- } \\
\text { ent doses of the active intervention were conflated and results were given in } \\
\text { the form of percentages only. }\end{array}$ \\
\hline
\end{tabular}

Baseline Imbalances Unclear risk

Baseline characteristics were described as "similar" between the 3 groups, but no specific reference was made to the those in the TBI subgroup, wherein the differences in years since traumatic event were larger than for those with stroke. It is reported that "a majority" (74\%) of the TBI group had previously received botulinum toxin treatment, but it was not reported whether this differed between intervention groups and placebo.

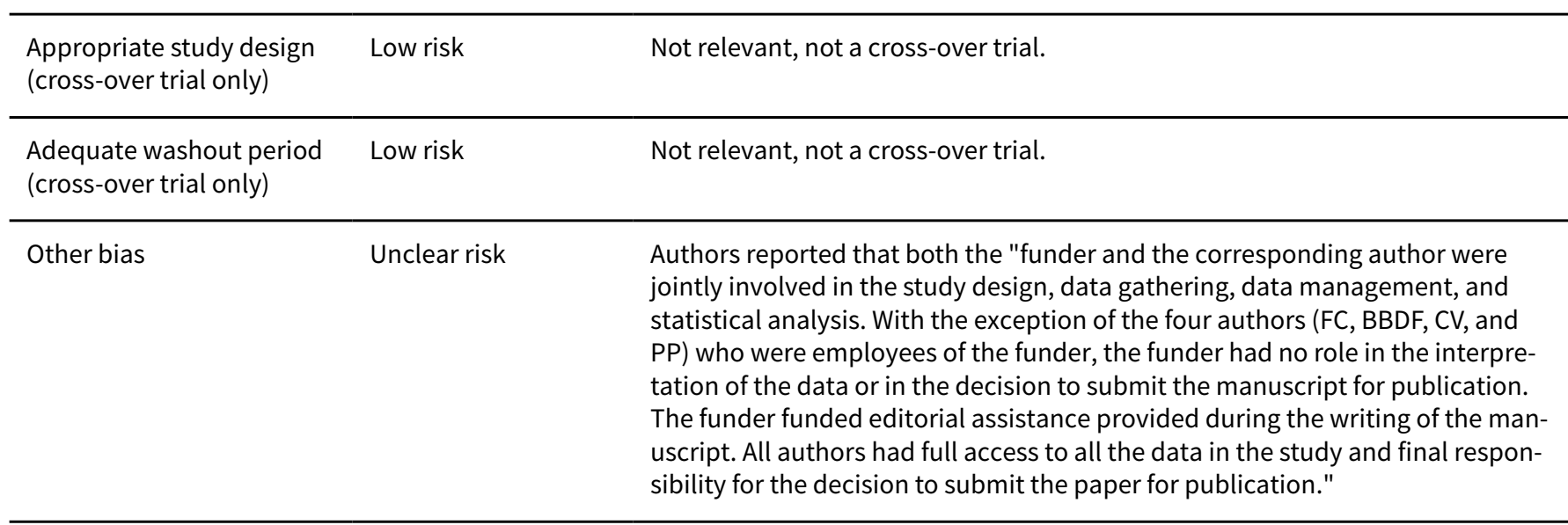




\begin{tabular}{ll}
\hline Methods & Randomised controlled trial. \\
& Setting: Sydney, Australia (Royal Rehabilitation Centre, Liverpool and Westmead Hospitals). \\
& Funding: Royal Rehabilitation Centre, Sydney and University of Sydney.
\end{tabular}

Funding: Royal Rehabilitation Centre, Sydney and University of Sydney.

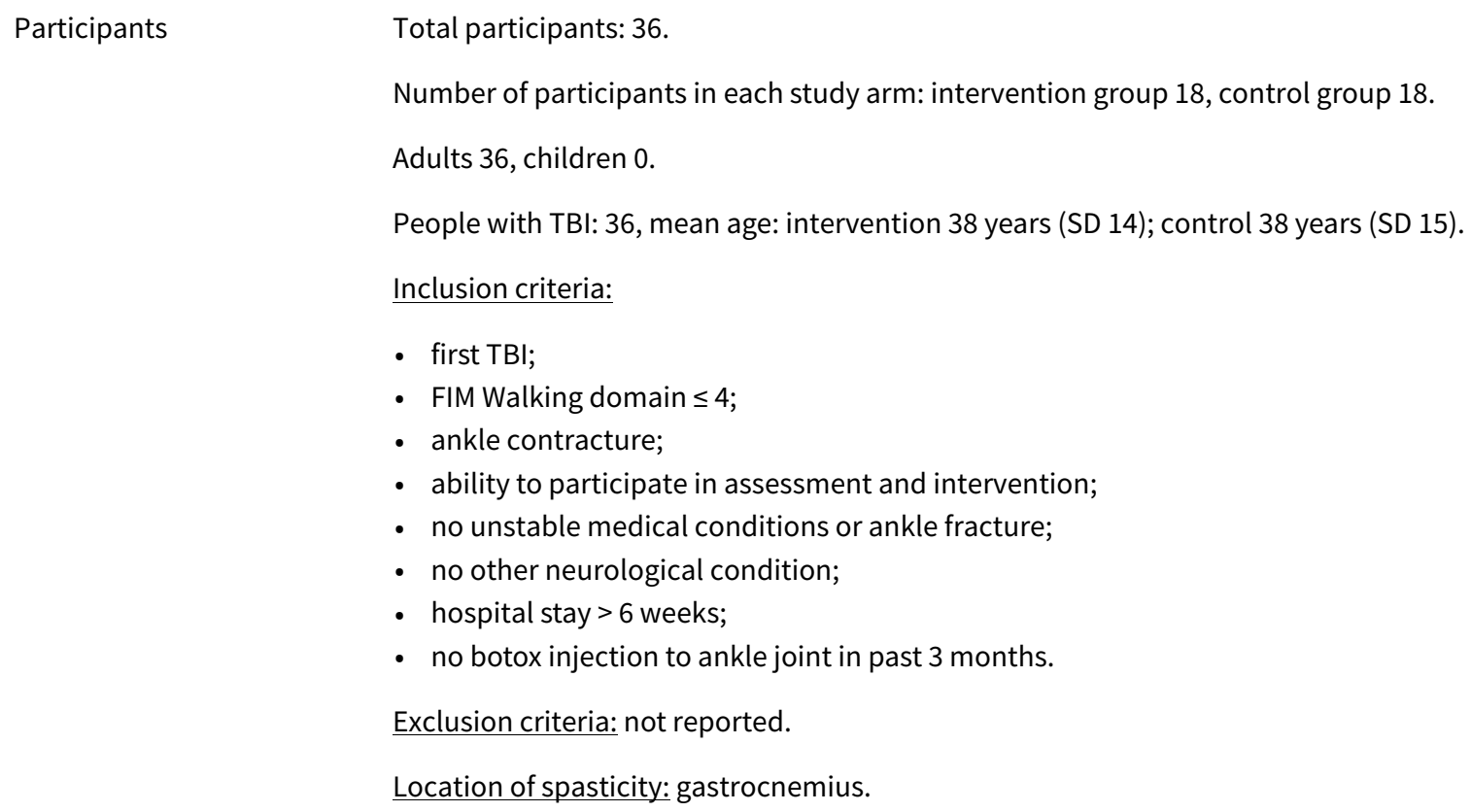
times a week, with 12 hours of ankle splinting a day, at least 5 days a week (total duration of intervention programme: 6 weeks).

Control: tilt table standing for 30 minutes, 3 times a week (total duration of control programme: 6 weeks).

\section{Outcomes} Outcome assessed at: baseline, and weeks 6 and 10 (follow-up).

\section{Primary outcomes:}

- passive ankle dorsiflexion measured at $12 \mathrm{Nm}$.

Secondary outcomes:

- passive dorsiflexion measured 3, 5, 7,9 $\mathrm{Nm}$;

- FIM Walking domain;

- walking speed;

- spasticity (ankle plantarflexor muscle spasticity was rated based on reaction to passive stretch at high speed (not angle of catch) using the 5-point Tardieu Scale);

- physiotherapist and participant global perceived effect of treatment and treatment credibility.

Length of follow-up: 10 weeks. ity was measured at baseline and as an outcome measure, but this was not mentioned as an inclusion criteria. The author confirmed that 35/36 participants had spasticity during the study, which we decided was sufficient to meet the inclusion criteria for this review.

We selected the study's primary outcome of passive dorsiflexion (measured at $12 \mathrm{Nm}$ of torque) as the measure to include under our review outcome, Neuromusculoskeletal and movement-related func- 
Similarly, we selected walking speed over the FIM Walking domain as the most appropriate measure of mobility in the review. The FIM Walking domain was not included.

\section{Risk of bias}

\begin{tabular}{lll}
\hline Bias & Authors' judgement & Support for judgement \\
\hline $\begin{array}{ll}\text { Random sequence genera- } \\
\text { tion (selection bias) }\end{array}$ & Low risk & $\begin{array}{l}\text { "All participants were randomly allocated to one of two groups using a blocked } \\
\text { randomisation schedule" and "The random allocation sequence was comput- } \\
\text { er-generated." }\end{array}$
\end{tabular}

Allocation concealment Low risk
(selection bias)

"The random allocation sequence was computer-generated by a person not involved in participant recruitment. Group allocation was concealed using consecutively numbered, sealed, opaque envelopes, which were kept off-site."

\begin{tabular}{lll}
\hline $\begin{array}{l}\text { Blinding of participants } \\
\text { and personnel (perfor- }\end{array}$ & High risk & $\begin{array}{l}\text { "Assessors and medical staff were blinded to group allocation, but treating } \\
\text { physiotherapists and participants were not." }\end{array}$
\end{tabular}

mance bias)

All outcomes

\begin{tabular}{|c|c|c|}
\hline $\begin{array}{l}\text { Blinding of outcome as- } \\
\text { sessment (detection bias) } \\
\text { All outcomes }\end{array}$ & Low risk & $\begin{array}{l}\text { "The outcomes were measured by one of the five blinded and trained asses- } \\
\text { sors who assessed participants of both groups" and "The blinding of the as- } \\
\text { sessors was reasonably successful. Assessors were unblinded in two of the } \\
\text { end-of-intervention assessments and one of the follow-up assessments. In two } \\
\text { of these assessments, a third person, who was otherwise not involved in the } \\
\text { study, was asked to take the readings from the dynamometer for the passive } \\
\text { ankle range." While the blinding was broken in some assessments, all the out- } \\
\text { comes included in this review were observer-reported/objective. }\end{array}$ \\
\hline
\end{tabular}

\begin{tabular}{|c|c|c|}
\hline $\begin{array}{l}\text { Incomplete outcome data } \\
\text { (attrition bias) }\end{array}$ & Unclear risk & $\begin{array}{l}\text { Participants lost to follow-up by week } 10 \text { (end of trial): } 1 / 18(6 \%) \text { in interven- } \\
\text { tion group, and } 3 / 18(17 \%) \text { in control group. Reasons provided, and were unre- } \\
\text { lated to the trial. Authors reported conducting an ITT analysis, without imput- } \\
\text { ing data. Given imbalance in loss to follow-up, and relatively large percentage } \\
\text { in } 1 \text { group, rated as unclear. }\end{array}$ \\
\hline
\end{tabular}

Selective reporting (re- Low risk Protocol available, all planned outcomes reported.
porting bias)

\begin{tabular}{ll}
\hline Baseline Imbalances & Unclear risk
\end{tabular}$\quad \begin{aligned} & 1 / 36 \text { participants did not have spasticity during the study (unclear whether } \\
& \text { they belonged to intervention or control group) and the median time from in- } \\
& \text { jury to baseline assessment was longer in the intervention group (140 days) } \\
& \text { compared to control group (83 days). }\end{aligned}$

\begin{tabular}{lll}
\hline $\begin{array}{l}\text { Appropriate study design } \\
\text { (cross-over trial only) }\end{array}$ & Low risk & Not relevant, not a cross-over trial. \\
\hline $\begin{array}{l}\text { Adequate washout period } \\
\text { (cross-over trial only) }\end{array}$ & Low risk & Not relevant, not a cross-over trial. \\
\hline Other bias & Unclear risk & $\begin{array}{l}\text { The number of tilt table sessions was markedly different in the intervention } \\
\text { group (30 sessions) compared to the control group (18 sessions). }\end{array}$ \\
\hline
\end{tabular}


Meythaler 1996

Methods
Randomised cross-over trial comparing bolus intrathecal baclofen and placebo.

Setting: university tertiary care outpatient rehabilitation clinic.

Funding: grant R49/CCR403641 from the US Department of Health and Human Services, Centers for Disease Control and Prevention - National Center for Injury Prevention and Control to the University of Alabama-Birmingham Injury Control Research Center.

Participants

Total participants 11 including 10 participants with TBI (90\% male).

Adults: 11, children: 0 .

People with TBI: mean age 24.0 years (SD 4.5, range 20-34).

Inclusion criteria:

- aged 18-65 years;

- diagnosis of severe chronic spastic hypertonia in the lower extremities (although the upper extremities could also be involved) of at least 1 year' duration that was defined by a mean Ashworth Scale of $\geq$ 3 or a mean spasm score of $\geq 2$, failure to respond satisfactorily to treatment with oral antispastic medications (including baclofen at 80-160 mg/day, and possibly diazepam, clonidine, dantrolene sodium, or a combination) or occurrence of unacceptable adverse effects at effective treatment dosages.

\section{Exclusion criteria:}

- pregnant or failure to use an adequate contraception (if not menopausal);

- history of hypersensitivity to baclofen;

- severely impaired renal function;

- severe hepatic disease;

- severe gastrointestinal disease.

Location of spasticity:

Upper limb: shoulder abduction, elbow extensions, elbow flexion and wrist extensions.

Lower limb: hip abduction, hip flexion, knee flexion and ankle dorsiflexion.

The authors did not report if the participants had bilateral or unilateral symptoms.

Interventions

Baclofen: intrathecal administration (Lioresal Intrathecal) supplied in single-use ampoules $(10 \mathrm{mg} / 20$ $\mathrm{mL}$ ampoules; $500 \mu \mathrm{g} / \mathrm{mL}$ ) and diluted with preservative-free $0.9 \%$ normal saline to obtain a concentration of $50 \mu \mathrm{g} / 1 \mathrm{~mL}$. All participants received baclofen $50 \mu \mathrm{g}$. A lumbar puncture was performed at either the L3-L4 or the L2-L3 interspace, and $1 \mathrm{~mL}$ was injected.

Placebo: preservative-free normal saline.

Cross-over phase in administering the opposite treatment occurred at least 48 hours after the initial administration.

Outcomes

Outcome assessed at: baseline, and 1, 2, 4 and 6 hours.

Primary outcomes:

- spasticity: Ashworth Scale, Spasm score;

- adverse effect: complications or adverse effects were noted.

Secondary outcomes:

- deep tendon reflexes.

Length of follow-up: not reported. 
Meythaler 1996 (Continued)

Notes

\section{Risk of bias}

\begin{tabular}{|c|c|c|}
\hline Bias & Authors' judgement & Support for judgement \\
\hline $\begin{array}{l}\text { Random sequence genera- } \\
\text { tion (selection bias) }\end{array}$ & Unclear risk & $\begin{array}{l}\text { "Patients were randomised to receive..." Insufficient information to determine } \\
\text { whether adequate random sequence generation. }\end{array}$ \\
\hline $\begin{array}{l}\text { Allocation concealment } \\
\text { (selection bias) }\end{array}$ & Unclear risk & $\begin{array}{l}\text { Insufficient information to determine whether adequate allocation conceal- } \\
\text { ment. }\end{array}$ \\
\hline $\begin{array}{l}\text { Blinding of participants } \\
\text { and personnel (perfor- } \\
\text { mance bias) } \\
\text { All outcomes }\end{array}$ & Low risk & "Neither the patient nor the investigator know which substance was injected." \\
\hline $\begin{array}{l}\text { Blinding of outcome as- } \\
\text { sessment (detection bias) } \\
\text { All outcomes }\end{array}$ & Low risk & $\begin{array}{l}\text { Before cross-over: "Neither the patient nor the investigator know which sub- } \\
\text { stance was injected. Data for the Ashworth scale, spasm score, deep tendon } \\
\text { reflexes were then collected as described previously } 1,2,4 \text { and } 6 \text { hours post in- } \\
\text { jection by the same investigator." After cross-over, "Again neither the patient } \\
\text { nor the investigator knew which substance had been injected." }\end{array}$ \\
\hline $\begin{array}{l}\text { Incomplete outcome data } \\
\text { (attrition bias) }\end{array}$ & Low risk & All outcome data presented for all participants. \\
\hline $\begin{array}{l}\text { Selective reporting (re- } \\
\text { porting bias) }\end{array}$ & Unclear risk & Reported all expected outcomes but no protocol referenced. \\
\hline Baseline Imbalances & Low risk & Baseline data provided. \\
\hline $\begin{array}{l}\text { Appropriate study design } \\
\text { (cross-over trial only) }\end{array}$ & Low risk & A cross-over study design was reasonable due to a small sample size. \\
\hline $\begin{array}{l}\text { Adequate washout period } \\
\text { (cross-over trial only) }\end{array}$ & Low risk & $\begin{array}{l}\text { "The crossover phase of the study occurred during a second outpatient clinic } \\
\text { visit at least } 48 \text { hours after the initial administration." Appropriate washout pe- } \\
\text { riod for baclofen. }\end{array}$ \\
\hline Other bias & Low risk & No other bias noted. \\
\hline
\end{tabular}

Meythaler 1997

Methods Randomised double-blind placebo controlled cross-over trial, initial stage of trial prior to baclofen pump insertion.

Setting: outpatient rehabilitation clinic that was part of a single tertiary care university medical centre

(10 participants) and inpatients from the same university medical centre (2 participants).

Funding: Medtronic, Inc.

Participants

Total participants 12 including 9 participants with TBI (92\% male).

Adults: 12 , children: 0 , age range $17-39$ years, mean 28 years.

Inclusion criteria:

- aged 10-75 years; 
- diagnosis of severe chronic spastic hypertonia in lower extremities (although upper extremities could also be involved) of $\geq 6$ months' duration that was defined by a mean Ashworth Scale score of $\geq 3$ in the affected extremities ( $\geq 2$ extremities) or a mean spasm score of $\geq 2$ in the affected extremities;

- did not respond satisfactorily to treatment with oral antispasmodic medications (including baclofen and possibly diazepam, clonidine, dantrolene sodium, or a combination of these);

- experienced unacceptable adverse effects at effective treatment dosages of these drugs.

Exclusion criteria: none reported.

Location of spasticity:

Lower extremities, upper extremities could be included, $>2$ extremities affected.

Interventions

Baclofen: continuous intrathecal infusion of baclofen $50 \mu \mathrm{g}$. A lumbar puncture was performed at either the L3-L4 or the L2-L3 interspace, and $1 \mathrm{~mL}$ bolus was injected. Participants also received intensive inpatient rehabilitation to benefit from the decreased motor tone or increased voluntary motor control (or both) they experience with the intrathecal baclofen.

Placebo: preservative-free normal saline.

Cross-over occurred during a second outpatient clinic at least 48 hours after the initial administration.

$\begin{array}{ll}\text { Outcomes } & \text { Outcomes assessed at 1, 2, } 4 \text { and } 6 \text { hours post injection. } \\ & \text { Primary outcome: } \\ \text { - Ashworth Scale, spasm frequency, deep tendon reflexes; } \\ \text { - adverse effects: not reported; stated "no untoward effects." } \\ \text { Secondary outcomes: not reported. } \\ \text { Length of follow-up: not reported. } \\ \text { Notes } \\ \text { No data for randomised component, prior to pump insertion. Author contacted and was attempting to } \\ \text { locate the data; however, no further information received. }\end{array}$

\section{Risk of bias}

\begin{tabular}{lll}
\hline Bias & Authors' judgement & Support for judgement \\
\hline $\begin{array}{l}\text { Random sequence genera- } \\
\text { tion (selection bias) }\end{array}$ & Unclear risk & Study reported as randomised but method not described. \\
\hline $\begin{array}{l}\text { Allocation concealment } \\
\text { (selection bias) }\end{array}$ & Unclear risk & Allocation concealment not described. \\
\hline $\begin{array}{l}\text { Blinding of participants } \\
\begin{array}{l}\text { and personnel (perfor- } \\
\text { mance bias) }\end{array}\end{array}$ & Low risk & "Neither the patient nor the investigator knew which substance was injected \\
$\begin{array}{l}\text { All outcomes } \\
\text { until after the second trial phase was completed." }\end{array}$ & \\
\hline $\begin{array}{l}\text { Blinding of outcome as- } \\
\text { sessment (detection bias) } \\
\text { All outcomes }\end{array}$ & Unclear risk & $\begin{array}{l}\text { While the authors reported that the 'investigator' was blinded, it was unclear if } \\
\text { this investigator assessed outcomes. }\end{array}$ \\
\hline $\begin{array}{l}\text { Incomplete outcome data } \\
\text { (attrition bias) }\end{array}$ & Low risk & No loss to follow-up (follow-up data for all 12 participants reported). \\
\hline $\begin{array}{l}\text { Selective reporting (re- } \\
\text { porting bias) }\end{array}$ & Unclear risk & Protocol not reported. \\
\hline
\end{tabular}


Meythaler 1997 (Continued)

\begin{tabular}{lll} 
Baseline Imbalances & Low risk & Baseline imbalances unclear but not relevant for a cross-over trial. \\
\hline $\begin{array}{l}\text { Appropriate study design } \\
\text { (cross-over trial only) }\end{array}$ & Low risk & A cross-over study design was reasonable due to a small sample size. \\
\hline $\begin{array}{l}\text { Adequate washout period } \\
\text { (cross-over trial only) }\end{array}$ & Low risk & $\begin{array}{l}\text { "The crossover phase of the study occurred during a second outpatient clinic } \\
\text { visit at least 48 hours after the initial administration." Appropriate washout pe- } \\
\text { riod for baclofen. }\end{array}$ \\
\hline Other bias & High risk & $\begin{array}{l}\text { Unit of analysis issue. The outcomes were analysed by looking at upper vs low- } \\
\text { er extremities. "Rather than consider each muscle separately, scores for mus- } \\
\text { cle tone, spasms, and reflexes were averaged for the upper or lower extremi- } \\
\text { ties in each patient." }\end{array}$ \\
\hline
\end{tabular}

Meythaler 1999a

\begin{tabular}{|c|c|}
\hline \multirow[t]{3}{*}{ Methods } & Single-centre, randomised, double-blind, placebo-controlled cross-over trial. \\
\hline & $\begin{array}{l}\text { Setting: spasticity clinic in a tertiary care university-based outpatient physical medicine and rehabilita- } \\
\text { tion clinic. }\end{array}$ \\
\hline & Funding: Medtronic Inc. \\
\hline
\end{tabular}

Participants

Total participants 6 including 3 participants with TBI (60\% male).

Adults 6, children 0.

Inclusion criteria:

- aged 14-75 years;

- diagnosis of severe chronic spastic hypertonia in lower limbs (although upper limbs could also be involved) for at least a 6-month duration that was defined by a mean Ashworth score $\geq 3$ in the affected limbs ( $\geq 1$ limbs) or a mean spasm score $\geq 2$ in the affected limb;

- either failure to respond satisfactorily to treatment with oral antispasticity medications (including baclofen and possibly diazepam, clonidine, dantrolene sodium, or a combination of these) or the occurrence of unacceptable adverse effects at effective treatment dosages.

Exclusion criteria: not reported.

Location of spasticity: lower extremities, upper extremities could be included, $>2$ extremities affected.

Interventions

Baclofen: continuous intrathecal infusion of baclofen $50 \mu \mathrm{g}$. A lumbar puncture was performed at either the L3-L4 or the L2-L3 interspace, and $1 \mathrm{~mL}$ was injected. Participants also received intensive inpatient rehabilitation to benefit from the decreased motor tone or increased voluntary motor control (or both) they experience with the intrathecal baclofen.

Placebo: preservative-free normal saline.

Cross-over occurred during a second outpatient clinic at least 48 hours after the initial administration.

Outcomes

Outcomes assessed at 1, 2, 4 and 6 hours' post injection.

Primary outcome:

- Ashworth Scale, spasm frequency, deep tendon reflexes;

- adverse effects: not identified; stated "no untoward effects.

Secondary outcomes: not reported. 
Meythaler 1999a (Continued)

Length of follow-up: not reported.

Notes

No data for randomised component, prior to pump insertion. Author contacted and was attempting to locate the data; however, no further information received.

\section{Risk of bias}

\begin{tabular}{|c|c|c|}
\hline Bias & Authors' judgement & Support for judgement \\
\hline $\begin{array}{l}\text { Random sequence genera- } \\
\text { tion (selection bias) }\end{array}$ & Unclear risk & Study reported as randomised but method not described. \\
\hline $\begin{array}{l}\text { Allocation concealment } \\
\text { (selection bias) }\end{array}$ & Unclear risk & Allocation concealment not described. \\
\hline $\begin{array}{l}\text { Blinding of participants } \\
\text { and personnel (perfor- } \\
\text { mance bias) } \\
\text { All outcomes }\end{array}$ & Low risk & $\begin{array}{l}\text { "Neither the patient nor the investigator knew which substance was injected } \\
\text { until after the second trial phase was completed." }\end{array}$ \\
\hline $\begin{array}{l}\text { Blinding of outcome as- } \\
\text { sessment (detection bias) } \\
\text { All outcomes }\end{array}$ & Unclear risk & $\begin{array}{l}\text { While the authors reported that the 'investigator' was blinded, it was unclear if } \\
\text { this investigator assessed outcomes. }\end{array}$ \\
\hline $\begin{array}{l}\text { Incomplete outcome data } \\
\text { (attrition bias) }\end{array}$ & Low risk & No loss to follow-up (follow-up data for all 6 participants reported). \\
\hline $\begin{array}{l}\text { Selective reporting (re- } \\
\text { porting bias) }\end{array}$ & High risk & $\begin{array}{l}\text { Protocol not published but authors reported they collected data at } 2 \text { time } \\
\text { points but only } 1 \text { time point published. }\end{array}$ \\
\hline Baseline Imbalances & Low risk & Baseline imbalances unclear but not relevant for a cross-over trial. \\
\hline $\begin{array}{l}\text { Appropriate study design } \\
\text { (cross-over trial only) }\end{array}$ & Low risk & A cross-over study design was reasonable due to a small sample size. \\
\hline $\begin{array}{l}\text { Adequate washout period } \\
\text { (cross-over trial only) }\end{array}$ & Low risk & $\begin{array}{l}\text { "The crossover phase of the study occurred during a second outpatient clinic } \\
\text { visit at least } 48 \text { hours after the initial administration." Appropriate washout pe- } \\
\text { riod for baclofen. }\end{array}$ \\
\hline Other bias & High risk & $\begin{array}{l}\text { Unit of analysis issue. The outcomes were analysed by looking at upper vs low- } \\
\text { er extremities. "Rather than consider each muscle separately, scores for mus- } \\
\text { cle tone, spasms, and reflexes were averaged for the upper or lower extremi- } \\
\text { ties in each patient." }\end{array}$ \\
\hline
\end{tabular}

Meythaler 1999b

Methods Randomised, double-blind, placebo-controlled cross-over trial.

Setting: outpatient rehabilitation clinic, tertiary care university medical centre.

Funding: Medtronic, Inc.

Participants

Total participants: 17 , all 17 participants with TBI ( $82 \%$ male).

Adults: not reported, children: not reported; age range: 10-55 years.

Inclusion criteria: 
Meythaler 1999b (Continued)

- aged 14-75 years;

- diagnosis of severe chronic spastic hypertonia in the lower limbs (although the upper limbs could also be involved) for $\geq 6$ months that was defined by a mean Ashworth score $\geq 3$ in the affected limbs ( $\geq 1$ limbs) or a mean spasm score $\geq 2$ in the affected limb;

- either failure to respond satisfactorily to treatment with oral antispasticity medications (including baclofen and possibly diazepam, clonidine, dantrolene sodium, or a combination of these) or the occurrence of unacceptable adverse effects at effective treatment dosages.

Exclusion criteria: not reported.

Location of spasticity: lower extremities, upper extremities could be included, > 2 extremities affected.

Interventions

Baclofen: continuous intrathecal infusion of baclofen $50 \mu \mathrm{g}$. A lumbar puncture was performed at either the L3-L4 or the L2-L3 interspace, and $1 \mathrm{~mL}$ was injected. Participants also received intensive inpatient rehabilitation to benefit from the decreased motor tone or increased voluntary motor control (or both) they experience with the intrathecal baclofen. After implantation of the infusion device, all participants received intrathecal baclofen $100 \mu \mathrm{g} /$ day continuously.

Placebo: preservative-free normal saline.

Cross-over occurred during a second outpatient clinic at least 48 hours after the initial administration.

Outcomes Outcomes assessed at 1, 2, 4 and 6 hours post injection, 1, 3, 6, 9 months post pump placement.

Primary outcome:

- Ashworth Scale, spasm frequency, deep tendon reflexes;

- adverse effects: not identified; stated "no untoward effects."

Secondary outcomes: not reported.

Length of follow-up: 1 year.

Notes

No data for randomised component, prior to pump insertion. Author contacted and was attempting to locate the data; however, no further information received.

"Postoperatively all patients in this study received 24 to 36 hours of intravenous vancomycin and gentamicin for prophylaxis of infection."

Inclusion criteria stated minimum age of 14 years, yet at least some participants as young as 10 years.

\section{Risk of bias}

\begin{tabular}{|c|c|c|}
\hline Bias & Authors' judgement & Support for judgement \\
\hline $\begin{array}{l}\text { Random sequence genera- } \\
\text { tion (selection bias) }\end{array}$ & Unclear risk & Study reported as randomised but method not described. \\
\hline $\begin{array}{l}\text { Allocation concealment } \\
\text { (selection bias) }\end{array}$ & Unclear risk & Allocation concealment not described. \\
\hline $\begin{array}{l}\text { Blinding of participants } \\
\text { and personnel (perfor- } \\
\text { mance bias) } \\
\text { All outcomes }\end{array}$ & Low risk & $\begin{array}{l}\text { "Neither the patient nor the investigator knew which substance was injected } \\
\text { until after the second trial phase was completed." }\end{array}$ \\
\hline $\begin{array}{l}\text { Blinding of outcome as- } \\
\text { sessment (detection bias) } \\
\text { All outcomes }\end{array}$ & Unclear risk & $\begin{array}{l}\text { While the authors report that the 'investigator' was blinded, it was unclear if } \\
\text { this investigator assessed outcomes. }\end{array}$ \\
\hline
\end{tabular}


Meythaler 1999b (Continued)

Incomplete outcome data Low risk Outcome data for all participants reported. (attrition bias)

\begin{tabular}{lll}
\hline $\begin{array}{l}\text { Selective reporting (re- } \\
\text { porting bias) }\end{array}$ & Unclear risk & No published protocol. \\
\hline Baseline Imbalances & Low risk & Baseline imbalances not clear but not relevant for a cross-over trial. \\
\hline $\begin{array}{l}\text { Appropriate study design } \\
\text { (cross-over trial only) }\end{array}$ & Low risk & A cross-over study design was reasonable due to a small sample size. \\
\hline $\begin{array}{l}\text { Adequate washout period } \\
\text { (cross-over trial only) }\end{array}$ & Unclear risk & Washout period not stated. \\
\hline $\begin{array}{l}\text { Other bias } \\
\text { High risk }\end{array}$ & $\begin{array}{l}\text { Unit of analysis issue. Outcomes were analysed by looking at upper vs lower } \\
\text { extremities. "Rather than consider each muscle separately, scores for muscle } \\
\text { tone, spasms, and reflexes were averaged for the upper or lower extremities in } \\
\text { each patient." }\end{array}$ \\
\hline
\end{tabular}

Methods Randomised, double-blind, cross-over trial (no information provided about randomisation method): Phase 1 study.

Setting: not reported; assumed Jerusalem, Israel.

Funding: Teva GTC.

Participants

Inclusion criteria:

- children aged 8-18 years with TBI who had spasticity "that interferes with task performance;"

- documented loss of consciousness for $>24$ hours or initial GCS $<8$;

- able to co-operate and understand general explanations.

Exclusion criteria:

- history of allergy to tizanidine or any inactive component (including lactose intolerance);

- use of other hypnotic medication within 3 days of baseline visit and during study;

- botulinum toxin A therapy within 6 weeks of baseline, or use of baclofen pump during trial;

- use of CYP1A2 inhibitors (e.g. ciprofloxacin or fluvoxamine) for duration of study;

- girls taking oral contraceptives;

- significant abnormalities in clinical screening laboratory parameters (alanine transaminase, aspartate aminotransferase, bilirubin $>2 \times$ upper limit of normal; creatinine $>2 \mathrm{mg} / \mathrm{dL}$; white blood cell count $<2300 / \mathrm{mm}^{3}$, platelets $<80,000 / \mathrm{mm}^{3}$ );

- taking other medications that may have adversely interfered with actions of study medication or outcome variables within 2 weeks or 5 half-lives of the baseline visit

Location of spasticity: not reported.

Interventions Intervention: tizanidine hydrochloride (administered sublingually).

Comparison: placebo.

Outcomes

\section{Primary outcomes:}

- improvement in spasticity, cognition and daily function at 4 weeks. 


\section{Secondary outcomes:}

- improvement in night-time sleep parameters as measured by actigraphy at 4 weeks.

\section{Notes}

Communication with authors: this was a pilot conducted in the Alyn Rehabilitation Hospital in Jerusalem. They reported the pilot yielded negative results, was not continued and that none of the results were published.

\section{Risk of bias}

\begin{tabular}{|c|c|c|}
\hline Bias & Authors' judgement & Support for judgement \\
\hline $\begin{array}{l}\text { Random sequence genera- } \\
\text { tion (selection bias) }\end{array}$ & Unclear risk & Random sequence generation not described. \\
\hline $\begin{array}{l}\text { Allocation concealment } \\
\text { (selection bias) }\end{array}$ & Unclear risk & Allocation concealment method not described. \\
\hline $\begin{array}{l}\text { Blinding of participants } \\
\text { and personnel (perfor- } \\
\text { mance bias) } \\
\text { All outcomes }\end{array}$ & Unclear risk & $\begin{array}{l}\text { Study described as "double blind" but whether both participants and person- } \\
\text { nel were blinded was unclear. }\end{array}$ \\
\hline $\begin{array}{l}\text { Blinding of outcome as- } \\
\text { sessment (detection bias) } \\
\text { All outcomes }\end{array}$ & Unclear risk & $\begin{array}{l}\text { Study described as "double blind" but whether outcome assessors were blind- } \\
\text { ed was unclear. }\end{array}$ \\
\hline $\begin{array}{l}\text { Incomplete outcome data } \\
\text { (attrition bias) }\end{array}$ & Unclear risk & Withdrawals and loss to follow-up not described. \\
\hline $\begin{array}{l}\text { Selective reporting (re- } \\
\text { porting bias) }\end{array}$ & High risk & $\begin{array}{l}\text { Trial data "negative" as reported by authors, and no available data; unpub- } \\
\text { lished. }\end{array}$ \\
\hline Baseline Imbalances & Unclear risk & No information about participant demographics. \\
\hline $\begin{array}{l}\text { Appropriate study design } \\
\text { (cross-over trial only) }\end{array}$ & Unclear risk & Not reported. \\
\hline $\begin{array}{l}\text { Adequate washout period } \\
\text { (cross-over trial only) }\end{array}$ & Unclear risk & Not reported. \\
\hline Other bias & Unclear risk & Inadequate information to make a judgement. \\
\hline
\end{tabular}

Pittaccio 2013

\begin{tabular}{ll} 
Methods & Randomised cross-over trial. \\
& Setting: Italy (at the Istituro Eugenio Media). \\
& Funding: Fondazione Cariplo (Philanthropic organisation). \\
\hline Participants & Total participants: 25 overall study, including 16 with TBI (72\% male in overall study). \\
& $\begin{array}{l}\text { Overall participants (TBI not reported separately): age: } 7.75 \text { years (SD 5.40, range 4-19). However, the } \\
\text { review author team calculated this (using the individual participant ages provided in the paper and, } \\
\text { which resulted in a mean age of } 9.08 \text { years (SD 5.38)). }\end{array}$
\end{tabular}


Pittaccio 2013 (Continued)

Adults: 0, children: 16 .

Inclusion criteria:

- acquired quadriplegia or hemiplegia;

- aged 4-18 years;

- Ashworth Score for the target $\operatorname{limb}>1$.

Exclusion criteria:

- pathologies of the target joint or skin affections in the target area.

Location of spasticity:

upper limb: elbow (flexors);

lower limb: ankle (extensors).

Interventions

Pseudoelastic orthosis: spring-loaded orthosis comprised of 2 parts that could rotate relative to one another around a common axis. Each orthosis was individually customised and worn for 1 month.

Traditional static splint: no further details provided about the splint, other than it was worn for 1 month.

Washout period: no washout period as study authors considered it unethical to leave participants without any treatment.
Outcomes
Outcome assessed at: baseline, and 1 (at cross-over) and 2 months (end of second treatment).
Unclear which were primary and secondary outcomes
- range of motion;
- spasticity: Modified Ashworth Scale.
Length of follow-up: 2 months.

\section{Notes}

\section{Risk of bias}

\begin{tabular}{lll}
\hline Bias & Authors' judgement & Support for judgement \\
\hline $\begin{array}{l}\text { Random sequence genera- } \\
\text { tion (selection bias) }\end{array}$ & Unclear risk & No detail on method of randomisation reported. \\
\hline $\begin{array}{l}\text { Allocation concealment } \\
\text { (selection bias) }\end{array}$ & Unclear risk & No details on method of allocation concealment (if any). \\
\hline $\begin{array}{l}\text { Blinding of participants } \\
\text { and personnel (perfor- } \\
\text { mance bias) }\end{array}$ & High risk & $\begin{array}{l}\text { Blinding within this study was impossible due to the nature of the 2 active } \\
\text { treatments (traditional splints appear very different to the experimental 'pseu- } \\
\text { doelastic' ones). }\end{array}$ \\
\hline
\end{tabular}

\begin{tabular}{|c|c|c|}
\hline $\begin{array}{l}\text { Blinding of outcome as- } \\
\text { sessment (detection bias) }\end{array}$ & High risk & $\begin{array}{l}\text { See above. In addition, no attempts to blind outcome assessors or data ana- } \\
\text { lysts to the treatment status of participants was reported. }\end{array}$ \\
\hline
\end{tabular}

All outcomes

$\begin{array}{ll}\begin{array}{l}\text { Incomplete outcome data } \\ \text { (attrition bias) }\end{array} & \text { Low risk } \\ \end{array}$


Pittaccio 2013 (Continued)

Selective reporting (reporting bias)
High risk

No published protocol. Furthermore, there was a pronounced tendency in the paper to report perceived benefits in detail (e.g. data regarding rigidity outcomes for ankles in particular) whilst few details and no numerical data were provided for results wherein no difference between treated groups was apparent (e.g. for spasticity as measured by the Modified Ashworth Scale) despite these being collected after both treatment phases as well as at baseline. Whilst this does not indicate 'suppression' of data, it obviates meta-analyses (should comparable trials be identified).

\begin{tabular}{lll}
\hline Baseline Imbalances & Low risk & Baseline imbalances not clear but not relevant for a cross-over trial. \\
\hline $\begin{array}{l}\text { Appropriate study design } \\
\text { (cross-over trial only) }\end{array}$ & Low risk & A cross-over study design was reasonable due to a small sample size. \\
\hline $\begin{array}{l}\text { Adequate washout period } \\
\text { (cross-over trial only) }\end{array}$ & Low risk & $\begin{array}{l}\text { Investigators considered it unethical to have a washout period; investigators } \\
\text { also went to lengths to confirm that the sequential order of treatments did not } \\
\text { make any difference to the final outcome ( } p=0.30, T 2-T 0, T P \text { vs PT, paired 2- } \\
\text { tailed Student's t test, 23 participants). }\end{array}$ \\
\hline
\end{tabular}

Other bias

Unclear risk

Although the inclusion criteria stated that participants had to be aged 4-18 years and have a score $>1$ on the Modified Ashworth Scale, 1 participant was 19 years of age and had a score of 0 .

\section{Verplancke 2005}

$\begin{array}{ll}\text { Methods } & \text { Randomised controlled trial. } \\ \text { Setting: acute general hospital in the UK. } \\ \text { Funding: Allergan Inc. and 3M Health Care Ltd. }\end{array}$

\section{Participants}

Total participants: 35, 71\% male, including 20 participants with TBI.

Adults: 35 , children 0.

Serial casting + botulinum toxin A 200 U: total 12 participants, median age 41.5 years; TBI 6 participants.

Serial casting + placebo (saline): total 12 participants, median age 33.5 years; TBI 6 participants.

Control (physiotherapy): total 11 participants, median age 40 years; TBI 8 participants.

Inclusion criteria:

- participants were screened twice weekly for 4 weeks and their passive range of ankle dorsiflexion was measured in a supine position by a goniometer attached to a multi-myometer and pressure strain gauge device (MIE Medical Research, Leeds, UK) at a force of $65 \mathrm{~N}$ and by the same person, who documented the higher of 2 joint range measurements;

- unable to achieve 3 degrees of passive ankle dorsiflexion at $65 \mathrm{~N}$ of force.

Exclusion criteria:

- pregnant;

- history of deep vein thrombosis within the previous 12 months;

- severe lower limb injury or lower limb fracture;

- previous exposure to continuous muscle relaxants;

- hypersensitivity to botulinum toxin;

- received botulinum toxin injections within the previous 3 months. 
Verplancke 2005 (Continued)

\section{Location of spasticity:}

lower limb: gastrocnemius and soleus.

The authors did not report if the participants had bilateral or unilateral symptoms.

Interventions $\quad$ Physiotherapy (control): standard programme of physiotherapy, as currently practiced in the neurosciences unit, but were not supplied with sheepskin bootees.

Casting and placebo: lower leg casting plus injections with saline into gastrocnemius and soleus muscles, those in casting and placebo were injected with $0.5 \mathrm{~mL} 0.9 \%$ normal saline into each of 4 standard points into gastrocnemius and soleus muscles, giving a total of $4 \mathrm{~mL}$. They were additionally placed in a bespoke 'combicast' made up of Soft Cast and Scotchcast Plus (supplied by 3M Health Care Ltd, Loughborough, UK), which held the lower leg and foot in a neutral plantargrade position, but still allowed soft tissue functioning within the rest of the limb.

Casting and botulinum toxin A: lower leg casting + injections with botulinum toxin A into gastrocnemius and soleus muscles. These participants were placed in casts in the same way as for casting and placebo participants, but were additionally given an injection of botulinum toxin A $200 \mathrm{U}$ (Allergan Pharmaceuticals Inc., Irvine, CA, USA) per leg, equally divided into gastrocnemius and soleus muscles. Each $100-U$ vial of botulinum toxin A was diluted.

Outcome assessed at: baseline and 12 weeks.
Primary outcomes:
- spasticity: Modified Ashworth Scale;
- adverse effect: not listed as an outcome measure, but was reported in the results section.
Secondary outcomes:
- range of movement (ankle);
- Glasgow Outcome Scale;
- Glasgow Coma Scale.
Length of follow-up: not reported.

Notes

Risk of bias

\begin{tabular}{lll}
\hline Bias & Authors' judgement & Support for judgement \\
\hline $\begin{array}{l}\text { Random sequence genera- } \\
\text { tion (selection bias) }\end{array}$ & Unclear risk & $\begin{array}{l}\text { "Patients were enrolled in a strict numeric order, but the treatments were ran- } \\
\text { domised in groups of three (i.e., block randomisation in groups of three)." }\end{array}$ \\
\hline $\begin{array}{l}\text { Allocation concealment } \\
\text { (selection bias) }\end{array}$ & Unclear risk & No Information provided. \\
\hline $\begin{array}{l}\text { Blinding of participants } \\
\text { and personnel (perfor- } \\
\text { mance bias) } \\
\text { All outcomes }\end{array}$ & High risk & $\begin{array}{l}\text { "This ensured that blinding of the active (casting +/- botulinum toxin A) treat- } \\
\text { ments still occurred and that recruitment produced an even spread of patients } \\
\text { within the groups. Blinding the assessor was not possible for control (phys- } \\
\text { iotherapy) patients, as they were not cast. Those treating patients were also } \\
\text { blinded." The authors attempted to blind the personnel; however, this was im- } \\
\text { possible due to some participants not receiving a cast. }\end{array}$ \\
\hline
\end{tabular}

$\begin{array}{ll}\begin{array}{l}\text { Blinding of outcome as- } \\ \text { sessment (detection bias) }\end{array} & \text { Low risk }\end{array} \quad \begin{aligned} & \text { "The observer was blinded between the active groups, but the absence of a } \\ & \text { cast in control patients may have biased the findings. This is actually unlikely, } \\ & \text { as the primary outcome measure was a quantifiable number at a given force }\end{aligned}$


Verplancke 2005 (Continued)

and previous data were not available to the assessor for comparison until all the measurements were carried out."

Incomplete outcome data Unclear risk (attrition bias)

\begin{abstract}
4 participants were withdrawn from the study but it was not reported which groups they from. However, the final measure used in these participants was the 1 taken prior to their exclusion.

"In order to prevent fixed contracture formation, patients were withdrawn from the study if they became unable to dorsiflex to $>-10$ degrees. At the time it was considered unethical to continue without using botulinum toxin A and/ or casting, and rescue treatment was administered (botulinum toxin injections for groups controls and cast and saline and normal saline injections for cast and botulinum toxin patients). As the assessor continued to be blinded to treatment after rescue treatment was administered, assessment of patients' spasticity continued, but the final measurement prior to exclusion was used for statistical analysis."
\end{abstract}

\begin{tabular}{|c|c|c|}
\hline $\begin{array}{l}\text { Selective reporting (re- } \\
\text { porting bias) }\end{array}$ & High risk & $\begin{array}{l}\text { All outcomes were reported but no published protocol. No baseline data for } \\
\text { the primary outcome (ankle dorsiflexion). No between-group comparisons for } \\
\text { the secondary outcomes. }\end{array}$ \\
\hline Baseline Imbalances & Unclear risk & $\begin{array}{l}\text { "...patients in the three groups were sufficiently uniform in their characteris- } \\
\text { tics;" however, the authors later stated that, "The patients in all the groups } \\
\text { were similar in most respects, but control patients had the smallest range of } \\
\text { dorsiflexion at entry and exit." }\end{array}$ \\
\hline $\begin{array}{l}\text { Appropriate study design } \\
\text { (cross-over trial only) }\end{array}$ & Low risk & Not relevant, not a cross-over trial. \\
\hline $\begin{array}{l}\text { Adequate washout period } \\
\text { (cross-over trial only) }\end{array}$ & Low risk & Not relevant, not a cross-over trial. \\
\hline Other bias & Low risk & No concerns noted. \\
\hline
\end{tabular}

EQ-5D: EuroQol; FIM: Functional Independence Measure; ITT: intention to treat; SD: standard deviation; SF-36: 36-item Short Form; TBI: traumatic brain injury.

Characteristics of excluded studies [ordered by study ID]

\begin{tabular}{ll}
\hline Study & Reason for exclusion \\
\hline Armstrong 1997 & Number of TBI participants $<50 \%$ threshold. Total 19 participants, TBI 2 participants. \\
\hline Ashby 1972 & Number of TBI participants $<50 \%$ threshold. Total 15 participants, TBI 4 participants. \\
\hline Baricich 2008 & All participants had had a stroke. \\
\hline Barnes 2010 & Number of TBI participants $<50 \%$ threshold. Total 192 participants, TBI 11 participants. \\
\hline Basmajian 1973 & All participants had multiple sclerosis, spinal cord injury, dermoid cyst or meningioma. \\
\hline Basmajian 1974 & $\begin{array}{l}\text { All participants had multiple sclerosis, spinal cord injury, demyelinating spinal cord disease or con- } \\
\text { genital quadriplegia. }\end{array}$ \\
\hline Bensmail 2010 & Control group not affected by spasticity and there was no randomisation. \\
\hline
\end{tabular}




\begin{tabular}{|c|c|}
\hline Study & Reason for exclusion \\
\hline Bes 1988 & No valid measure for spasticity \\
\hline Bovend'Eerdt 2009 & Unable to identify if brain injured participants were due to trauma \\
\hline Boyd 2001 & All participants had cerebral palsy. \\
\hline Burbaud 1996 & Number of TBI participants $<50 \%$ threshold. Total 23 participants, TBI 4 participants. \\
\hline Burke 1975 & Number of TBI participants $<50 \%$ threshold. Total 9 participants, TBI 2 participants. \\
\hline Chang 2009 & Number of TBI participants $<50 \%$ threshold. Total 14 participants, TBI 3 participants. \\
\hline Childers 1996 & Number of TBI participants $<50 \%$ threshold. Total 17 participants, TBI 2 participants. \\
\hline Cocchiarella 1967 & All participants had cerebrovascular accident, cervical spondylosis or demyelinating disease. \\
\hline Cohan 1980 & $\begin{array}{l}\text { All participants had multiple sclerosis, infarction of the anterior thoracic spinal cord, degeneration } \\
\text { of the spinal cord, cerebral palsy, amyotrophic lateral sclerosis or cervical spondylosis. }\end{array}$ \\
\hline Copley 2013 & Number of TBI participants $<50 \%$ threshold. Total 10 participants, TBI 2 participants. \\
\hline Corry 1998 & All participants had cerebral palsy. \\
\hline Fazekas 2007 & Number of TBI participants $<50 \%$ threshold. Total 30 participants, TBI 8 participants. \\
\hline Fietzek 2014 & Number of TBI participants $<50 \%$ threshold. Total 52 participants, TBI 6 participants. \\
\hline Francisco 2002 & Number of TBI participants $<50 \%$ threshold. Total 13 participants, TBI 3 participants. \\
\hline Gracies 2009 & Number of TBI participants $<50 \%$ threshold. Total 21 participants, TBI 6 participants. \\
\hline Grazko 1995 & Number of TBI participants $<50 \%$ threshold. Total 20 participants, TBI 1 participants. \\
\hline Guo 2006 & Number of TBI participants $<50 \%$ threshold. Total 60 participants, TBI 17 participants. \\
\hline Harvey 1974 & No information could be obtained to clarify if any participants had a TBI. \\
\hline Harvey 2006 & Number of TBI participants $<50 \%$ threshold. Total 44 participants, TBI 7 participants. \\
\hline Hill 1994 & No valid measure for spasticity. \\
\hline Imle 1986 & No control/placebo comparison group. \\
\hline Krewer 2014 & Number of TBI participants $<50 \%$ threshold. Total 66 participants, TBI 3 participants. \\
\hline Lannin 2003 & Number of TBI participants $<50 \%$ threshold. Total 28 participants, TBI 2 participants. \\
\hline Leung 2012 & Majority of participants had stroke, not TBI. \\
\hline Levine 1969 & All participants had multiple sclerosis. \\
\hline Levine 1977 & All participants had multiple sclerosis or spinal cord injury. \\
\hline Mancini 2005 & All participants had stroke. \\
\hline
\end{tabular}




\begin{tabular}{|c|c|}
\hline Study & Reason for exclusion \\
\hline Martin 2014 & Not an RCT (a systematic review). \\
\hline Mayer 2008 & Compared botulinum toxin A injection technique; motor point vs quadrant. \\
\hline McPherson 1982 & No valid measure for spasticity. \\
\hline Meythaler 2001b & Number of TBI participants $<50 \%$ threshold. Total 17 participants, TBI 8 participants. \\
\hline Middel 1997 & All participants had multiple sclerosis or spinal cord injury. \\
\hline Moseley 1997 & Spasticity not an outcome measure. \\
\hline Moseley 2008 & Did not report whether the participants had spasticity. \\
\hline Nakhostin 2009 & Number of TBI participants $<50 \%$ threshold. Total 21 participants, TBI 1 participants. \\
\hline NCT00776048 & Observational study. \\
\hline NCT00900666 & Included $<50 \%$ people with TBI. \\
\hline Pagano 1990 & $\begin{array}{l}\text { All participants had multiple sclerosis, myelopathy, cerebrovascular accident or perinatal en- } \\
\text { cephalopathy. }\end{array}$ \\
\hline Penn 1988 & $\begin{array}{l}\text { It is unclear if the study included people with TBI, but would appear that it solely included people } \\
\text { with spinal cord injury or multiple sclerosis. }\end{array}$ \\
\hline Richardson 2000 & Unable to identify if the 12 brain-injured participants had experiences trauma. \\
\hline Roussan 1985 & All participants had multiple sclerosis, traumatic paraplegia or transverse myelopathy. \\
\hline Sahuquillo 2000 & Participants with cerebral vasospasms. \\
\hline Simpson 1996 & Participants had stroke. \\
\hline Simpson 2009 & Number of TBI participants $<50 \%$ threshold. Total 60 participants, TBI 11 participants. \\
\hline Smith 2000 & Number of TBI participants $<50 \%$ threshold. Total 21 participants, TBI 2 participants. \\
\hline Snow 1990 & All participants had multiple sclerosis. \\
\hline Suputtitada 2005 & All participants had stroke. \\
\hline Thibaut 2015 & Number of TBI participants $<50 \%$ threshold. Total 17 participants, TBI 7 participants. \\
\hline Van Schaeybroeck 2000 & Number of TBI participants $<50 \%$ threshold. Total 1 participant, TBI 1 participant. \\
\hline Yelnik 2007 & All participants had stroke. \\
\hline Zhao 2015 & Number of TBI participants $<50 \%$ threshold. Total 60 participants, TBI 1 participant. \\
\hline
\end{tabular}

$\mathrm{RCT}$ : randomised controlled trial; TBI: traumatic brain injury.

Characteristics of studies awaiting assessment [ordered by study ID] 
2009-015868-34

\begin{tabular}{|c|c|}
\hline Methods & $\begin{array}{l}\text { Randomised controlled trial (completed). } \\
\text { Setting: European sites (multiple), Russia, US. } \\
\text { Funding: Ipsen Pharma SAS. }\end{array}$ \\
\hline Participants & $\begin{array}{l}348 \text { people with hemiparesis with lower limb spasticity due to stroke or TBI (unclear what percent- } \\
\text { age had a } \mathrm{TBI} \text { ). }\end{array}$ \\
\hline Interventions & $\begin{array}{l}\text { Intervention: Dysport (abobotulinumtoxinA) intramuscular injection } 500 \mathrm{U} / \mathrm{mL} \text {. } \\
\text { Comparator: placebo (no further information provided). }\end{array}$ \\
\hline Outcomes & $\begin{array}{l}\text { Outcome assessed at: baseline, } 4 \text { weeks } \\
\text { Primary outcomes: } \\
\text { - spasticity (Modified Ashworth Scale) change from baseline in the gastrocnemius-soleus complex } \\
\text { muscle tone (knee extended). } \\
\text { Secondary outcomes: } \\
\text { - mean Physician's Global Assessment Score; } \\
\text { - mean change from baseline in comfortable barefoot walking speed without walking aids. }\end{array}$ \\
\hline Notes & $\begin{array}{l}\text { Results are unpublished and it states on the clinical trials registry site: "Results removed from pub- } \\
\text { lic view." Contacted study sponsor in April } 2017 \text { seeking further information about results for par- } \\
\text { ticipants with TBI but no further information received. }\end{array}$ \\
\hline
\end{tabular}

\section{EUCTR2011-005375-16-SE}

\begin{tabular}{|c|c|}
\hline Methods & $\begin{array}{l}\text { Randomised controlled trial (completed). } \\
\text { Setting: Norway, Sweden, Denmark, Finland. } \\
\text { Funding: Institut Produits Synthèse (IPSEN) AB. }\end{array}$ \\
\hline Participants & $\begin{array}{l}88 \text { participants, with upper limb spasticity due to stroke or TBI (unclear what percentage had a } \\
\text { TBI). }\end{array}$ \\
\hline Interventions & $\begin{array}{l}\text { Intervention: low-concentration dilution }(100 \mathrm{U} / \mathrm{mL} \text { ) Dysport (abobotulinumtoxinA) injected via the } \\
\text { neuromuscular junction targeted technique. } \\
\text { Comparison: high-concentration dilution }(300 \mathrm{U} / \mathrm{mL}) \text { Dysport (abobotulinumtoxinA) injected via } \\
\text { "current clinical practice technique." }\end{array}$ \\
\hline Outcomes & $\begin{array}{l}\text { Outcomes measured as change from baseline at } 4 \text { and } 12 \text { weeks post-treatment. } \\
\text { Primary outcomes: } \\
\text { - spasticity (Modified Ashworth Scale); } \\
\text { - adverse events. } \\
\text { Secondary outcomes: } \\
\text { - pain (spasticity related pain measured by visual analogue scale); } \\
\text { - Global Attainment Scale. }\end{array}$ \\
\hline
\end{tabular}


EUCTR2011-005375-16-SE (Continued)

Notes

Results available on the EU Clinical Trials Register site but the results for people with TBI are not presented separately, and it is unclear what percentage of participants had a brain injury. The authors reported that "Due to slow recruitment rate it was clear that the study would not be completed in a reasonable time frame, therefore the study was stopped early." Contacted study sponsor in April 2017 but no further information received.

Gracies 2016

Methods 3-arm randomised controlled trial (completed).

Setting: US, Australia, Belgium, Czech Republic, France, Hungary, Italy, Poland, Portugal, Russian Federation, Slovakia.

Funding: Ipsen.

\begin{tabular}{|c|c|}
\hline Participants & $\begin{array}{l}388 \text { participants with stroke or TBI with lower limb spasticity. While the number of participants } \\
\text { with TBI was not reported, a poster presented on the results of the follow-up open-label study (see } \\
\text { Notes) reported } 43 / 352 \text { participants with TBI. }\end{array}$ \\
\hline \multirow[t]{3}{*}{ Interventions } & Intervention: abobotulinumtoxinA 1000 U, 1 cycle. \\
\hline & Intervention: abobotulinumtoxinA 1500 U, 1 cycle. \\
\hline & Control: "placebo", 1 cycle. \\
\hline \multirow[t]{3}{*}{ Outcomes } & Outcomes measured at 4 weeks. \\
\hline & Primary outcomes: \\
\hline & $\begin{array}{l}\text { - spasticity in gastrocnemius/soleus muscles (Modified Ashworth Scale); } \\
\text { - adverse event. }\end{array}$ \\
\hline Notes & $\begin{array}{l}\text { Found a protocol (see reference list) and a poster on ResearchGate, which describes the results } \\
\text { for the follow-up open-label study. While the number of participants with TBI would appear to be } \\
\text { below } 50 \% \text { the authors may subsequently publish, or be able to provide, the data for participants } \\
\text { with TBI only. }\end{array}$ \\
\hline
\end{tabular}

\begin{tabular}{ll}
\hline Methods & Randomised controlled trial (complete). \\
& Setting: Iran. \\
& Funding: Ahvaz Jundishapur University of Medical Sciences \\
\hline Participants & $\begin{array}{l}40 \text { participants with diffuse axonal injury without chronic hepatic or renal disease; aged } 15-60 \\
\text { years. }\end{array}$ \\
\hline Interventions & Intervention: oral cyproheptadine $2 \mathrm{mg} / \mathrm{kg}$ with oral baclofen $25 \mathrm{mg} / \mathrm{kg}$ every 8 hours for 15 days. \\
\hline Comparison: oral baclofen $25 \mathrm{mg} / \mathrm{kg}$ every 8 hours for 15 days. \\
\hline Primary outcome: \\
\hline
\end{tabular}


IRCT2014041112777N (Continued)

Notes
The clinical trial entry stated that, "patients will be randomly allocated into two groups according to table of random numbers" and that the trial is complete (recruitment was expected to end in December 2014). We found a published paper by the same investigators (Rasras 2014) also treating spasticity in people with TBI with considerable overlap (i.e. identical inclusion criteria) but with somewhat different interventions (baclofen, cyproheptadine + baclofen, baclofen + tizanidine + baclofen, and cyproheptadine + tizanidine). We noted that the randomisation procedure in this trial did not appear to be truly random. It was described as follows: "the first to third patients were randomly placed in the first to third groups. The next patients were distributed successfully within the groups with respect to their registration in the ward. This was continued until the sample size reached the required number." We contacted the trialists in August 2017 to clarify if the protocol and published paper were the same study but received no reply.

\section{NCT02052024}

\begin{tabular}{|c|c|}
\hline Methods & $\begin{array}{l}\text { Randomised controlled trial (complete; final data collection August 2015). } \\
\text { Setting: US. } \\
\text { Funding: Georgetown University (Solstice Neurosciences, a pharmaceutical company, listed as a } \\
\text { collaborator). }\end{array}$ \\
\hline Participants & $\begin{array}{l}\text { People aged } \geq 18 \text { years with spasticity due to a disorder or trauma (e.g. spinal cord injury, brain in- } \\
\text { jury, tumour, stroke, multiple sclerosis or peripheral nerve injury). }\end{array}$ \\
\hline Interventions & $\begin{array}{l}\text { Intervention: botulinum toxin A (Botox), } 100 \mathrm{U} \text { per injection, 1-3 injections per muscle at each visit. } \\
\text { Comparator: botulinum toxin B (Myobloc), } 5000 \mathrm{U} \text { per injection, 1-3 injections per muscle at each } \\
\text { visit. } \\
\text { Number of visits per week not reported but treatment administered for } 36 \text { weeks. }\end{array}$ \\
\hline Outcomes & $\begin{array}{l}\text { Primary outcomes: } \\
\text { - adverse events (muscle atrophy, measured by volume and cross-sectional area of muscle) at } 36 \\
\text { weeks; } \\
\text { - spasticity (Modified Ashworth Scale), measured before, during and after treatment at every visit, } \\
\text { up to } 36 \text { weeks. }\end{array}$ \\
\hline
\end{tabular}

Notes

We are unable to find any published results for this trial. As such, it was unclear what percentage of participants had TBI, or whether the results for this group is (or could be) presented separately.

TBI: traumatic brain injury.

Characteristics of ongoing studies [ordered by study ID]

\section{ACTRN12615000821594}

Trial name or title
Effectiveness of Combining Serial Casting and Botulinum Toxin for the Management of Ankle Contractures after Traumatic Brain Injury: a Randomised Controlled Study.

Randomised controlled trial ( 2 arms, with cross-over).

Setting: Brain Injury Unit, Sydney, Australia.

Funding: Royal Rehab Foundation (charitable). 
Age range: $18-85$ years.

Inclusion criteria:

- diagnosed with first TBI;

- presents with an ankle contracture of a severe degree;

- able to receive botulinum toxin injections and serial casting;

- unlikely to be discharged in 12 weeks; and

- provides consent to participate in the study (the participants or the person legally responsible for them).

\section{Exclusion criteria:}

- unstable medical conditions or recent ankle fracture;

- within 3 months after receiving botulinum toxin;

- severe ankle varus or knee/hip flexion contractures (which affects the reliability of measuring ankle dorsiflexion).

Location of spasticity:

Calf muscles/ankle. Specific muscles that may be treated include soleus, gastrocnemius, flexor hallucis longer and flexor digitorium longus and tibialis posterior where necessary.

Interventions

Botulinum toxin and serial casting: $\geq 1$ botulinum toxin injections into calf muscles (dose dependent on number of muscles needing injection, but not in excess of $400 \mathrm{~mL}$ ). Serial casting with be commenced within a few days (duration of casting and number of cast applied may vary based on the participants' responses to casting), After completion of casting, a customised ankle splint will be used immediately. The splint will be worn 24 hours a day for the initial 2 weeks during which the splint will only be removed for hygiene reasons and therapy. Participants will receive usual care as well (see usual care).

Usual care: placed on a wait list for 6 weeks during which they receive no botulinum toxin, splinting and passive stretch-based interventions for the ankle. Usual care includes multidisciplinary rehabilitation provided by the unit as appropriate. This consisted of physiotherapy, occupational therapy, speech therapy, recreational therapy and psychological therapy. Physiotherapy included an individualised motor training programme which might involve lower limb exercises, practice of sit to stand, standing and walking. Also involves positioning of participants' feet in dorsiflexion while seated and lying.

\section{Outcomes}

\section{Primary outcome:}

- Passive dorsiflexion range at a standardised torque, measured within 3 days after completion of serial casting.

\section{Secondary outcomes:}

- Spasticity of ankle plantarflexors (Tardieu Scale score and Modified Ashworth Scale score), measured within 3 days after completion of serial casting;

- FIM Walking score and 10-m walk test, measured within 3 days after completion of serial casting;

- therapist questionnaire (perceived effectiveness, adverse events and treatment worth), designed specifically for study.

\begin{tabular}{ll}
\hline Starting date & 1 July 2015 (date of first participant enrolment). \\
\hline Contact information & $\begin{array}{l}\text { Dr Joan Wai King Leung, Brain Injury Unit, Royal Rehab, Ryde, NSW. Email: joan.leung@royalre- } \\
\text { hab.com.au. }\end{array}$ \\
\hline Notes & Anticipated end date (as per clinical trials entry last updated in 13 July 2016): 1 September 2018. \\
& $\begin{array}{l}\text { Note that spasticity is not an inclusion criterion, but as per the other study by this investigator (Le- } \\
\text { ung 2014), spasticity is being measured at baseline, and is an outcome. In future updates, the re- }\end{array}$
\end{tabular}


ACTRN12615000821594 (Continued)

view author team will contact the lead investigator to determine how many of the participants had spasticity at baseline to therefore confirm it meets the inclusion criteria for the review.

FIM: Functional Independence Measure; TBI: traumatic brain injury.

\section{DATA AND ANALYSES}

\section{Comparison 1. Casting plus botulinum toxin A versus casting plus placebo}

\begin{tabular}{lllll}
\hline Outcome or subgroup title & No. of studies & $\begin{array}{l}\text { No. of partici- } \\
\text { pants }\end{array}$ & Statistical method & Effect size \\
\hline 1 Spasticity at 12 weeks & 1 & Mean Difference (IV, Fixed, 95\% CI) & Totals not selected \\
\hline
\end{tabular}

Analysis 1.1. Comparison 1 Casting plus botulinum toxin $\mathrm{A}$ versus casting plus placebo, Outcome 1 Spasticity at 12 weeks.

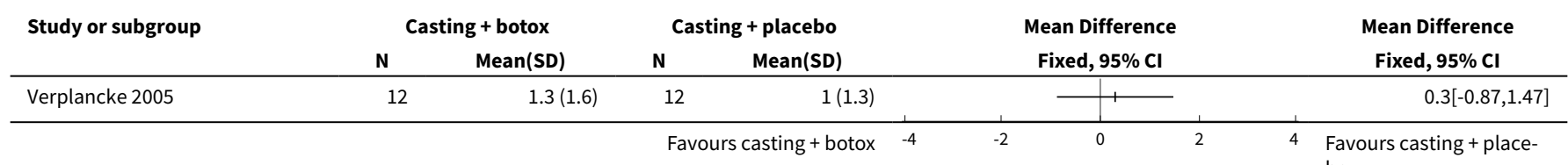

\section{Comparison 2. Casting plus botulinum toxin A versus physiotherapy}

\begin{tabular}{lllll}
\hline Outcome or subgroup title & No. of studies & $\begin{array}{l}\text { No. of partici- } \\
\text { pants }\end{array}$ & Statistical method & Effect size \\
\hline 1 Spasticity at 12 weeks & 1 & Mean Difference (IV, Fixed, 95\% CI) & Totals not selected \\
\hline
\end{tabular}

Analysis 2.1. Comparison 2 Casting plus botulinum toxin A versus physiotherapy, Outcome 1 Spasticity at 12 weeks.

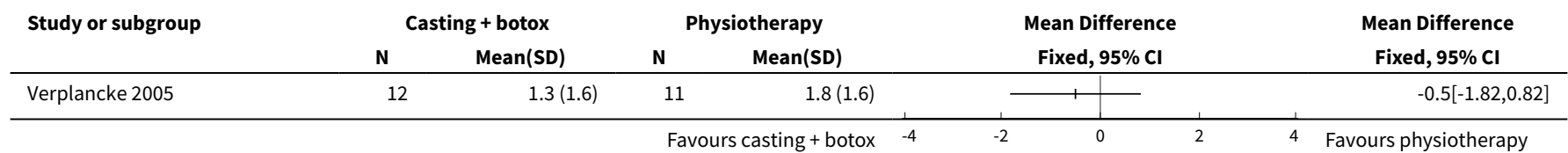

\section{Comparison 3. Casting plus placebo versus physiotherapy}

\begin{tabular}{lllll}
\hline Outcome or subgroup title & No. of studies & $\begin{array}{l}\text { No. of partici- } \\
\text { pants }\end{array}$ & Statistical method & Effect size \\
\hline 1 Spasticity at 12 weeks & 1 & Mean Difference (IV, Fixed, 95\% CI) & Totals not selected \\
\hline
\end{tabular}


Analysis 3.1. Comparison 3 Casting plus placebo versus physiotherapy, Outcome 1 Spasticity at 12 weeks.

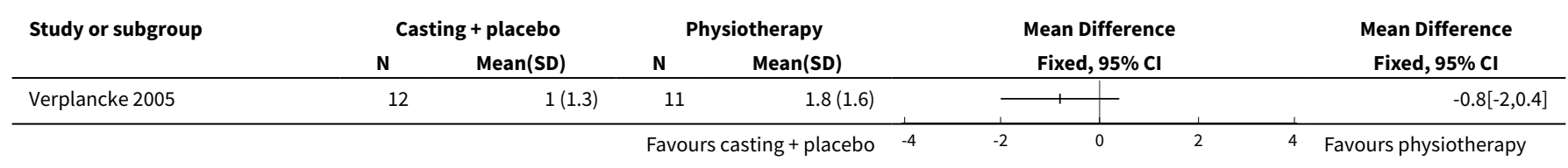

\section{Comparison 4. Tilt table plus electrical stimulation plus splint versus tilt table}

\begin{tabular}{lllll}
\hline $\begin{array}{l}\text { Outcome or subgroup } \\
\text { title }\end{array}$ & No. of studies & $\begin{array}{l}\text { No. of partici- } \\
\text { pants }\end{array}$ & Statistical method & Effect size \\
\hline 1 Spasticity & 1 & Mean Difference (IV, Fixed, 95\% CI) & Totals not selected \\
\hline $\begin{array}{l}\text { 2 Passive ankle dorsiflex- } \\
\text { ion }\end{array}$ & 1 & Mean Difference (IV, Fixed, 95\% CI) & Subtotals only \\
\hline 3 Walking speed & 1 & Mean Difference (IV, Fixed, 95\% Cl) & Subtotals only \\
\hline
\end{tabular}

Analysis 4.1. Comparison 4 Tilt table plus electrical stimulation plus splint versus tilt table, Outcome 1 Spasticity.

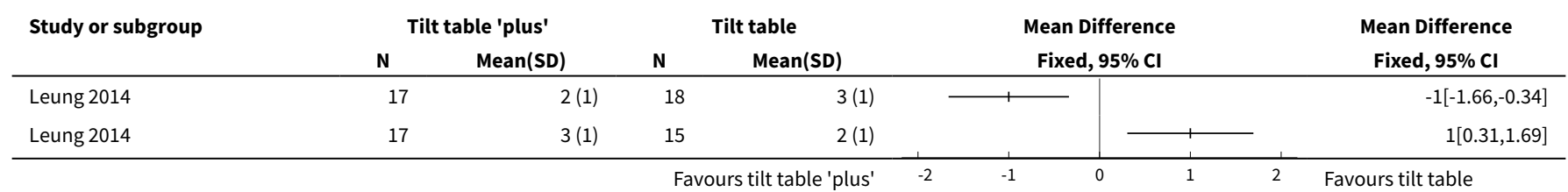

Analysis 4.2. Comparison 4 Tilt table plus electrical stimulation plus splint versus tilt table, Outcome 2 Passive ankle dorsiflexion.

\begin{tabular}{|c|c|c|c|c|c|c|c|}
\hline \multirow[t]{2}{*}{ Study or subgroup } & \multicolumn{2}{|c|}{ Tilt table 'plus' } & \multicolumn{2}{|c|}{ Title table } & \multirow{2}{*}{$\begin{array}{c}\text { Mean Difference } \\
\text { Fixed, } 95 \% \mathrm{Cl}\end{array}$} & \multirow[t]{2}{*}{ Weight } & \multirow{2}{*}{$\begin{array}{c}\text { Mean Difference } \\
\text { Fixed, } 95 \% \mathrm{Cl}\end{array}$} \\
\hline & $\mathbf{N}$ & Mean(SD) & $\mathbf{N}$ & Mean(SD) & & & \\
\hline Leung 2014 & 16 & $-2(5)$ & 15 & $-3(7)$ & \begin{tabular}{l|l} 
& 1 \\
\end{tabular} & $0 \%$ & $1[-3.31,5.31]$ \\
\hline Leung 2014 & 16 & $-5(6)$ & 17 & $-3(9)$ & & $0 \%$ & $-2[-7.19,3.19]$ \\
\hline
\end{tabular}

Analysis 4.3. Comparison 4 Tilt table plus electrical stimulation plus splint versus tilt table, Outcome 3 Walking speed.

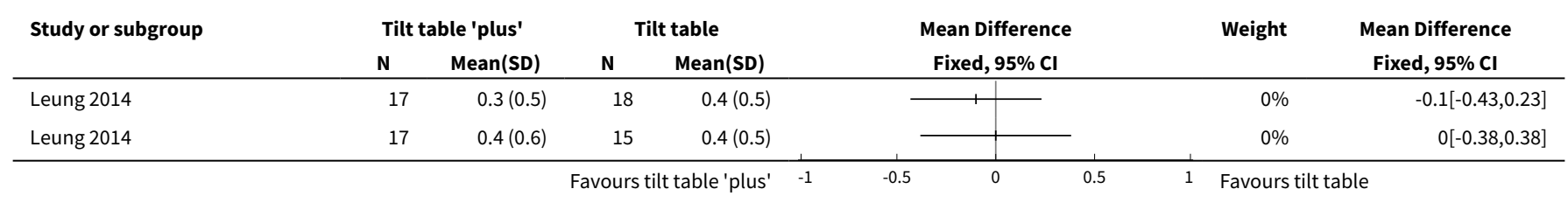




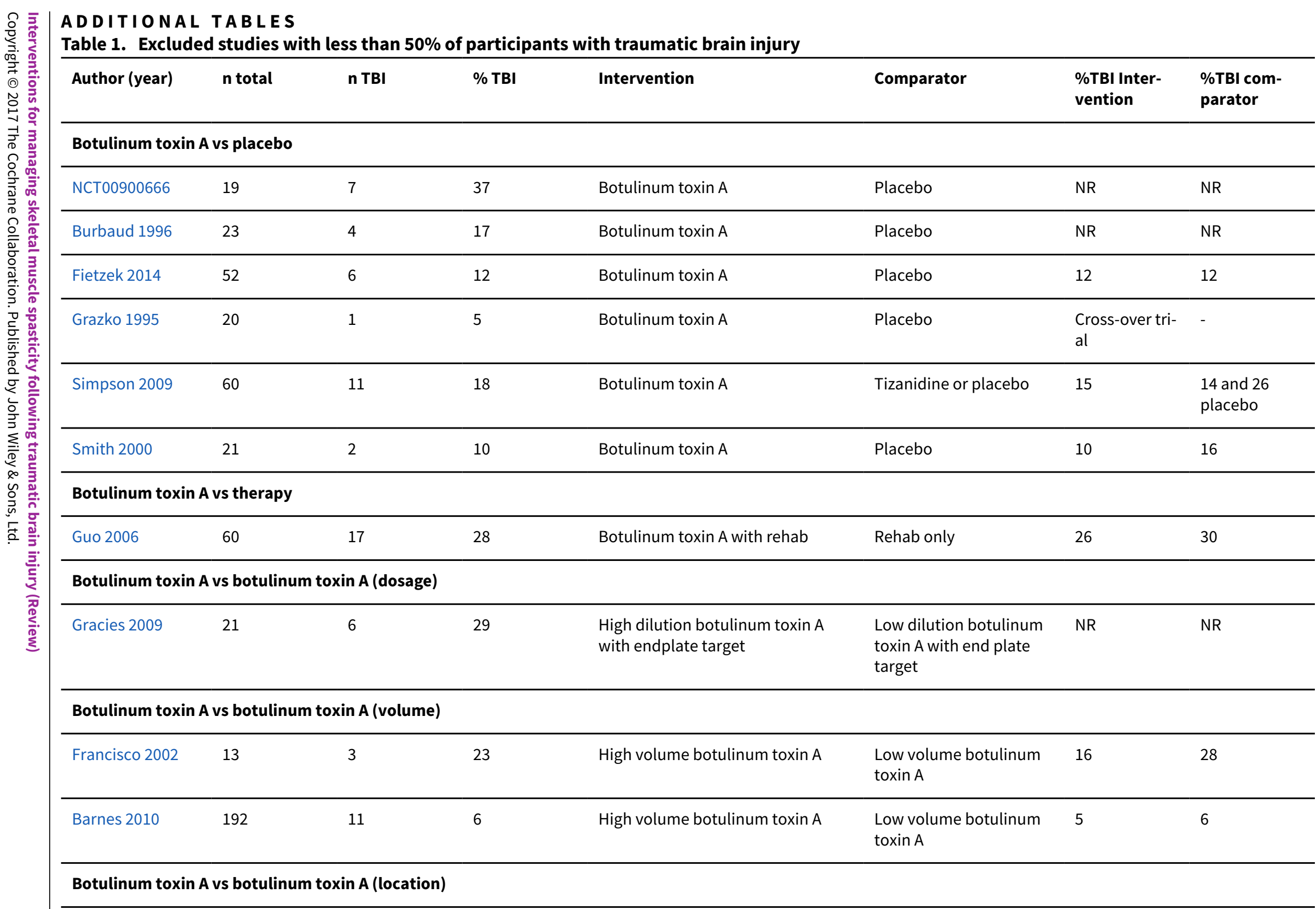




\begin{tabular}{|c|c|c|c|c|c|c|c|}
\hline Childers 1996 & 17 & 2 & 12 & $\begin{array}{l}\text { Botulinum toxin } \mathrm{A} \text { injections to- } \\
\text { wards mid belly }\end{array}$ & $\begin{array}{l}\text { Botulinum toxin A injec- } \\
\text { tions away from mid bel- } \\
\text { ly }\end{array}$ & 0 & 25 \\
\hline Gracies 2009 & 21 & 6 & 29 & $\begin{array}{l}\text { High dilution botulinum toxin } \mathrm{A} \\
\text { with endplate target }\end{array}$ & $\begin{array}{l}\text { Low dilution botulinum } \\
\text { toxin A with end plate } \\
\text { target }\end{array}$ & NR & NR \\
\hline \multicolumn{8}{|c|}{ Baclofen vs placebo } \\
\hline Armstrong 1997 & 19 & 2 & 11 & Intrathecal dose of baclofen & Saline & 16 & 0 \\
\hline $\begin{array}{l}\text { Van Schaey- } \\
\text { broeck } 2000\end{array}$ & 11 & 1 & 9 & Intrathecal baclofen & Placebo & 16 & 0 \\
\hline \multicolumn{8}{|c|}{ Cyclobenzaprine vs placebo } \\
\hline Ashby 1972 & 15 & 4 & 27 & Cyclobenzaprine & Placebo & $\begin{array}{l}\text { Cross-over tri- } \\
\text { al }\end{array}$ & - \\
\hline \multicolumn{8}{|c|}{ Phenothiazine vs placebo } \\
\hline Burke 1975 & 9 & 2 & 22 & Phenothiazine & Placebo & $\begin{array}{l}\text { Cross-over tri- } \\
\text { al }\end{array}$ & - \\
\hline \multicolumn{8}{|c|}{ Tizanidine vs placebo } \\
\hline Meythaler 2001b & 17 & 8 & 47 & Tizanidine & Placebo & $\begin{array}{l}\text { Cross-over tri- } \\
\text { al }\end{array}$ & - \\
\hline \multicolumn{8}{|c|}{ Tizanidine vs botulinum toxin $\mathrm{A}$} \\
\hline Simpson 2009 & 60 & 11 & 18 & Botulinum toxin $\mathrm{A}$ & Tizanidine or placebo & 15 & $\begin{array}{l}14 \text { and } 26 \\
\text { placebo }\end{array}$ \\
\hline \multicolumn{8}{|c|}{ Tizanidine vs diazepam } \\
\hline Bes 1988 & 105 & 16 & 15 & Tizanidine & Diazepam & 10 & 20 \\
\hline \multicolumn{8}{|c|}{ Casting vs control } \\
\hline Harvey 2006 & 44 & 7 & 16 & Splint & No splint & 13 & 21 \\
\hline
\end{tabular}




\begin{tabular}{|c|c|c|c|c|c|c|c|}
\hline \multicolumn{8}{|c|}{ Casting vs therapy } \\
\hline Harvey 2006 & 44 & 7 & 16 & Splint & No splint & 13 & 21 \\
\hline \multicolumn{8}{|c|}{ Splinting vs control } \\
\hline Copley 2013 & 10 & 2 & 20 & Individualised hand splint & No splint & 33 & 0 \\
\hline Lannin 2003 & 28 & 2 & 7 & Stretching and hand splint & Stretching only & NR & NR \\
\hline Thibaut 2015 & 17 & 7 & 41 & Soft splints & No treatment & NR & NR \\
\hline \multicolumn{8}{|c|}{ Splinting vs therapy } \\
\hline Lannin 2003 & 28 & 2 & 7 & Stretching and hand splint & Stretching only & NR & NR \\
\hline Thibaut 2015 & 17 & 7 & 41 & Soft splints & Stretching & NR & NR \\
\hline \multicolumn{8}{|c|}{ Functional electrical stimulation vs control } \\
\hline Chang 2009 & 14 & 3 & 21 & $\begin{array}{l}\text { Upper limb botulinum toxin A in- } \\
\text { jections for higher hand function }\end{array}$ & $\begin{array}{l}\text { Upper limb botulinum } \\
\text { toxin A injections for } \\
\text { lower hand function }\end{array}$ & 33 & 0 \\
\hline \multicolumn{8}{|c|}{ Electrical stimulation + splinting vs splinting } \\
\hline Leung 2012 & 36 & 5 & 14 & $\begin{array}{l}\text { Electrical stimulation to the wrist } \\
\text { and finger extensor muscles for } \\
1 \text { hour a day + wrist splint for } 12 \\
\text { hours a day, over } 4 \text { weeks }\end{array}$ & $\begin{array}{l}\text { Wrist splint for } 12 \text { hours } \\
\text { a day, over } 4 \text { weeks }\end{array}$ & 6 & 22 \\
\hline \multicolumn{8}{|c|}{ Repetitive peripheral magnetic stimulation vs sham } \\
\hline Krewer 2014 & 66 & 3 & 5 & $\begin{array}{l}\text { Repetitive peripheral magnetic } \\
\text { stimulation }\end{array}$ & Sham stimulation & 10 & 0 \\
\hline \multicolumn{8}{|c|}{ Transcutaneous electrical acupoint stimulation vs another dose } \\
\hline Zhao 2015 & 60 & 1 & 2 & $\begin{array}{l}\text { Transcutaneous electrical acupoint } \\
\text { stimulation }(100 \mathrm{~Hz})\end{array}$ & $\begin{array}{l}\text { Transcutaneous electri- } \\
\text { cal acupoint stimulation } \\
(2 \mathrm{~Hz})\end{array}$ & 0 & 5 \\
\hline
\end{tabular}




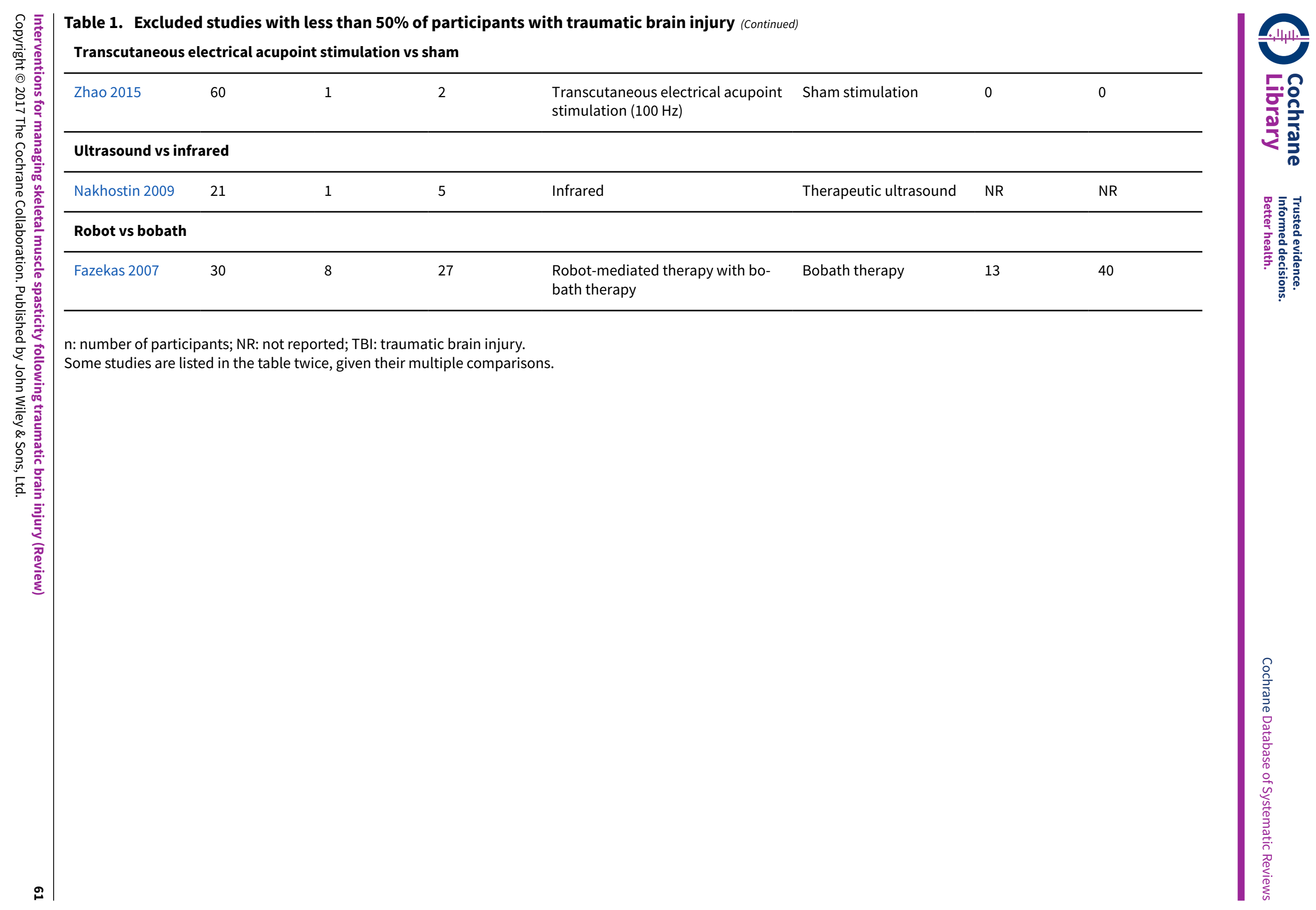


Table 2. Primary outcome measures

\begin{tabular}{|c|c|c|c|}
\hline Outcome measure & Domains with score & $\begin{array}{l}\text { Studies referring } \\
\text { to this outcome }\end{array}$ & $\begin{array}{l}\text { Time point analy- } \\
\text { sis }\end{array}$ \\
\hline \multirow{5}{*}{$\begin{array}{l}\text { Ashworth Scale } \\
\text { (0-4, lower score } \\
=\text { better; Pandyan } \\
\text { 1999) }\end{array}$} & \multirow{2}{*}{$\begin{array}{l}\text { 0: no increase in muscle tone. } \\
\text { 1: slight increase in muscle tone, manifested by a catch and re- } \\
\text { lease or by minimum resistance through remainder of range of } \\
\text { motion }\end{array}$} & Meythaler 1996; & $\begin{array}{l}\text { Baseline, and } 1,2 \text {, } \\
4,6 \text { hours }\end{array}$ \\
\hline & & Pittaccio 2013 & $\begin{array}{l}\text { Baseline, and } 4,8 \\
\text { weeks }\end{array}$ \\
\hline & $\begin{array}{l}\text { 2: more marked increase in muscle tone through most of the } \\
\text { range of motion; limb easily moved. }\end{array}$ & & \\
\hline & $\begin{array}{l}\text { 3: considerable increase in muscle tone; passive movement is } \\
\text { difficult. }\end{array}$ & & \\
\hline & 4: rigid limb. & & \\
\hline
\end{tabular}

Modified Ashworth

Scale (0-5, low-

er score = better;

Pandyan 1999)
$0:$ no increase in muscle tone.

1: slight increase in muscle tone, manifested by a catch and release or is moved in flexion, extension/abduction, adduction, etc.

1+: slight increase in muscle tone, manifested by a catch, followed by minimal resistance throughout the remainder (less than half) of the range of motion.

2: More marked increase in muscle tone through most of the range of motion, but the affected part is easily moved.

3: considerable increase in muscle tone, passive movement is difficult.

4: affected part is rigid flexion or extension/abduction or adduction.

\begin{tabular}{ll} 
Verplancke 2005 & Baseline, 12 weeks \\
\hline Gracies 2015 & Baseline, 4 weeks
\end{tabular}

Tardieu Scale (TS;

2 measurements:

Quality of Muscle

Reaction 0-4, lower score better, and Angle of muscle reaction, R2 - R1; Haugh 2006)

\section{Quality of muscle reaction}

0: no resistance throughout the course of the passive movement.

\begin{tabular}{ll} 
Gracies 2015 & Baseline, 4 weeks \\
\hline Leung 2014 & $\begin{array}{l}\text { Baseline, and } 6 \text { and } \\
10 \text { weeks }\end{array}$
\end{tabular}

1: slight resistance throughout the course of the passive movement, with no clear catch at precise angle.

2: clear catch at precise angle, interrupting the passive movement, followed by release.

3: fatigable clonus ( $<10$ seconds when maintaining pressure) occurring at precise angle.

4: infatigable clonus (> 10 seconds when maintaining pressure) occurring at precise angle.

Angle of muscle reaction (also referred to as R2 - R1)

Measured relative to the position of minimal stretch of the muscle (corresponding to angle) where it is relative to the resting anatomic position.

R2: first measure (the maximum passive range of movement of the muscle group). 
Table 2. Primary outcome measures (Continued)

$\mathrm{R} 1$ : second measure (the angle at which the initial 'catch' or muscle resistance is felt when the muscle is moved from its shortest to longest position using a 'rapid velocity stretch').

Table 3. Secondary outcome measures

\section{Outcome measure Domains with score}

\section{Studies referring} to this outcome

\begin{tabular}{|c|c|c|c|}
\hline \multirow{21}{*}{$\begin{array}{l}\text { Glasgow Coma } \\
\text { Scale (Teasdale } \\
\text { 1974) } \\
\text { (3-15, higher score = } \\
\text { better) }\end{array}$} & Eye opening $(E)$ & Verplancke 2005 & $\begin{array}{l}\text { b. Body functions } \\
\text { b1-b8 }\end{array}$ \\
\hline & 3: to voice & & \\
\hline & 2: to pain & & \\
\hline & 1: none & & \\
\hline & Verbal response $(\mathrm{V})$ & & \\
\hline & 5: normal conversation & & \\
\hline & 4: disoriented conversation & & \\
\hline & 3: words, but not coherent & & \\
\hline & 2: no words, only sounds & & \\
\hline & 1: none & & \\
\hline & Motor response (M) & & \\
\hline & 6: normal & & \\
\hline & 5: localised to pain & & \\
\hline & 4: withdraws to pain & & \\
\hline & $\begin{array}{l}\text { 3: decorticate posture (an abnormal posture that can include } \\
\text { rigidity, clenched fists, legs held straight out, and arms bent in- } \\
\text { ward towards the body with the wrists and fingers bend and } \\
\text { held on the chest) }\end{array}$ & & \\
\hline & $\begin{array}{l}\text { 2: decerebrate (an abnormal posture that can include rigidity, } \\
\text { arms and legs held straight out, toes pointed downward, head } \\
\text { and neck arched backwards) }\end{array}$ & & \\
\hline & 1: none & & \\
\hline & The final GCS score or grade is the sum of these numbers. & & \\
\hline & Severe: GCS 3-8 (minimum possible score is 3 ) & & \\
\hline & Moderate: GCS 9-12 & & \\
\hline & Mild: GCS 13-15 & & \\
\hline
\end{tabular}

Glasgow Outcome

1975)
To generalise and categorise the outcomes of people with TBI.

1: dead
Verplancke 2005

b1-b8 
Table 3. Secondary outcome measures (Continued)

$(1-5$, higher score $=2$ : vegetative state (meaning the person is unresponsive, but better) alive; a "vegetable" in lay language)

3: severely disabled (conscious but the person requires others for daily support due to disability)

4: moderately disabled (the person is independent but disabled)

5: good recovery (the person has resumed most normal activities but may have minor residual problems)

\begin{tabular}{|c|c|c|c|}
\hline $\begin{array}{l}\text { Range of move- } \\
\text { ment }\end{array}$ & $\begin{array}{l}\text { The joint is taken through the total arc of movement from flex- } \\
\text { ion to extension }\end{array}$ & $\begin{array}{l}\text { Verplancke } 2005 \\
\text { (ankle) }\end{array}$ & $\begin{array}{l}\text { Body function } \\
\text { b7 }\end{array}$ \\
\hline $\begin{array}{l}\text { Deep tendon reflex- } \\
\text { es }\end{array}$ & $\begin{array}{l}\text { 0: reflexes absent } \\
\text { 1: hyporeflexia } \\
\text { 2: normal } \\
\text { 3: mild hyperreflexia } \\
\text { 4: } 3 \text { or } 4 \text { beats clonus only } \\
\text { 5: clonus }\end{array}$ & Meythaler 1996 & $\begin{array}{l}\text { Body function } \\
\text { b750 }\end{array}$ \\
\hline $\begin{array}{l}\text { Disability Assess- } \\
\text { ment Scale (DAS; } \\
\text { Brashear 2002; 0-3, } \\
\text { lower score better) }\end{array}$ & $\begin{array}{l}\text { People are interviewed to determine the extent of functional } \\
\text { impairment in: hygiene, dressing, limb position and pain, ac- } \\
\text { cording to the following scale: } \\
\text { 0: no disability } \\
\text { 1: mild disability (noticeable but does not interfere significantly } \\
\text { with normal activities) } \\
\text { 2: moderate disability (normal activities require increased ef- } \\
\text { fort or assistance, or both) } \\
\text { 3: severe disability (normal activities limited) }\end{array}$ & Gracies 2015 & $\begin{array}{l}\text { Activities and par- } \\
\text { ticipation }\end{array}$ \\
\hline
\end{tabular}

ICF: International Classification of Functioning.

Table 4. Adverse effects

\begin{tabular}{llc}
\hline Adverse effect & Number of participants affected & Studies \\
\hline Deep vein thrombosis & 1 participants withdrawn from physiotherapy group. & Verplancke 2005 \\
\hline $\begin{array}{l}\text { Contracture at subtalar } \\
\text { joint }\end{array}$ & 1 participants withdrawn from the casting + placebo group. & Verplancke 2005 \\
\hline $\begin{array}{l}\text { No adverse events or } \\
\text { changes in alertness level } \\
\text { were observed in the ba- } \\
\text { clofen group or placebo } \\
\text { arm }\end{array}$ & Not applicable. & Meythaler 1996 \\
\hline $\begin{array}{l}\text { Unspecified "treatment } \\
\text { emergent AE ladverse ef- }\end{array}$ & $7 / 23$ participants, no other information given. & Gracies 2015 (O'Dell \\
\hline
\end{tabular}


Table 4. Adverse effects (Continued)

fects]": "none were unex-

pected"

Skin rashes/oedema/tolerability issues
No pseudoelastic device required adjustment for comfort; $30 \%$ of traditional devices did. Families reported novel treatment tolerated for $40 \%$ longer than traditional (Pittaccio 2013).

2 participants adherence to splinting was affected by 'skin problems' and 'poor tolerance' (Leung 2014).

$50 \%$ of participants in casting group and $41.7 \%$ of participants in casting + botulinum toxin A group developed 'minor skin damage'. Overall, $90 \%$ of those resolved spontaneously or with therapeutic dressing (Verplancke 2005).
Leung 2014; Pittaccio

2013; Verplancke 2005

Fainting, fatigue, storming1

Several participants' adherence to the tilt table was affected due to faint-

Leung 2014 ing, fatigue and storming.

1When someone with a head injury responds to a sensation with a tonic posture or sympathetic response.

\section{APPENDICES}

\section{Appendix 1. 2016 Search strategies}

\section{Cochrane Injuries Group Specialised Register}

(spastic ${ }^{\star}$ or spasm ${ }^{\star}$ ) or ((muscle ${ }^{\star}$ or muscular) and (spasm or cramp ${ }^{\star}$ or clonus or hypertoni ${ }^{\star}$ or overact $\left.\left.{ }^{\star}\right)\right)$

\section{MEDLINE (OvidSP)}

1. exp Brain Injuries/

2. exp Craniocerebral Trauma/

3. exp Brain Edema/

4. exp Glasgow Coma Scale/

5. exp Glasgow Outcome Scale/

6. exp Unconsciousness/

7. exp Cerebrovascular Trauma/

8. ((head or crani* or cerebr ${ }^{\star}$ or capitis or brain ${ }^{\star}$ or forebrain* or skull* or hemispher* or intra-cran* or inter-cran*) adj3 (injur ${ }^{\star}$ or trauma* or lesion* or damag* or wound ${ }^{\star}$ or destruction ${ }^{\star}$ or oedema* or edema* or fractur ${ }^{\star}$ or contusion* or concus ${ }^{\star}$ or commotion ${ }^{\star}$ or pressur $\left.{ }^{\star}\right)$ ).ti,ab. (108776)

9. ((head or crani* or cerebr ${ }^{\star}$ or brain* or intra-cran* or inter-cran*) adj3 (haematoma* or hematoma* or haemorrhag* or hemorrhag* or bleed $^{\star}$ or pressure)).ti,ab.

10. (Glasgow adj3 scale).ti,ab.

11. "rancho los amigos scale".ti,ab.

12. ("diffuse axonal injury" or "diffuse axonal injuries").ti,ab.

13. "persistent vegetative state".ti,ab.

14. ((unconscious ${ }^{\star}$ or coma* or concuss ${ }^{\star}$ ) adj3 (injur ${ }^{\star}$ or trauma* or damag* or wound ${ }^{\star}$ or fracture* or contusion* or haematoma* or hematoma* or haemorrhag* ${ }^{\star}$ or hemorrhag* or bleed $^{\star}$ or pressure)).ti,ab.

15. or/1-14

16. Muscle Spasticity/

17. Spasm/

18. Muscle Hypertonia/

19. ( spastic $^{\star}$ or spasm*).ti,ab.

20. ((muscle ${ }^{\star}$ or muscular) adj3 (spasm ${ }^{\star}$ or cramp $^{\star}$ or clonus or hypertoni ${ }^{\star}$ or overact $\left.\left.^{\star}\right)\right)$.ti,ab.

21.16 or 17 or 18 or 19 or 20

22. randomised controlled trial.pt.

23. controlled clinical trial.pt.

24. randomized.ab.

25. placebo.ab. 
26. drug therapy.fs.

27. randomly.ab.

28. trial.ab.

29. groups.ab.

30.22 or 23 or 24 or 25 or 26 or 27 or 28 or 29

31. exp animals/ not humans.sh.

32. 30 not 31

33. 15 and 21 and 32

\section{Embase Classic + Embase (OvidSP)}

1. exp Brain Injuries/

2. exp Brain Edema/

3. exp Craniocerebral Trauma/

4. exp Glasgow Coma Scale/

5. exp Glasgow Outcome Scale/

6. exp Unconsciousness/

7. exp Cerebrovascular Trauma/

8. ((head or crani* ${ }^{\star}$ or cerebr ${ }^{\star}$ or capitis or brain* or forebrain* or skull* or hemispher ${ }^{\star}$ or intra-cran* or inter-cran*) adj3 (injur* or trauma* or lesion ${ }^{\star}$ or damag or wound $^{\star}$ or destruction ${ }^{\star}$ or oedema* or edema* $^{\star}$ or fractur ${ }^{\star}$ or contusion ${ }^{\star}$ or concus ${ }^{\star}$ or commotion or pressur $\left.^{\star}\right)$ ).ti,ab. 9. ((head or crani* or cerebr ${ }^{\star}$ or brain ${ }^{\star}$ or intra-cran* or inter-cran*) adj3 (haematoma* or hematoma* or haemorrhag* or hemorrhag* or bleed $^{\star}$ or pressure)).ti,ab.

10. (Glasgow adj3 scale).ti,ab.

11. "rancho los amigos scale".ti,ab.

12. ("diffuse axonal injury" or "diffuse axonal injuries").ti,ab.

13. "persistent vegetative state".ti,ab.

14. ((unconscious ${ }^{\star}$ or coma* or concuss ${ }^{\star}$ ) adj3 (injur ${ }^{\star}$ or trauma* or damag* or wound* or fracture* or contusion* or haematoma* or hematoma* or haemorrhag* or hemorrhag* or bleed ${ }^{\star}$ or pressure)).ti,ab.

15.1 or 2 or 3 or 4 or 5 or 6 or 7 or 8 or 9 or 10 or 11 or 12 or 13 or 14

16. exp Muscle Spasticity/

17. exp Spasm/

18. exp Muscle Hypertonia/

19. ( spastic $^{\star}$ or spasm*).ti,ab.

20. ((muscle ${ }^{\star}$ or muscular) adj3 (spasm ${ }^{\star}$ or cramp $^{\star}$ or clonus or hypertoni ${ }^{\star}$ or overact $\left.\left.^{\star}\right)\right) . t i, a b$.

21.16 or 17 or 18 or 19 or 20

22. 15 and 21

23. exp Randomized Controlled Trial/

24. exp controlled clinical trial/

25. exp controlled study/

26. comparative study/

27. randomi?ed.ab,ti.

28. placebo.ab.

29. *Clinical Trial/

30. exp major clinical study/

31. randomly.ab.

32. (trial or study).ti.

33. 23 or 24 or 25 or 27 or 28 or 29 or 30 or 31 or 32

34. exp animal/ not (exp human/ and exp animal/)

35.33 not 34

36. 22 and 35

\section{Appendix 2. 2017 prepublication search strategies}

Cochrane Injuries Group Specialised Register (SR-INJ) (all years to 22-June-2017)

(spastic ${ }^{\star}$ or spasm ${ }^{\star}$ ) or ((muscle* or muscular) and (cramp* or

clonus or contractur ${ }^{\star}$ or hypertoni ${ }^{\star}$ or overact $\left.^{\star}\right)$ ) [all fields] IN REGISTER

\section{Ovid MEDLINE Databases}

(Epub Ahead of Print, In-Process \& Other Non-Indexed Citations, Ovid MEDLINE(R) Daily and Ovid MEDLINE(R) 1946 to 22-June-2017)

1. exp Brain Injuries/

2. exp Craniocerebral Trauma/

3. exp Brain Edema/

4. exp Glasgow Coma Scale/ 
5. exp Glasgow Outcome Scale/

6. exp Unconsciousness/

7. exp Cerebrovascular Trauma/

8. ((head or crani* ${ }^{\star}$ or cerebr ${ }^{\star}$ or capitis or brain ${ }^{\star}$ or forebrain ${ }^{\star}$ or skull* or hemispher $^{\star}$ or intra-cran* or inter-cran $^{\star}$ ) adj3 (injur ${ }^{\star}$ or trauma* or

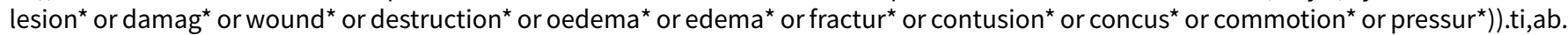
(108776)

9. ((head or crani* or cerebr ${ }^{\star}$ or brain* or intra-cran* or inter-cran*) adj3 (haematoma* or hematoma* or haemorrhag* or hemorrhag* or bleed $^{*}$ or pressure)).ti,ab.

10. (Glasgow adj3 scale).ti,ab.

11. "rancho los amigos scale".ti,ab.

12. ("diffuse axonal injury" or "diffuse axonal injuries").ti,ab.

13. "persistent vegetative state".ti,ab.

14. ((unconscious* or coma* or concuss ${ }^{\star}$ ) adj3 (injur ${ }^{\star}$ or trauma* or damag* or wound ${ }^{\star}$ or fracture* or contusion* or haematoma* or hematoma* or haemorrhag* or hemorrhag* or bleed ${ }^{\star}$ or pressure)).ti,ab.

15. or/1-14

16. Muscle Spasticity/

17. Spasm/

18. Muscle Hypertonia/

19. (spastic ${ }^{\star}$ or spasm).ti,ab.

20. ((muscle ${ }^{\star}$ or muscular) adj3 (spasm* or cramp ${ }^{\star}$ or clonus or hypertoni ${ }^{\star}$ or overact $\left.\left.{ }^{\star}\right)\right) . t i, a b$.

21.16 or 17 or 18 or 19 or 20

22. randomized controlled trial.pt.

23. controlled clinical trial.pt.

24. (RCT or randomised or randomized).ab.

25. placebo.ab.

26. drug therapy.fs.

27. randomly.ab.

28. trial.ti,ab.

29. groups.ab.

30.22 or 23 or 24 or 25 or 26 or 27 or 28 or 29

31. exp animals/ not humans.sh.

32. 30 not 31

33. 15 and 21 and 32

The Cochrane Library, Central Register of Controlled Trials (CENTRAL), Issue 6, June 2017

\#1 MeSH descriptor: [Brain Injuries] explode all trees

\#2 MeSH descriptor: [Brain Damage, Chronic] explode all trees

\#3 MeSH descriptor: [Head Injuries, Closed] explode all trees

\#4 (TBI or mTBI or sTBI):ti,ab,kw (Word variations have been searched)

\#5 "diffuse axonal injury":ti,ab,kw (Word variations have been searched)

\#6 ((head or brain or cerebr* or crani*) near (injur ${ }^{\star}$ or trauma*)):ti,ab,kw (Word variations have been searched)

$\# 7$ (\#1 or \#2 or \#3 or \#4 or \#5 or \#6)

\#8 MeSH descriptor: [Muscle Hypertonia] explode all trees

\#9 spastic* or spasm*:ti,ab,kw (Word variations have been searched)

\#10 ((muscle* or muscular) near (spasm ${ }^{\star}$ or cramp ${ }^{\star}$ or clonus or contractur ${ }^{\star}$ or hypertoni ${ }^{\star}$ or overact $\left.\left.^{\star}\right)\right)$ :ti,ab,kw (Word variations have been searched)

$\# 11$ ( \#8 or \#9 or \#10)

$\# 12$ (\#7 and \#11)

\#13 ((cerebral palsy or stroke or post stroke) not ((head or brain) and (injur ${ }^{\star}$ or trauma $\left.\left.\left.{ }^{\star}\right)\right)\right)$ :ti (Word variations have been searched) \#14 (\#12 not \#13)

NLM PubMed (22 June 2017)

Precision maximising search: ((randomised[tiab] OR randomized[tiab] OR placebo[tiab] OR trial[ti] OR randomized controlled trial[pt]) AND ("Craniocerebral Trauma"[Mesh] OR TBI OR mTBI OR sTBI OR "brain injury" OR "brain injuries" OR "traumatic brain" OR "brain trauma") AND ("Muscle Spasticity"[MeSH] OR spastic[tiab] OR spasticity[tiab]) AND (publisher[sb] OR inprocess[sb] OR pubmednotmedline[sb]))

Ovid Embase < 1974 to 2017 Week 25>

1 randomized controlled trial/

2 controlled clinical trial/

3 randomi\#ed.ti,ab,kw.

4 randomization/ 
5 placebo.ti,ab,kw.

6 placebo/

$7{ }^{\star}$ Clinical Trial/

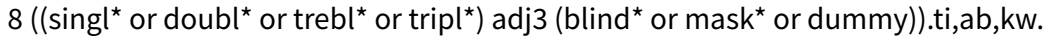

9 double blind procedure/

10 (RCT or at random or (random* adj (assign* or allocat ${ }^{\star}$ or divid* or division or number))).ti,ab,kw.

11 trial.ti.

12 or/1-11

13 ((animal or nonhuman) not (human and (animal or nonhuman))).de.

1412 not 13

15 head injury/

16 exp brain injury/

17 exp brain injury assessment/

18 ((head or crani* or cerebr ${ }^{\star}$ or capitis or brain* or forebrain* or skull* or hemispher* or intra-cran* or

intracran ${ }^{\star}$ or intra-cereb* or intracereb*) adj3 (infarct ${ }^{\star}$ or injur ${ }^{\star}$ or trauma* or damag $^{\star}$ or wound ${ }^{\star}$ or fracture* or contusion $\left.{ }^{\star}\right)$ ).ab,ti,kw.

19 (Glasgow adj3 (coma or outcome) adj3 (scale* or score*)).ab,ti,kw.

20 diffuse axonal injur*.ti,ab,kw.

21 ((midbrain or mid brain) adj syndrome).ti,ab,kw.

22 (TBI or mTBI or sTBI).ti,ab,kw.

23 or/15-22

24 muscle hypertonia/ or spastic paraplegia/ or spastic paresis/ or spasticity/

25 spasmolysis/

26 ( spastic $^{*}$ or spasm $\left.^{\star}\right) . t i, a b$.

27 ((muscle or muscular) adj3 (spasm $^{\star}$ or cramp ${ }^{\star}$ or clonus or contractur ${ }^{\star}$ or hypertoni ${ }^{\star}$ or overact $\left.{ }^{\star}\right)$ ).ti,ab.

28 muscle contracture/ or muscle spasm/

29 or/ $24-28$

3014 and 23 and 29

31 remove duplicates from 30

\section{Web of Science (WoS)}

Indexes=SCI-EXPANDED, CPCI-S, ESCI Timespan=All years to 22-June-2017

Search 1. (TS=("head injur" or "head trauma" or "brain injur" or "brain trauma" or "traumatic brain" or TBI or mTBI or sTBI or "traumatic head" or "cerebr* injur" or "cerebr trauma*" or "crani* injur*" or "crani* trauma*") AND TS=(spastic*)) AND (TS=(RCT or randomized or randomised or "at random" or placebo) or TS=(random* same (allocat* or assign* or divi* or number)) OR TI=(efficacy or effectiveness))

Search 2 (22-June-2017), citation search. References in WoS citing included studies identified to July 2016. WoS records were downloaded into EndNote and filtered for RCTs by searching for: ((RCT or randomised or randomized or randomly or placebo or double-blind) [all fields] or trial[title field])

\section{Clinical Trial Registers \\ ClinicalTrials.gov}

Basic search 1: (spastic OR spasticity OR spasm OR spasms OR contracture OR contractures OR muscle hypertonia | Interventional Studies | TBI OR sTBI OR mTBI or "brain injury" OR "brain injuries" OR "head injury" OR "head injuries" OR "traumatic brain" OR "brain trauma") OR Basic search 2: (Ipsen AND spasticity)

Trials for cerebral palsy or stroke patients (only) will be manually removed.

\section{WHO International Clinical Trials Registry Platform (ICTRP)}

Basic search: TBI AND spastic OR TBI AND spasticity OR TBI AND spasm OR TBI AND spasms OR TBI AND contracture OR TBI AND contractures OR TBI AND muscle hypertonia OR mTBI AND spastic OR mTBI AND spasticity OR mTBI AND spasm OR mTBI AND spasms OR mTBI AND contracture OR mTBI AND contractures OR mTBI AND muscle hypertonia OR sTBI AND spastic OR sTBI AND spasticity OR sTBI AND spasm OR sTBI AND spasms OR sTBI AND contracture OR STBI AND contractures OR sTBI AND muscle hypertonia OR brain injury AND spastic OR brain injury AND spasticity OR brain injury AND spasm OR brain injury AND spasms OR brain injury AND contracture OR brain injury AND contractures OR brain injury AND muscle hypertonia OR

brain injuries AND spastic OR brain injuries AND spasticity OR brain injuries AND spasm OR brain injuries AND spasms OR brain injuries AND contracture OR brain injuries AND contractures OR brain injuries AND muscle hypertonia OR head injury AND spastic OR head injury AND spasticity OR head injury AND spasm OR head injury AND spasms OR head injury AND contracture OR head injury AND contractures OR head injury AND muscle hypertonia OR head injuries AND spastic OR head injuries AND spasticity OR head injuries AND spasm OR head injuries AND spasms OR head injuries AND contracture OR head injuries AND contractures OR head injuries AND muscle hypertonia

\section{CONTRIBUTIONSOFAUTHORS}

MC, KP and AS carried out study selection, data extraction and assessment of risk of bias. 
OC, JW, KP, MC and AS completed analyses.

AS and KP led the writing of the manuscript, with input from MC and the coauthors.

\section{DECLARATIONS OF INTEREST}

Kate Phillips is the director of a private multidisciplinary community rehabilitation service and is a practising neurological physiotherapist, treating people who have had a TBI. Kate is a clinical consultant on the Clinical Panel of the Transport Accident Commission in Victoria, Australia. The Transport Accident Commission is a Victorian Government owned organisation, its role is to pay for treatment and benefits for people injured in transport accidents.

All authors were supported to complete this work by a grant received from the Transport Accident Commission, Victoria.

AS, MC, VP, DO, RG, JW, OC and LP declare no conflicts of interest.

\section{SOURCES OF SUPPORT}

\section{Internal sources}

- From 2010 to 2012, Kate Phillips was supported by a PhD scholarship provided by Monash University, Victoria, Australia.

\section{External sources}

- Neurotrauma Evidence Translation Program, Australia.

The Neurotrauma Evidence Translation program is funded by the Transport Accident Commission, Victoria, Australia

- National Institute for Health Research (NIHR), UK.

This project was supported by the UK National Institute for Health Research, through Cochrane Infrastructure funding to the Cochrane Injuries Group. The views and opinions expressed are those of the authors and do not necessarily reflect those of the Systematic Reviews Programme, NIHR, NHS or the Department of Health.

\section{DIFFERENCES BETWEEN PROTOCOLANDREVIEW}

The original protocol was published in 2010. Since that time the methodology of systematic reviews has evolved. To bring the protocol and subsequent review in line with the latest Cochrane methodology we made several necessary post-hoc adjustments to the assumptions and processes. These were separately highlighted throughout the text.

During screening, we found a number of studies with clinically diverse populations. As people with TBI were poorly represented (making up of only $26 \%$ of the participants), we therefore devised a threshold of $50 \%$ (meaning that the study needed to have at least $50 \%$ of participants with TBI to be included in the review) to ensure the evidence would be applicable to the TBI population. We also made a posthoc decision to use the Tardieu or Modified Tardieu Scale as our preferred measure of spasticity, in preference to the Modified Ashworth Scale, in the instance that studies reported both these measures.

We added an information size calculation post-hoc, in line with updated Cochrane Injuries Group editorial policy, and 'Summary of findings' tables, in line with updated Cochrane standards.

Due to the paucity of data, a number of planned methods outlined in the protocol could not be implemented. These included the planned meta-analysis, investigation of statistical heterogeneity, subgroup analysis, sensitivity analysis and assessment of reporting biases. These methods will be retained for review updates pending sufficient studies.

The following authors joined the team since the publication of the protocol: AS, MC, OC, JW and LP.

\section{NOTES}

Since the publication of the protocol in 2010, network meta-analysis methods have been developed and adopted where necessary in Cochrane Reviews. We recognise that the most appropriate design for our review (which aims to assess the effectiveness of a number of interventions) would be that of a network meta-analysis.

However, in light of a number of issues identified while carrying out this review (such as the paucity of the data, number of available interventions, presence of heterogeneity, lack of 'pure' datasets for the condition of interest, etc.), we are aware that even if we were to alter the design of this review, a network meta-analysis would not be feasible. The current state of the available literature also indicates that in the short-term future updates of this review will encounter similar issues. We have hence retained the original protocol design and have presented our findings as a narrative.

The network meta-analysis design remains a viable future plan should adequate data become available. 


\section{N D EX TERMS}

\section{Medical Subject Headings (MeSH)}

Baclofen [therapeutic use]; Botulinum Toxins, Type A [therapeutic use]; Brain Injuries, Traumatic [*complications]; Casts, Surgical; Electric Stimulation Therapy; Head-Down Tilt; Muscle Relaxants, Central [therapeutic use]; Muscle Spasticity [etiology] [therapy]; Neuromuscular Agents [therapeutic use]; Randomized Controlled Trials as Topic

\section{MeSH check words}

Humans 